\title{
WestVirginiaUniversity
}

THE RESEARCH REPOSITORY @ WVU

Graduate Theses, Dissertations, and Problem Reports

2008

\section{Spatial modeling of propagule pressure in Ailanthus altissima}

\author{
Matthew A. Kaproth
}

West Virginia University

Follow this and additional works at: https://researchrepository.wvu.edu/etd

\section{Recommended Citation}

Kaproth, Matthew A., "Spatial modeling of propagule pressure in Ailanthus altissima" (2008). Graduate Theses, Dissertations, and Problem Reports. 2653.

https://researchrepository.wvu.edu/etd/2653

This Thesis is protected by copyright and/or related rights. It has been brought to you by the The Research Repository @ WVU with permission from the rights-holder(s). You are free to use this Thesis in any way that is permitted by the copyright and related rights legislation that applies to your use. For other uses you must obtain permission from the rights-holder(s) directly, unless additional rights are indicated by a Creative Commons license in the record and/ or on the work itself. This Thesis has been accepted for inclusion in WVU Graduate Theses, Dissertations, and Problem Reports collection by an authorized administrator of The Research Repository @ WVU. For more information, please contact researchrepository@mail.wvu.edu. 
Spatial modeling of propagule pressure in Ailanthus altissima

Matthew A. Kaproth

Thesis submitted to the Eberly College of Arts and Sciences at West Virginia University in partial fulfillment of the requirements for the degree of

Master of Science

In

Biology

Dr. James B. McGraw, Ph.D., Chair

Stephen DiFazio, Ph.D.

Timothy Warner, Ph.D.

Department of Biology

Morgantown, WV

2008

Keywords: Ailanthus altissima, invasive species, remote sensing, cellular automata, seed dispersal, hydrochory, germination

Copyright 2008 Matthew A. Kaproth 


\title{
Abstract \\ Spatial modeling of propagule pressure in Ailanthus altissima
}

\author{
Matthew A. Kaproth
}

Ailanthus altissima (tree of heaven) is a non-native invasive tree spreading within central Appalachia. This dioecious, deciduous, and allelopathic species copiously produces samaras, capable of traveling at least $200 \mathrm{~m}$ through primary wind-dispersal. Removal of A. altissima individuals prior to timbering and other forest disturbances may help prevent spread into forest interiors. To aid in species management, this study investigated the use of remote sensing to identify the location and abundance of samaras in mixed mesophytic forests through supervised classifications. From empirical measurements, the estimated number of seeds per classified unit area was determined and the relationship between quantified propagule sources and individual seed primary dispersal was spatially modeled using a cellular automata model. The predicted seed dispersion pattern was compared to empirical seed trap measurements. Secondary seed dispersal, germination and seedling survival parameters were determined through field experiments. Specifically, I found that remote sensing can be successfully used to distinguish $A$. altissima samara clusters from surrounding closed canopy vegetation. The identified total area of classified $A$. altissima samara clusters was determined to be linearly related to total canopy seed yield, however model predictions of seed dispersal patterns generally predicted greater numbers

of seeds per seed trap compared to measured outcomes. Seed dispersal predictions using all classified $A$. altissima samara clusters provided no positive relationships with observed values (Site II, $\mathrm{p}=0.2997$; negative relationship at Site III, $\mathrm{p}=0.0053$ ). Manually delineating seed sources through photo interpretation resulted in a positive relationship between model estimates and observed seed rain (Site II, $\mathrm{p}=0.0225$ ), but may still contain commission errors (Site III, $\mathrm{p}=0.7002$ ). Microsite survey observations of seed germination indicate the frequency of safe sites was high in disturbed environments (canopy gaps), but seedling survival was negligible in the year this study was performed. Measurements of secondary dispersal on land and water (hydrochory) indicate the species can be dispersed with multiple dispersal agents. Hydrochory was shown to be able to contribute greatly to the species' long distance dispersal, as seeds can reach water bodies, stay viable for long periods of immersion, and can be dispersed downstream distances more than two orders of magnitude greater than primary dispersal. This was the first demonstration of hydrochory in this species. From these studies, it appears that polychory may contribute greatly to this species dispersal and I can infer the same polychory occurs in other terrestrial species, and may contribute to invasive success. 


\section{Acknowledgments}

I would like to express my sincere appreciation to Dr. James B. McGraw, chairman of my committee, for his encouragement and scholarly guidance. The opportunity to pursue an important and interesting research question is precious. It could not come about without his commitment to my training, as well as the environment of excellence he provided. His friendship and collegiality is especially valued.

I would also like to thank the members of my committee, Drs. Stephen DiFazio and Timothy Warner, for critically reviewing my thesis. Dr. Warner provided many opportunities for advice and collaboration, which have helped me grow academically as well as personally. Important portions of my computer analysis were made possible (and understandable) with the help of Dr. DiFazio. Critical portions of my experiments were performed with the help of Margaret Harlacher and Marcin Bojanczyk. Dr. Jane Molofsky of the University of Vermont provided training opportunities, encouragement and time necessary to complete this thesis.

Thanks are extended to Departmental and University colleagues for their time, help and sharing of experiences: Dr. Rick Landenberger, Dr. Chintamani Manish, Dr. Gancho Slavov, Dr. Richard Thomas, Dr. Skip Van Bloem, Dr. Cun-Quan Zhang, Nathan Kota, Christopher Buyarski, Michelle LaRue, Patricia Lutsie, Katie Blankenship, Mark Guido, Adam Martin, Britni Schoonover, and Johnathan Weems of the Core Arboretum.

I recognize that landowners Brooks Javin and Charles Hunter, members of the Forks of Cheat Forest, and Brian Mills of Mountaineer Air Services have been generous with their resources and time.

I thank and acknowledge my sister and brother, Kate Kaproth-Joslin and Bryan Kaproth, and my parents Michael and Nancy Kaproth. I haven't gotten to where I am without their help, love, and encouragement. Finally, it is with special appreciation that I 
express my gratitude and love to my best friend, Maggie, who supported me on each step of this memorable West Virginia journey.

Funding provided by a West Virginia View Grant, with additional funds from USDA Grant 2002-35320-12535 to James McGraw, Timothy Warner, and Rick Landenberger, and NSF grants DEB 0212411 and 0613611 to James McGraw. 


\section{Table of Contents}

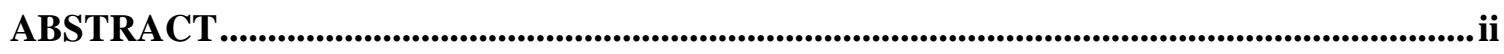

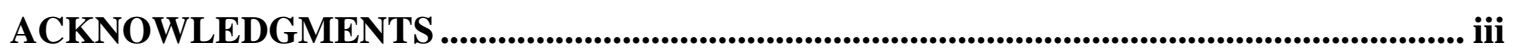

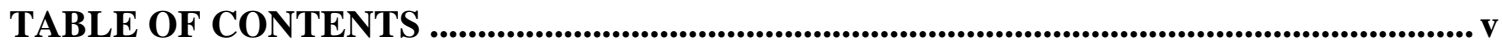

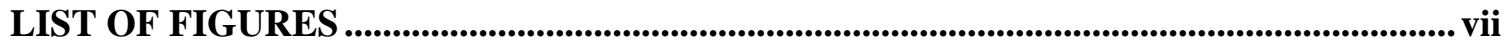

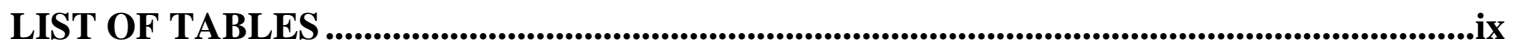

CHAPTER 1: GENERAL INTRODUCTION ........................................................................... 1

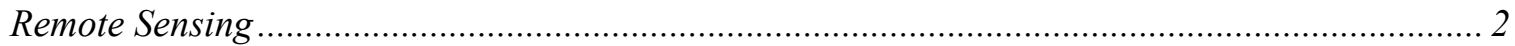

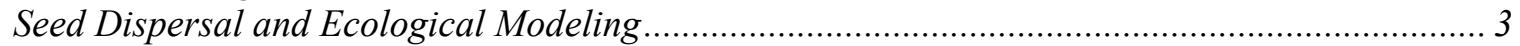

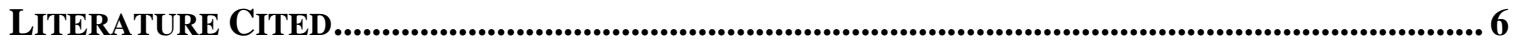

CHAPTER 2: REMOTE SENSING DETERMINATION OF PROPAGULE PRESSURE

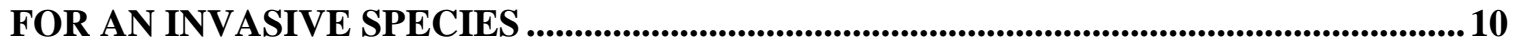

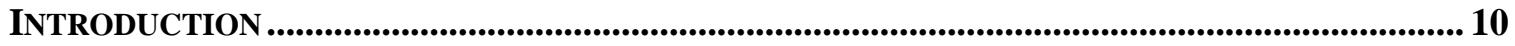

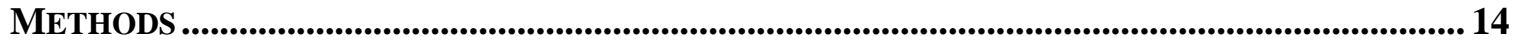

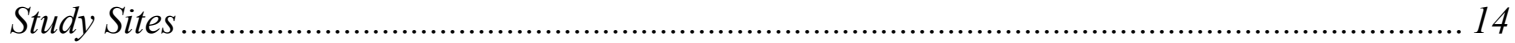

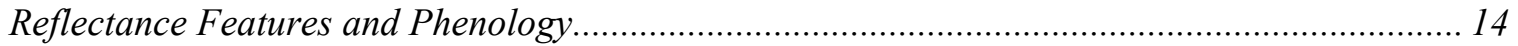

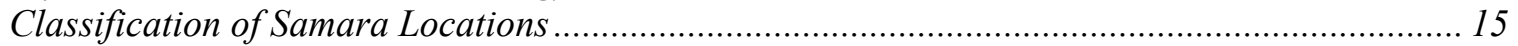

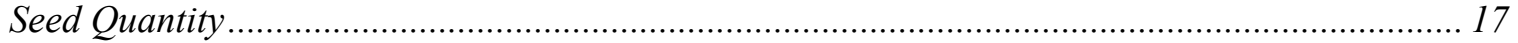

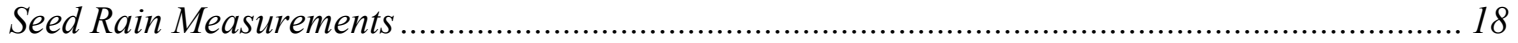

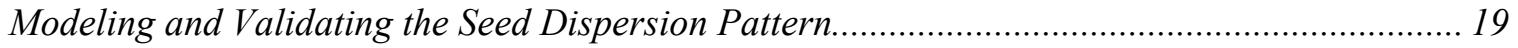

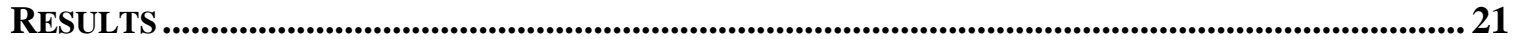

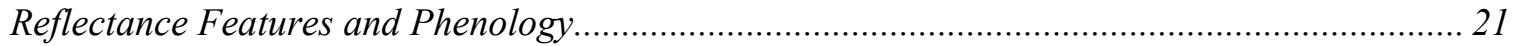

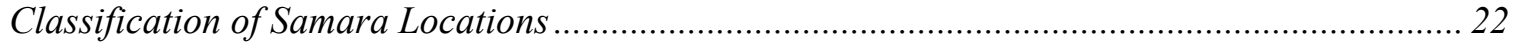

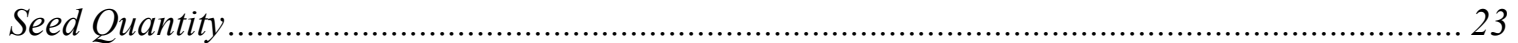

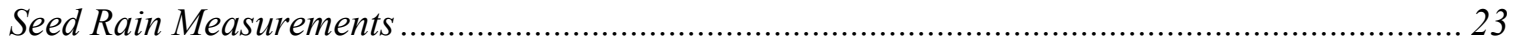

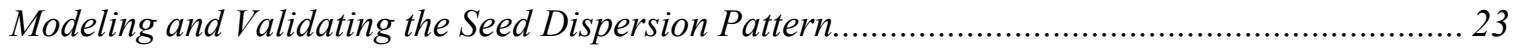

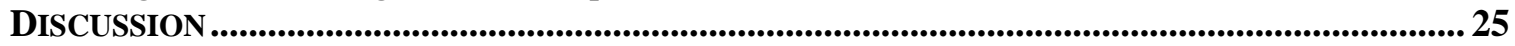

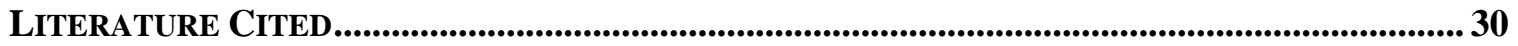

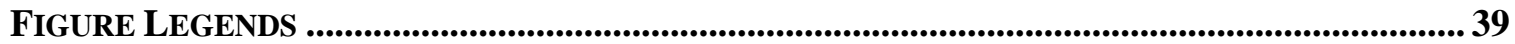

CHAPTER 3: AILANTHUS ALTISSIMA SEED GERMINATION AND SURVIVAL IN MIXED MESOPHYTIC FOREST ENVIRONMENTS ......................................................... 63

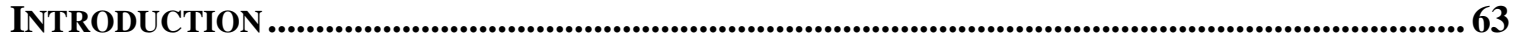

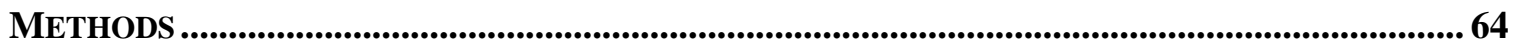

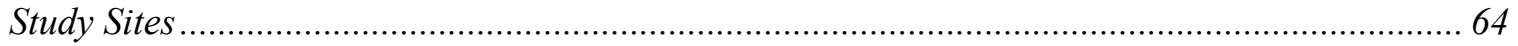




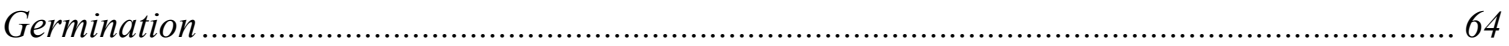

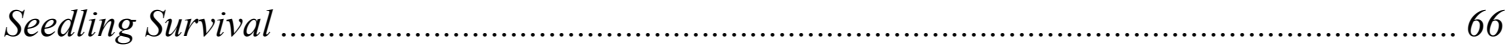

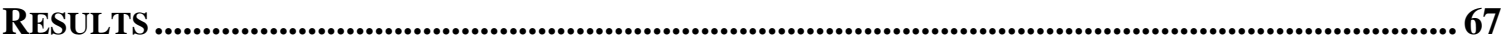

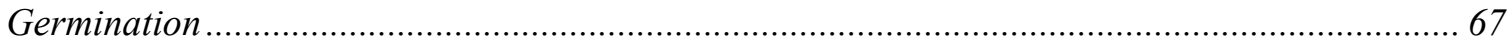

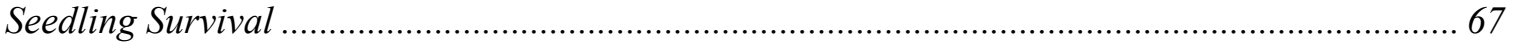

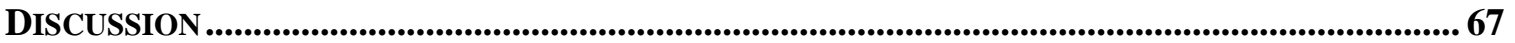

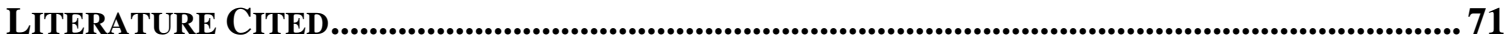

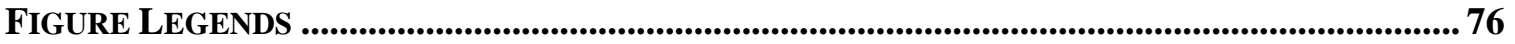

\section{CHAPTER 4: SEED VIABILITY AND DISPERSAL OF THE WIND-DISPERSED} INVASIVE AILANTHUS ALTISSIMA IN AQUEOUS ENVIRONMENTS.......................... 80

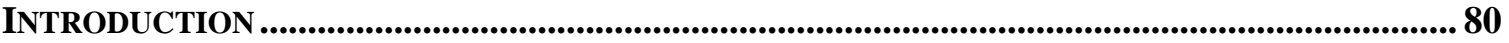

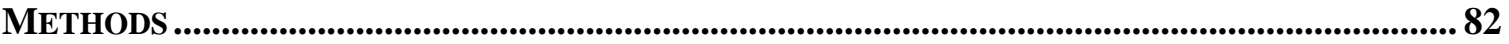

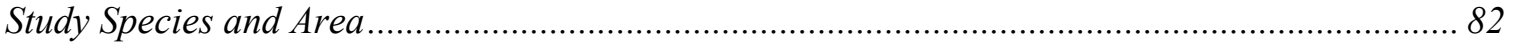

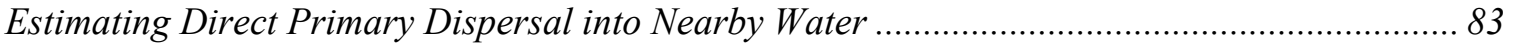

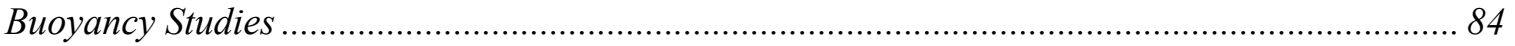

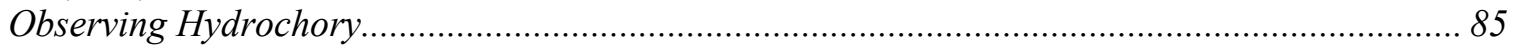

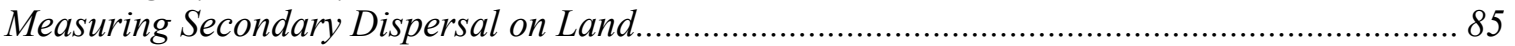

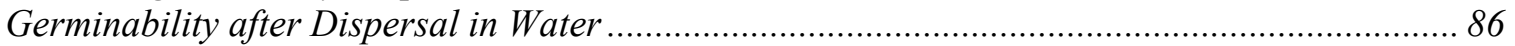

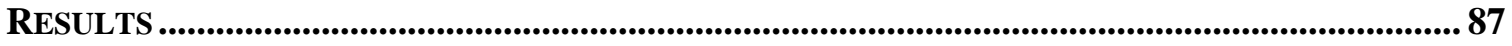

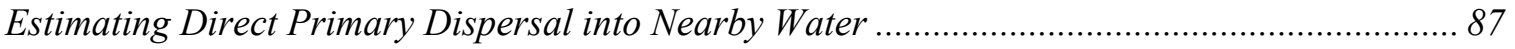

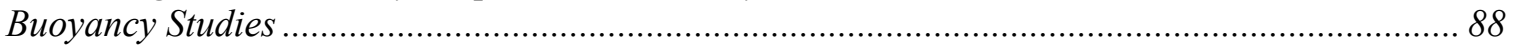

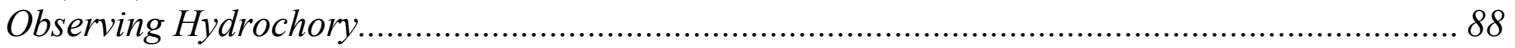

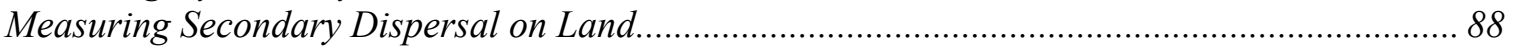

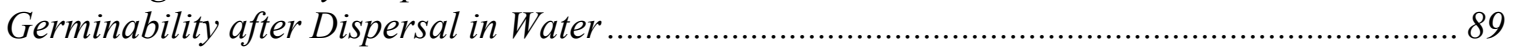

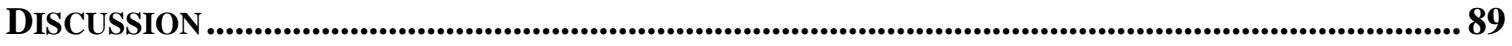

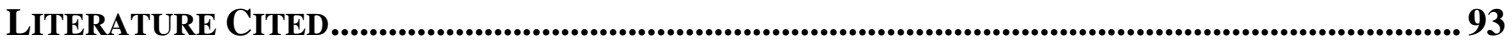

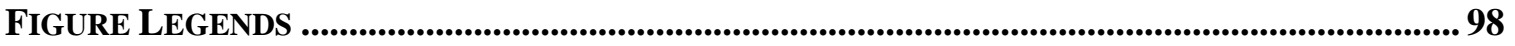

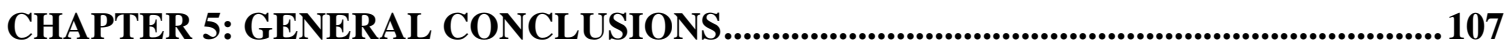

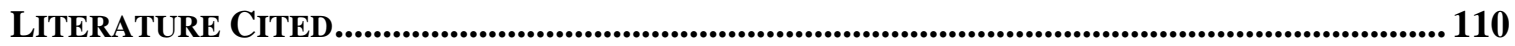

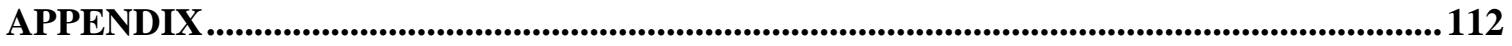

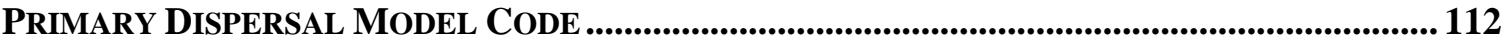

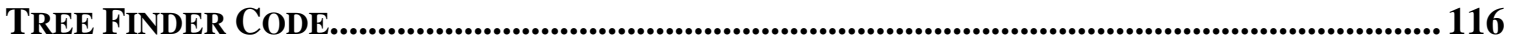

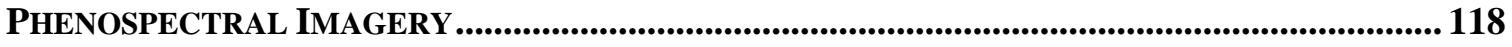

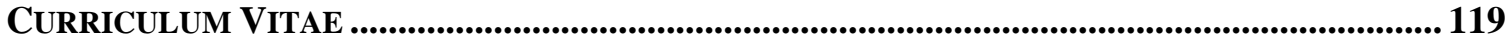




\section{List of Figures}

Figure 2.1: Schematic map of study sites in north-central WV

Figure 2.2: Aerial images of Site I, captured August 23, 2006. Left image was taken $1 \mathrm{~km}$

east of right images.

Figure 2.3: Aerial image mosaic of Site II, captured August 3, 2005 .......................................44

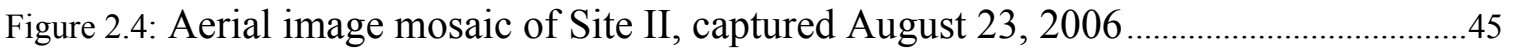

Figure 2.5: Aerial image mosaic of Site III, captured August 23, 2006 ....................................46

Figure 2.6: Example seed trap with mean seed dispersal, using model method $i$. Cells

values represent mean projected seed rain per $\mathrm{m}^{2}$.

Figure 2.7: Mean visible wavelength range reflectance factors of canopy vegetation

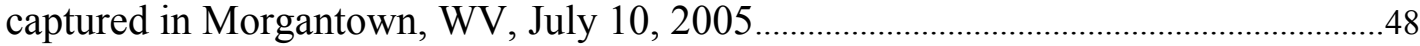

Figure 2.8.A: Aerial image of Site I, captured August 23, 2006. A mature A. altissima

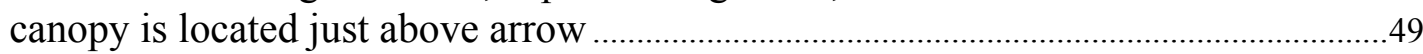

Figure 2.8.B: Supervised classification of August 23, 2006 imagery of Site I..........................49

Figure 2.9.A: Aerial image of Site II, captured August 3, 2005. A mature A. altissima

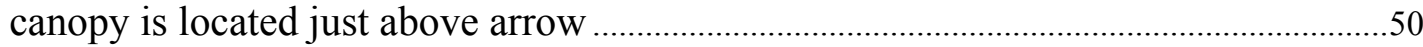

Figure 2.9.B: Supervised classification of August 3, 2005 imagery of Site II ...........................50

Figure 2.10.A: Aerial image of Site II, captured August 23, 2006. A mature A. altissima

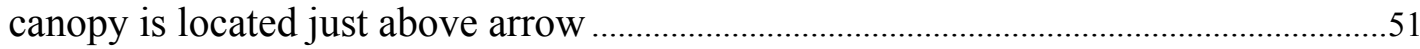

Figure 2.10.B: Supervised classification of August 23, 2006 imagery of Site II .......................51

Figure 2.11.A: Aerial image of Site III, captured August 23, 2006. A mature A. altissima canopy is located just above black arrow.....

Figure 2.11.B: Supervised classification of August 23, 2006 imagery of Site III. A mature

A. altissima canopy is located just above black arrow

Figure 2.12: Site II (2005). Regression of classified A. altissima samara area on manually delineated canopy unit area showing a positive linear relationship ...............................53

Figure 2.13: Site II (2006). Regression of classified A. altissima samara area on manually delineated canopy unit area showing a positive linear relationship ................................53

Figure 2.14: Site III (2006). Regression of classified $A$. altissima samara area on manually delineated canopy unit area showing a positive linear relationship ...............................54

Figure 2.15.A: Site I relationship between total estimated number of seeds and area of classified A. altissima samaras per manually delineated canopy unit. Trend line is constrained through the origin...

Figure 2.15.B: Site I relationship between total estimated number of seeds and area of manually delineated canopy unit. Trend line is constrained through the origin.........55

Figure 2.16: Positive log-linear relationship between total estimated seeds per tree and

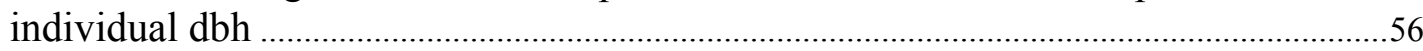

Figure 2.17.A: Mean projected seed dispersion pattern of manually delineated A. altissima at Site II from 2006-2007 using method $i$....................................................................57

Figure 2.17.B: Mean projected seed dispersion pattern of manually delineated A. altissima

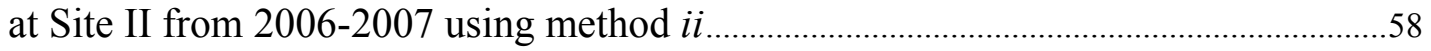

Figure 2.18.A: Mean projected seed dispersion pattern of manually delineated A. altissima at Site III from 2006-2007 using method $i$

Figure 2.18.B: Mean projected seed dispersion pattern of manually delineated A. altissima at Site III from 2006-2007 using method ii. 
Figure 2.19.A: Correspondence of mean projected seed rain predictions and observed seed rain per trap at Site II using model method $i$. 1:1 correspondence is represented by grey trend line

Figure 2.19.B: Positive relationship between mean projected seed rain predictions and observed seed rain per trap at Site II using model method ii. 1:1 correspondence is represented by grey trend line

Figure 2.20.A: Negative correspondence of mean projected seed rain predictions and observed seed rain per trap at Site III using model method $i$. 1:1 correspondence is represented by grey trend line

Figure 2.20.B: Correspondence of mean projected seed rain predictions and observed seed rain per trap at Site III using model method ii. 1:1 correspondence is represented by grey trend line.

Figure 3.1: Effect of location on percentage of germination safe sites ........................................77

Figure 3.2: Effect of microsite on percentage of germination safe sites.....................................78

Figure 3.3: Effect of microsite and site on percentage of germination safe sites .....................79

Figure 4.1: Log-linear curve fit to observed primary dispersal of $A$. altissima, relative to densities found at parent $(0 \mathrm{~m})$ to $100 \mathrm{~m}$ in an open field environment; adapted from Landenberger et al. 2007.

Figure 4.2: Primary dispersal into water, assuming equal dispersal in all directions ...........100

Figure 4.3: Percent (left axis) and estimated number (right axis) of seeds dispersing into water as a function of tree distance from water's edge, based upon a tree of $25 \mathrm{dbh}$ (cm)

Figure 4.4: Relationship between observed individual $A$. altissima $\mathrm{dbh}(\mathrm{cm})$ and distance from water on the projected number of seeds deposited directly into water as a function of Equation 1

Figure 4.5: Number of recovered A. altissima seeds at varying distances along the Monongahela River after 24 hours

Figure 4.6: Percent of seeds traveling a certain distance downhill through secondary dispersal events in a terrestrial environment over one-month on a (A) 48\%, (B) 33\%, or (C) $9 \%$ slope. Axis slant corresponds to slope. 104_Toc187579981

Figure 4.7: Mean ( \pm 2 s.e.) germination rate of $A$. altissima seeds incubated in aqueous conditions over five months

Figure 4.8: The effect of environment and location on the mean germination ( \pm 2 s.e.) of $A$. altissima seeds near Morgantown, WV. Columns with different letters are significantly different from one another (Tukey-Kramer HSD a posteriori test)......106 


\section{List of Tables}

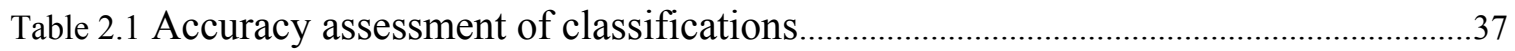

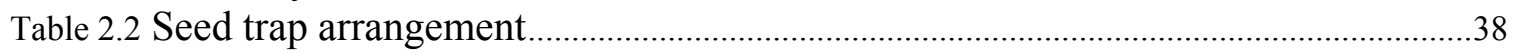

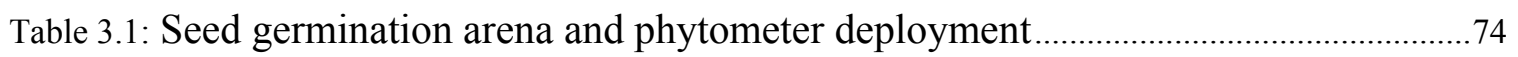

Table 3.2: Mean percent seed germination within safe site arenas .............................................75 


\section{Chapter 1: General Introduction}

Biotic invasion can be defined as rapidly spreading exotic species having detrimental effects on the environment (Mack et al. 2000). While most incidences of invasion of exotic species may be unsuccessful, occasionally some species thrive in the new landscape and outcompete their neighbors. Invasive plants can become established in the landscape and cause rapid changes to the plant community. Over time, they can dominate native species by competing for light, water, and nutrients (Knapp and Canham 2000). Some invasives also retard growth of neighboring species by releasing allelopathic chemicals into their environment (Call and Nilsen 2003). With the continued presence of the invasive, native species may be prevented or hindered from reestablishing themselves within the same community (Callaway and Aschehoug 2000), reducing biodiversity.

Invasion is aided by natural or human-caused disturbance (Mack et al. 2000). Within the eastern United States, timber harvesting is projected to rise over the next 35 years (Adams et al. 2000). The skid trails associated with log removal, and canopy-gaps formed by tree felling may facilitate invasive plant species to become established (Gaddy and Kohlsaat 1987, Trombulak and Frissell 2000, Call and Nilsen 2003).

Within central Appalachia, an exotic tree, Ailanthus altissima, has invaded neighboring disturbed forests (Call and Nilsen 2003, Kota 2005). The species is dioecious, deciduous, and produces copious amounts of wind-dispersed samaras (Landenberger et al. 2007). Some experimental work suggests A. altissima's leaf litter is allelopathic (Heisey 1990, Lawrence et al. 1991, Heisey 1996). Further, it dominates canopy-gaps, and is able to grow rapidly into the canopy (Knapp and Canham 2000), 
often outcompeting economically valuable early-successional native trees, such as Robinia pseudoacacia (Call 2002) and Liriodendron tulipifera (Kota 2005), especially in the quantity of germinated seeds (Kota et al. 2007).

Management of A. altissima to curb invasion into timbered areas may be possible through removal of all female trees within $200 \mathrm{~m}$ of a timbering operation prior to harvest (Kota 2005, Landenberger et al. 2007). One limitation to the feasibility of this practice is pinpointing the location of all of the female trees, particularly over large areas. Because of its dispersed pattern across the landscape, surveys by foot are unsuitable for the task of finding female trees, but the development of new technologies, specifically in remote sensing, may allow for rapid detection over large sites.

\section{Remote Sensing}

Remote sensing provides an opportunity to census large plots, captured as an image from afar (Lillesand and Kiefer 2000). If their acquisition is well-timed and they contain sufficient spatial and spectral resolution, these images can be used to classify objects. Recent trends toward capturing higher resolution images have led to improvements in the ability to detect and classify individual tree crowns (Clark et al. 2002, Lass et al. 2002, Brandtberg et al. 2003, Lass and Prather 2004). This was shown in an analysis of multi-temporal images in a northern West Virginia eastern hardwood forest that produced $76 \%$ species recognition (Key et al. 2001). Using current technology, it is unknown if a meaningful (beneficial to management) analysis can be produced for A. altissima.

A. altissima may have a unique phenospectral signature that will allow this species to be distinguished from others (Key et al. 2001, Ustin et al. 2004). For example, 
anthocyanins are conspicuous reddish leaf pigments, apparent in many species in both spring and fall, as well as in new tissues produced throughout the growing season (Gitelson et al. 2001). Furthermore, high total chlorophylls produced by A. altissima are indicated by strong absorption at blue and red wavelengths (Wolf 1956) and may provide unique absorption features in combination with the anthocyanin pigments.

Additionally, if spatial resolution is high enough, the large, spaced samara clusters produced by female $A$. altissima trees may be distinctive. As the samaras ripen over late summer, they display varying levels of pigments, which may appear unique spectrally (ranging from bright green to orange to red) and texturally to other non-seed-bearing canopy species. This phenology may not only allow for A. altissima classification from surrounding species, but also allow for identification of all female A. altissima.

Once classified and located spatially, A. altissima individuals can be incorporated into a spatially-explicit model. With information on location, density, and surrounding environment, a projection of how each tree could contribute to the spread of the species into the neighboring landscape could be produced.

\section{Seed Dispersal and Ecological Modeling}

Seed dispersal models provide powerful predictive tools for the management of species. They have been used to depict seed movement from each parent across a spatially-explicit landscape (He et al. 1999) and explain the variation in vegetation cover for invasive trees (Rouget and Richardson 2003). These propagule pressure predictions can indicate where a species is likely to expand its range (Eppstein and Molofsky 2007) as propagule pressure drives the spread of invasion into a plant community (Lockwood et 
al. 2005, Von Holle and Simberloff 2005). In areas of predicted propagule abundance, management efforts can be prioritized to minimize species establishment.

Seed dispersal model construction requires the incorporation of elements known to be a factor in the seed dispersion pattern. For example, previous research has shown that the dispersal curves of anemochorous (wind-dispersed) species can vary by landscape features and vegetation (Landenberger et al. 2007). Elements used in a model must be parameterized across an environmental gradient that reflects the model location (e.g. aspect and prevailing wind), which may be aided by remote sensing. Due to the spatially-explicit format of remote sensing data, one may be able to quantify not only the total propagules per parent, from the seed cluster size and frequency, but also classify surrounding landscape features. These parameterizations may be used in spatial modeling. In 2004, Molofsky and Bever proposed use of cellular automata in determining patterns of ecological systems. Taken together, using previous research, my own studies, and advances in remote sensing, I will incorporate elements influencing primary seed dispersal to predict the A. altissima seed dispersion pattern using rule-based cellular automata.

After seed dispersal, seed germination and seedling survival are known to also vary by environmental conditions. For example, A. altissima has known limitations on its germination and growth depending on the microsite it occupies. Specifically, germination is reduced in the shade of a full canopy (Kota 2005, Kota et al. 2007) and depends on aspect within disturbed forests (Kota 2005, Kota et al. 2007). Call and Nilsen (2003), in Virginia forests, found A. altissima occurrence to be limited to areas of high soil disturbance, similar to Kota et al.'s (2007) findings of seedling survival rates being 
higher in disturbed forests and dependent on aspect. Therefore, parameterization of species response to environments would be implemented when modeling species germination rate and seedling survival. A completely parameterized model may determine the suitability of each microsite for a species. In the case of an invasive species, microsites indicated by the model to be suitable would represent areas at risk of invasion.

The objectives of this study were to: (1) Develop a classification algorithm to detect female $A$. altissima in aerial imagery, using spectral information. (2) Create an ecological model projecting seed dispersal of A. altissima over a landscape. (3) Conduct field validation of model predictions by surveying over landscapes. (4) Characterize $A$. altissima secondary seed dispersal, germination, and seedling survival by surveying microsites across a landscape.

The first three objectives of detecting female $A$. altissima in aerial imagery along with predicting and validating seed dispersal are presented in Chapter 2 and written for publication in Remote Sensing of Environment. The fourth objective involves future model parameterization of seed germination and survival across landscapes and is presented in Chapter 3. Additionally, model parameterization of secondary dispersal was examined using $A$. altissima in aqueous environments, with an emphasis on potential hydrochory of terrestrial species. The hydrochory work is presented in Chapter 4 and has been submitted for publication in Forest Science. 


\section{Literature Cited}

Adams, M.B., J.A. Burger, A.B. Jenkins and L. Zelazny, 2000. Impact of harvesting and atmospheric pollution on nutrient depletion of eastern US hardwood forests. Forest Ecology and Management 138: 301-319.

Brandtberg, T., J.B. McGraw, T.A. Warner and R.E. Landenberger, 2003. Image restoration based on multiscale relationships of image structures. IEEE Transactions on Geoscience and Remote Sensing 41(1): 102-110.

Call, L.J., 2002. Analysis of intraspecific and interspecific interactions between the invasive exotic tree-of-heaven (Ailanthus altissima (Miller) Swingle) and the native black locust (Robinia pseudoacacia L.). Virginia Polytechnic Institute and State University Dept. of Biology, Electronic Thesis.

Call, L.J. and E.T. Nilsen, 2003. Analysis of spatial patterns and spatial association between the invasive Tree-of-heaven (Ailanthus altissima) and the native Black locust (Robinia pseudoacacia). American Midland Naturalist. 150: 1-14.

Callaway, R.M. and E.T. Aschehoug, 2000. Invasive plants versus their new and old neighbors: A mechanism for exotic invasion. Science 290(5491): 521-523.

Clark, J.S., B. Beckage, P. Cleveland, J. HilleRisLambers, J. Lichter, J. McLachlan, J. Mohan and P. Wyckoff, 1999. Interpreting recruitment limitation in forests. American Journal of Botany 86(1): 1-16.

Eppstein, M.J. and J. Molofsky, 2007. Invasiveness in plant communities with feedbacks. Ecology Letters 10:253-263. 
Gaddy, L.L., and T.L. Kohlsaat, 1987. Recreational impact on the natural vegetation, avifauna, herpetofauna of four South Carolina barrier islands (USA). Natural Areas Journal 7: 285-257.

Gitelson, A.A., M.N. Merzlak, and O.B. Chivkunova, 2001. Optical properties and nondestructive estimation of anthocyanin content in plant leaves. Photochemistry and Photobiology 74 (1): 38-45.

He, H.S., and D.J. Mladenoff, 1999. The effects of seed dispersal on the simulation of long-term forest landscape change. Ecosystems 2: 308-319.

Heisey, R.M., 1990. Allelopathic and herbicidal effects of extracts from tree of heaven (Ailanthus altissima). American Journal of Botany 77(5):662-670.

Heisey, R.M., 1996. Identification of an allelopathetic compound from Ailanthus altissima (Simaroubaceae) and characterization of its herbicidal activity. American Journal of Botany 83(2): 192-200.

Key, T., T.A. Warner, J.B. McGraw, and M.A. Fajvan, 2001. A comparison of multispectral and multitemporal information in high spatial resolution imagery for classification of individual tree species in a temperate hardwood forest. Remote Sensing of Environment 75: 100-112.

Knapp, L.B., and C.D. Canham, 2000. Invasion of an old-growth forest in New York by Ailanthus altissima: sapling growth and recruitment in canopy gaps. Journal of the Torrey Botanical Society 127(4): 307-315.

Kota, N.L., 2005. Comparative seed dispersal, seedling establishment and growth of exotic, invasive Ailanthus altissima (Mill.) Swingle and native Liriodendron tulipifera (L.). West Virginia University Dept. of Biology, Electronic Thesis. 
Kota, N.L., R.E. Landenberger, and J.B. McGraw, 2007. Germination and early growth of Ailanthus and tulip poplar in three levels of forest disturbance. Biological Invasions 9:197-211.

Kruckeberg, A.R., 2002. Geology and Plant Life. University of Washington Press: Seattle. p. 103, 124, 150.

Landenberger, R.E., N.L. Kota, and J.B. McGraw. 2007. Seed dispersal of the non-native invasive tree Ailanthus altissima into contrasting environments. Plant Ecol. 192:55-70.

Lawrence, J.G., A. Colwell, and O.J. Sexton, 1991. The ecological impact of allelopathy in Ailanthus altissima (Simaroubaceae). American Journal of Botany 78(7):948958.

Lass, L. W., D. C. Thill, B. Shafii, and T. S. Prather, 2002. Detecting spotted knapweed (Centaurea maculosa) with hyperspectral remote sensing technology. Weed Technology 16: 426-432.

Lass, L. W., and T. S. Prather, 2004. Detecting the locations of Brazilian Pepper trees in the Everglades with a hyperspectral sensor. Weed Technology 18: 437-442.

Lillesand, T.M. and R.W. Kiefer, 2000. Remote sensing and image interpretation. John Wiley \& Sons, Inc.: New York. p. 1.

Lockwood, J.L., P. Cassey, and T. Blackburn, 2005. The role of propagule pressure in explaining species invasions. TRENDS in Ecology and Evolution 20(5):223-228.

Mack, R.N., D. Simberloff, W.M. Lonsdale, H. Evans, M. Clout and F.A. Bazzaz, 2000. Biotic invasions: causes, epidemiology, global consequences, and control. Ecological Applications 10(3): 689-710. 
Molofsky, J. and J.D. Bever, 2004. A new kind of ecology? Bioscience. 54: 440-446.

Nathan, R. and H.C. Muller-Landau, 2000. Spatial patterns of seed dispersal, their determinants and consequences for recruitment. TREE 15(7):278-285.

Rouget, M. and D.M. Richardson, 2003. Inferring process from pattern in plant invasions: A semimechanistic model incorporating propagule pressure and environmental factors. American Naturalist 162(6):713-724.

Trombulak, S.C., and C.A. Frissell, 2000. Review of ecological effects of roads on terrestrial and aquatic communities. Conservation Biology 14(1): 18-30.

Von Holle, B. and D. Simberloff, 2005. Ecological resistance to biological invasion overwhelmed by propagule pressure. Ecology 86(12):3212-3218.

Ustin, S.L., D.A. Roberts, J.A. Gamon, G.P. Asner, and R.O. Green, 2004. Using imaging spectroscopy to study ecosystem processes and properties. BioScience 54 (6): 523-534.

Wolf, F.T., 1956. Changes in chlorophylls A and B in autumn leaves. American Journal of Botany 43: 714-718. 


\section{Chapter 2: Remote Sensing Determination of Propagule Pressure for an Invasive Species}

\section{Introduction}

How a community responds to disturbance depends largely on what species arrive and colonize the open niches (Grubb 1977, He and Mladenoff 1999, Kolar and Lodge 2001). With increasing frequency, natural communities are receiving high numbers of propagules (e.g. seeds) from invasive species (With 2002, With 2004, Lockwood et al. 2005), which can outcompete economically and ecologically valuable native species (Pimentel et al. 2000, Call and Nilsen 2003, Pimentel et al. 2005). Control of unwanted invasive species before a disturbance is a viable option for preventing dominance, but requires the removal of reproductive individuals contributing to the seed rain (Mack et al. 2000, Kota et al. 2007, Landenberger 2007). Management of a species is aided by early identification of the presence of threatening species and their spatial location (Kolar and Lodge 2001, Byres et al. 2002). For example, the invasive, non-native tree species, Ailanthus altissima (tree of heaven) is poised to expand its range within central Appalachian forests after spreading from city centers through the $20^{\text {th }}$ century to disturbed land through production of copious wind-dispersed seeds and rapid growth (Gleason and Cronquist 1963, Feret 1985, Knapp and Canham 2000, Call and Nilsen 2003, Kota et al. 2007, Landenberger et al. 2007). Due to low economic value and negative ecological effects (Swearingen 1999), A. altissima population control would be desirable. Based on dispersal data, removal of all seed-bearing trees within $200 \mathrm{~m}$ of a disturbance site has been recommended (Kota et al. 2007, Landenberger 2007). 
While intensive ground based surveys can pinpoint the location of potential invaders, this method is time-consuming and therefore may be impractical (Ustin et al. 2004). However, knowing the precise location of propagule sources over large areas would be valuable for mitigation efforts because colonization by an invasive plant population is often limited by the propagule pressure on a region (Leung et al. 2004, Lockwood et al. 2005).

Propagule pressure is defined by the number of dispersal events as well as the number of propagules an area receives (Lockwood et al.2005). To quantify propagule pressure, one needs to know not only the location of reproductive individuals and the dispersal curve of their propagules, but also the quantity of seeds the individual holds. One way to determine seed production indirectly is to establish a relationship to vegetative mass of the tree (Samson and Werk 1986). For example, Greene and Johnson (1994) found short term positive relationships between both basal area and leaf mass to seed production, however measurements of these attributes would require intensive ground based surveys.

As an alternative to intensive ground surveys, remote sensing allows surveys covering large areas, in a relatively short time span (Carson et al. 1995). Identification of landscape cover type (Ustin et al. 2004) and classification of invasive plants has been successful for monotypic vegetation covers (Lass and Prather 2004). However, with enhancements of spatial resolution, there has been increased emphasis on identifying individuals of a species in mixed communities (Key et al. 2001, Brandtberg et al. 2003, Landenberger et al. 2003, Lamar et al. 2005). If remote sensing can be used to not only identify a species, but quantify seed production of that species, it could become an even more useful tool in management of plant communities. Previous work in agricultural 
settings has shown that remotely sensed imagery can predict seed yield months before maturity (Shanahan et al. 2001, Pinter et al. 2003), but the application has had little utilization in natural communities thus far (Joshi et al. 2006).

Successful remote sensing of tree species is aided if the target class has a distinctive phenospectral signature (i.e. the timing of a biological appearance that has a characteristic spectral pattern) within the landscape (McGraw et al. 1998, Lass and Prather 2004), at least for a brief period of the year. In terms of the invasive A. altissima, field observations suggest this species may have a unique phenospectral signature that will allow it to be distinguished from others (Key et al. 2001, Ustin et al. 2004). For example, anthocyanins are conspicuous reddish pigments present in leaves of many species in both spring and fall (Gitelson et al. 2001). Actively growing A. altissima tissues produce anthocyanins that are visible until midsummer, when apical growth ceases. Furthermore, high total chlorophylls produced by A. altissima leaves are indicated by strong absorption at blue and red wavelengths (Wolf 1956), which may provide, in combination with the anthocyanin pigments, a characteristic absorption pattern.

It may also be possible to use remote sensing to differentiate between the sexes of this dioecious species. If spatial resolution is high enough, the large, spaced samara clusters produced by female A. altissima trees may be distinctive in aerial imagery. As the samaras ripen in late July and early August, they display varying levels of pigmentation, which may be characteristic both spectrally (ranging from bright green to orange to red) and texturally compared to other non-seed-bearing canopy species. This phenology may not only allow differentiation of female A. altissima from surrounding species, but also provide measures of A. altissima seed production for the population as a whole. 
Upon completion of a spatially-explicit population survey of propagule source location and quantity, propagule dispersal and subsequent propagule pressure can be predicted (DiFazio 2002, Rouget and Richardson 2003). Using a mechanistic cellular automata model (Travis and Dytham 1998, Molofsky and Bever 2004) will allow for incorporation of parameters influencing the seed dispersal pattern of a population in a landscape (Ribbens et al. 1994, Nathan and Muller-Landau 2000). Due to the high resolution and large-scale surveys provided through remote sensing, model predictions may suggest which portions of a landscape are potentially subject to invasion (Lass et al. 2002, Lass et al. 2004).

The purpose of this study was to determine if high-resolution imagery could be used to (1) distinguish A. altissima female trees by the presence of samara clusters within a diverse mixed mesophytic forest community and (2) quantify A. altissima seed sources. Using the identified propagule pressure sources, this study will (3) project the seed dispersion pattern of A. altissima using a spatially-explicit dispersal model and (4) validate predictions using field observations of seed rain.

The following studies were performed over two years across multiple sites in a mixed mesophytic forest landscape using a combination of aerial surveys and field work. We hypothesized that $A$. altissima samara clusters would have a unique recognizable signature allowing us to identify sources and quantity of propagule pressure, enabling seed dispersal pattern predictions. 


\section{Methods}

\section{Study Sites}

Three sites were used for field measurements and empirical validation. At Site I (Figures 2.1-2), an aerial survey followed by destructive sampling of A. altissima canopies was used to determine the relationship between pixels classified as samaras and seed production. The site, located $7.6 \mathrm{~km}$ northeast of Morgantown, WV, contained over 20 A. altissima females and ranged in elevation from $274 \mathrm{~m}$ to $365 \mathrm{~m}$.

Aerial surveys of A. altissima and field measurements of seed rain occurred at two additional study sites, both located along the river-fed impoundment of Cheat Lake, WV, and ranged in elevation from $271 \mathrm{~m}$ to $354 \mathrm{~m}$ (Figure 2.1). Both sites contained southfacing closed canopy forest and fields. Site II (Figures 2.3-4), ca. 25 ha in size was used to assess classification accuracy rates over two years and validate predictions of seed rain. Site III (Figure 2.5), with an area of 18 ha and was used to assess classification accuracy in 2006 as well as validate model projections of seed rain. A total of 137 and 173 mature A. altissima females were contained in or within $200 \mathrm{~m}$ of Site II and Site III, respectively.

\section{Reflectance Features and Phenology}

Spectral reflectance factor measurements of A. altissima and surrounding mixed mesophytic canopy tissues in northern West Virginia were made using a field spectroradiometer (Analytical Spectral Devices Inc. Full Range spectrometer, processed using ViewSpec Pro RS3 v2.1 software) on July 10, 2005 at noon in full sun. The $A$. altissima samaras at this date exhibited the characteristic high anthocyanin as shown by a distinctive red color (Gitelson et al. 2001). A Spectralon ${ }^{\circledR}$ barium sulfate reflectance standard was used to normalize for incident radiation. The instrument was used without 
foreoptics, which results in an estimated 20 degree field of view. The mean value of ten spectral measurements per vegetation class was used to account for variation of tissue and radiance.

The pigmentation of $A$. altissima seeds varies over time and location. To ensure year-to-year accuracy, aerial surveys were conducted over two years during peak seed cluster size and coloration intensity. In addition, overhead digital images of two $A$. altissima populations were obtained from an elevated ground position every two weeks to document phenological events of fruit development and desiccation that may influence spectral reflectance.

\section{Classification of Samara Locations}

Aerial images obtained for A. altissima samara identification were acquired in one flight per year during peak samara coloration. On August 3, 2005, three flightlines were flown over Site II (Figure 2.3). On August 23, 2006, three flightlines were flown over all sites (Figures 2.2, 2.4-2.5). The images were captured from a light aircraft traveling at approximately $51 \mathrm{~m} / \mathrm{sec}$ and $800 \mathrm{~m}$ above ground level, using a digital color Sigma SD9 camera. The images were acquired with a shutter speed of $1 / 1000 \mathrm{sec}$. Each image covered approximately $230 \mathrm{~m}$ by $153 \mathrm{~m}$, with $10.1 \mathrm{~cm}$ pixels. The Sigma camera is particularly suited for quantitative remote sensing because its Foveon CCD measures radiance intensity separately for each of the three bands of color (RGB) for each pixel, obviating the inaccuracies inherent with interpolation, associated with most other small format digital cameras.

The images were georectified using piecewise polynomials in ERDAS IMAGINE 9.0, with bicubic resampling and a control point error totaling $<0.3$ per image. 
Cartographic control was obtained from 2003 West Virginia State Address and Mapping Board color digital orthophotos, which have $60 \mathrm{~cm}$ pixels.

Supervised classification was conducted using training sites totaling $>100$ pixels for A. altissima samara clusters and non A. altissima samara clusters cover types, using Mahalanobis distance as a parametric rule. Each flight line was classified separately, with its own set of training data. Post classification smoothing was accomplished by replacing any isolated clump of less than nine contiguous pixels $\left(918 \mathrm{~cm}^{2}\right)$ of the same class with the most common class of the neighboring pixels (Lamar and McGraw 2005). The threshold of nine pixels was chosen from field observations of the minimum size of the samara clusters within the canopies of seed-producing A. altissima trees. Each flight line was classified separately, and then mosaicked. Applying the classifications separately prior to mosaicking was a simple way to deal with the slight differences in illumination intensity between the different flightlines.

The locations of A. altissima female boles were mapped in the field in February 2007 using a GARMIN V GPS. The canopy extent of each A. altissima female "canopy unit", defined as an unbroken single canopy or contiguous stand consisting primarily of samara tissue, was manually delineated on the aerial imagery based on field work and photo interpretation of the images. Manual masks were applied over large continuous areas consisting primarily of field, water, and man-made features that were lacking $A$. altissima canopy units to simplify the classification process.

Assessment of classification accuracy of samaras and non-samara cover types was determined using 200 random samples per class, to determine the standard "pixel-based" overall classification accuracy (Congalton et al. 1983) and Kappa statistics (Cohen 1960) 
for the each of the mosaicked site images. All random samples were selected from areas not used as training sites. Each site classification mosaic was then vectorized.

The classification accuracy for each site was also assessed by overlaying the classification of A. altissima samaras on the matching canopy unit, using the methodologies of "object-based" correspondence adapted from Lamar et al. (2005). A successful correspondence of a classified A. altissima samara polygon to its respective manually delineated $A$. altissima canopy unit was defined as at least a $25 \%$ overlap in area between a group of classified pixels and a canopy unit. This $1 / 4$ agreement may be low compared to other studies (Lamar et al. 2005), however, the random arrangement of seed clusters only cover a small proportion of an A. altissima canopy. An analysis of covariance (ANCOVA) was used to determine the relationship between the classified samara area $(\mathrm{Y})$, the area of the canopy unit $\left(\mathrm{X}_{1}\right)$, and study site $\left(\mathrm{X}_{2}\right)$ (SAS JMP v. 5.1.2). If required, dependent variables for all tests were transformed to meet the assumption of normality (or a Shapiro-Wilk $\mathrm{W}>0.8$ ). Statistical significance for all tests was recognized when $\mathrm{p}<\alpha=0.05$.

\section{Seed Quantity}

Seed quantification of A. altissima was obtained empirically by harvesting all samaras of six canopy units of A. altissima females that were manually identified in aerial imagery at Site I, three from the edge and three from the interior of the canopy. Some canopy units contained individual trees, while others contained multiple boles, likely clonal progeny of one original stem.

Each bole within the selected canopy units was felled separately in September, 2006 after seed desiccation, but before dispersal. Up to $\sim 10 \%$ of the seeds escaped 
collection by scattering broadly upon felling. Seeds remaining near or on the tree were collected, with the percent of uncollectible seeds being estimated visually. Seeds were allowed to air dry at ca. $17-21{ }^{\circ} \mathrm{C}$ and $40-50 \%$ relative humidity for three months. Dried seeds were then removed from stems and peduncles, and weighed. From each tree harvested, two $25 \mathrm{~g}$ samples of seeds were counted, and then total seed number per tree was estimated by extrapolation from the total weight.

Aerial images of Site I were processed, classified, and assessed using similar methodologies previously described in the previous section, Classification of Samara Locations.

A linear regression was used to determine the relationship between total estimated seeds per canopy unit $(\mathrm{Y})$ and the total area of classified samara pixels per A. altissima canopy unit (X) (SAS JMP v. 5.1.2). To determine if canopy unit area predicts the number of seeds, a linear regression was used to determine the relationship between total estimated seeds per canopy unit $(\mathrm{Y})$ and the total area per A. altissima canopy unit (X) (SAS JMP v. 5.1.2). Finally, to establish if ground-based quantification could produce yield estimates, a log-linear regression was used to determine the relationship between the total estimated seeds per harvested tree $(\mathrm{Y})$ and diameter at breast height (dbh) measured in $\mathrm{cm}(\mathrm{X})$ (SAS JMP v. 5.1.2).

\section{Seed Rain Measurements}

To determine the $A$. altissima seed rain over the study sites, $4000.25 \mathrm{~m}^{2}$ seed traps constructed of $13 \mathrm{~cm}$ high aluminum flashing with nylon mesh screen attached to the bottom (adapted from Landenberger et al. 2007) were evenly divided between Site II and Site III. Traps were staked down randomly within a total of eight $25 \mathrm{~m}$ x $50 \mathrm{~m}$ study 
areas contained in one of five microsites; canopy gap, closed canopy forest, forest/field edge, field, and forested shoreline. Each study area started with a minimum of 25 traps and was within $200 \mathrm{~m}$ of at least one mature A. altissima female (Table 2.2). The traps were deployed October 25, 2006 and observed for A. altissima seeds December 21, February 8, March 30, and June 13, 2007, with careful removal of all leaf debris on each date (Kota 2005, Landenberger et al. 2007).

We manually delineated the extent of each seed trap on the aerial imagery based on GPS field work obtained in February 2007 and photo interpretation of the images (accuracy ca. $5 \mathrm{~m}$ ). The percent slope of each trap was obtained using a Warren-Knight ${ }^{\circledR}$ abney level. Due to steep slopes and wind, some traps were overturned between censuses, however, only traps with a complete record were used for comparison against seed dispersion model predictions (Table 2.2).

\section{Modeling and Validating the Seed Dispersion Pattern}

A spatially-explicit dispersal model, similar to a cellular automaton model updated once (Molofsky and Bever 2004), was developed to predict the seed dispersion pattern of A. altissima samaras across a landscape (MATLAB v. 7.4.0.287 (R2007a)). The point-source model used masked classified site mosaics consisting of 16-bit tiff images for parameterization of the landscape size, propagule pressure sources, and quantity. Projections of Site II and Site III's 2006-2007 seed dispersion patterns were produced using two methods: (i) Using all classified A. altissima samara cluster pixels, and (ii) using the classified A. altissima samara cluster pixels only within the manually delineated canopy units. 
Cell sizes varied slightly for the two sites due to image projections, with each classified samara cluster cell representing 139 or 163 seeds for Site II and III, respectively. These densities were determined from the linear regression results described above. The model projected each seed's dispersal distance from its source cell based on a probability calculated from an exponential curve fit of mean seed dispersal frequency (Equation 1) for A. altissima samaras from point source measurements of two field and forest sources (Landenberger et al. 2007), where $x$ equals the distance from the source and $y$ equals the relative abundance:

$$
y=0.2054 e^{-0.0208 x}
$$

For simplicity, we assumed there was no variation in seed dispersal by direction (direction of dispersal was a function of a random number generation), elevation, or vegetation cover class, and that the maximum dispersal distance was $200 \mathrm{~m}$ (Kota 2005, Landenberger et al. 2007) (Appendix). A matrix of cells receiving seed rain could remain empty, receive one seed, or receive multiple seeds. Each projection was run 100 times, to produce a mean seed dispersal total for each cell.

The resultant mean seed dispersal pattern projections were georeferenced to mapped canopy units using ArcGIS 9.2, then overlaid with spatially explicit field observations of seed rain (seed traps). Due to the discrete nature of cellular automata, the number of cells within a seed trap varied (Figure 2.6), however the summation of mean predicted seed rain per trap was normalized by area. To validate the dispersal models, four linear regressions were used to determine the relationship between the measured seed rain per seed trap $(\mathrm{Y})$ and the normalized predicted seed rain sum per trap at each site using parameterization model method $i$ or $i i$ (X) (SAS JMP v. 5.1.2), with measured 
seed rain observations weighted by the exposed cross-sectional area of the trap as modified by slope. Due to the wide range of observed and predicted seed rain, and a preponderance of zeroes, residuals were skewed to the right.

\section{Results}

\section{Reflectance Features and Phenology}

In the visible wavelength range, the mean peak reflectance factor of $A$. altissima upper and lower surface samara tissue was observed to occur at a wavelength of $585 \mathrm{~nm}$ and $574 \mathrm{~nm}$, respectively. The mean peak reflectance factor of all leaves sampled was $557 \mathrm{~nm}, 28 \mathrm{~nm}$ shorter than the upper surface samara tissue (Figure 2.7). Peak visible wavelength reflectance factor of upper and lower surface samara tissue was $28.1 \%$ and $54.4 \%$, respectively, while neighboring tree canopies had a mean peak reflectance factor of $26.2 \%$.

Starting June 28, 2005 and 2006, ground-based images showed that developing $A$. altissima samaras appeared to produce red (anthocyanin) coloration, which intensified until the end of July (July 27, 2005) or early August (August 10, 2006) (Appendix). The date of peak samara coloration varied between years, possibly due to yearly weather variation (Chmielewski and Rtözer 2001). Anthocyanin pigmentation of seeds varied among trees and has been observed to vary with exposure to sunlight (e.g. upper and lower surfaces) (Merzlyak and Chivkunova 2000). Seed color loss and desiccation did not begin prior to late August (August 30, 2005) or early September (September 8, 2006). 


\section{Classification of Samara Locations}

The overall and specific classification accuracy varied by year, but similar patterns of users and producers accuracy were obtained (Table 2.1; Figures 2.7-2.10), with high rates of commission error (low users accuracy) for A. altissima samaras occurring on bright closed canopy and bare soils. Omission rates of A. altissima samara tissue were low or zero. However, more detail of these rates can be interpreted from the correspondence assessment below. Kappa values for non A. altissima covers were similar between years and study sites (1.00), but close to random values of $\sim 0.05$ for $A$. altissima samaras. Low overall accuracy and Kappa values reflect the low proportion of A. altissima samara pixels available for sampling (all random samples were selected from areas not used as training sites). Specifically, classified A. altissima samara pixels represented $2.88 \%$ of Site II's cover in 2005. In 2006, A. altissima samara pixels represented only $1.93 \%$ and $2.02 \%$ of Site II and Site III, respectively.

Assessment of 1:1 correspondence ( $\geq 25 \%$ overlap) between the area of classified A. altissima samaras and the area of manually delineated canopy units of Site II for 2005 and 2006 (Figures 2.12 and 2.13, respectively) resulted in correspondence of $46 \%$ and $38 \%$ of the canopy units, respectively. Classifications of the 2006 Site III images showed that $78 \%$ of the canopy units had a 1:1 correspondence (Figure 2.14). After a natural log transformation, an ANCOVA did find the area of classified A. altissima samara pixels increased with manually-delineated canopy unit area $(\mathrm{F}=222.5681, \mathrm{p}<0.0001)$, as expected. The area of classified A. altissima samara pixels did not differ between sites ( $\mathrm{F}=0.5427, \mathrm{p}=0.5821$ ), and the relationship between the area of classified $A$. altissima samaras and the area of manually delineated canopy units did not vary by site $(F=0.1926$, $\mathrm{p}=0.8250)$. 


\section{Seed Quantity}

Total estimated seeds per manually delineated canopy unit had a strong linear relationship with the area of classified A. altissima samara pixels ( $\mathrm{p}=0.0007$; Figure 2.15.A), with $1 \mathrm{~m}^{2}$ of samara pixels comprising 10,323 seeds. Total estimated seeds per manually delineated canopy unit had a strong linear relationship with the area of the manually delineated canopy unit $(\mathrm{p}=0.0002$; Figure $2.15 . \mathrm{B})$. Total estimated seeds per tree had a positive $\log$-linear relationship with bole $\mathrm{dbh}(\mathrm{p}=0.0018$; Figure 2.16$)$. The average seed count per $25 \mathrm{~g}$ sample was $834.0 \pm 20.5$.

Site I classification accuracy patterns (users and producers) were similar to or slightly better than Site II and III (Table 2.1). The site did have high rates of commission error for A. altissima seeds ( 1 - users accuracy) occurring on bright covers, but there was no omission of $A$. altissima samaras ( $0 \%)$. The higher accuracy values at Site I may be due to a lower range of signatures for A. altissima seeds at this smaller study site.

\section{Seed Rain Measurements}

The total number of traps sampled for the entire study period was 338 , and these received a total of 725 seeds from October 25, 2006 to June 13, 2007. The majority of seed rain sampled (77.4\%) occurred between October 25 and Dec 21, 2006, during which time one trap $10 \mathrm{~m}$ from a female A. altissima received a cluster of 153 seeds. Overall, the mean seed rain was $8.58 \pm 1.92$ per $\mathrm{m}^{2}$. For the model validation we omitted the single seed cluster, resulting in a mean seed rain of $6.77 \pm 0.56$ per $\mathrm{m}^{2}$.

\section{Modeling and Validating the Seed Dispersion Pattern}

Site II contained an estimated total of 64,232,224 and 31,664,478 A. altissima seeds in 2005 and 2006, respectively calculated from the linear relationship between area of classified samara pixels and the number of seeds per classified pixel on an area basis. 
When estimated using only manually delineated canopy units, Site II contained an estimated total of 3,922,576 and 2,574,141 A. altissima seeds in 2005 and 2006, respectively. The difference reflected the large commission errors in the classification process. Site III contained an estimated total of 52,910,452 A. altissima seeds in 2006, however when estimated using only manually delineated canopy units, this site contained an estimated 2,192,676 in 2006.

Using modeling method $i$, where all classified $A$. altissima seed pixels were used as dispersal sources, the mean seed dispersion pattern for the 2006-2007 dispersal season broadly covered the study sites, with abundant densities predicted near canopy units and areas with classification commission errors. The mean seed rain per trap was predicted to be $58.4 \pm 3.3$ and $52.9 \pm 2.6$ at Sites II and III, respectively (Figures 2.17.A and 2.18.A). Using modeling method $i i$, where only classified A. altissima seed pixels within manually delineated canopy units were used as seed sources, the mean seed dispersion pattern for the 2006-2007 dispersal season was localized around the canopy units (Figures 2.17.B and 2.18.B). The mean seed rain per trap was predicted to be $6.6 \pm 0.9$ and $18.8 \pm 3.0$ at Sites II and III, respectively. Using both methods, a large quantity of seeds were projected to fall in the surrounding closed canopy forest, canopy gaps, shoreline, and water.

Using model method $i$, we determined there was no correspondence of predicted seed rain values to the observed seed rain for Site II $(y=0.0039 x+1.0896, p=0.2997$, Figure 2.19.A), however, there was a negative relationship observed at Site III ( $\mathrm{y}=-$ $0.0155 \mathrm{x}+2.9999, \mathrm{p}=0.0053$; Figure 2.20.A). Using delineated seed sources in model method $i i$, we observed a positive relationship between predicted seed rain and observed 
seed rain per trap at Site II $(y=0.0072 x+1.1612, p=0.0225$, Figure 2.19.B), however, no correspondence was observed at Site III $(y=-0.0082 x+2.201, p=0.7002$, Figure 2.20.B).

\section{Discussion}

Determination of A. altissima propagule pressure sources through remote sensing appears possible. A. altissima samara clusters have a distinctive spectral reflectance compared to the surrounding canopy vegetation and there is a positive linear relationship between the area of classified A. altissima seeds and the total seed yield of a canopy unit as determined by the harvest.

Specifically, the mean spectral reflectance of canopy vegetation showed distinctive reflectance peaks of $A$. altissima samaras that were at longer wavelengths than the surrounding vegetation. Previous studies found the peak anthocyanin wavelength reflectance factor of four unrelated species at $550 \mathrm{~nm}$ (Gitelson et al. 2001), similar to the reflectance factor peak found for neighboring leaf tissue measured (Figure 2.6), but 24 $\mathrm{nm}$ shorter than upper A. altissima samara surfaces. The longer peak wavelength may be due to the overlapping absorption patterns of anthocyanin and chlorophyll (Sims and Gamon 2002), both present in high concentrations in A. altissima samaras. Additionally, abaxial samara surfaces producing low amounts of anthocyanin reflect more than twice the amount of visible light at their mean peak than surrounding canopy leaves. These "bright" lower surfaces, which may be exposed by wind, and other highly reflective samara tissue that naturally have low amounts of anthocyanin, result in a range of signatures for a single class. 
Due to anticipated pigmentation variances from one tree to another, the $A$. altissima samara training classes encompassed a wide range of spectral values. The supervised classifications were frequently unable to distinguish between other features with high reflectivity, such as abaxial surfaces of Liriodendron tulipifera (tulip poplar) leaves. Previous work had shown bright canopy tissues could be partitioned if a separate class was developed for it in the classification, if needed (Kaproth unpublished data). In addition, high rates of commission overestimate the area of individuals, as seen in similar work with Argyroxiphium sandwicense (Haleakala silverswords) in Hawaii (Landenberger et al. 2003), but increased resolution and hyperspectral imaging could reduce sources of error. While the supervised classification procedure had difficulty discerning between $A$. altissima samaras and other areas of high reflectance, its use would nevertheless enable managers to highlight a much smaller area to intensively investigate, and of most importance, errors of omission were small to ensure no $A$. altissima went undetected.

This application of remote sensing also allows for the identification of propagule quantity. The relationship of seed yield and classified samara area is independent of canopy location, and this shade-intolerant species bears a proportion of samaras on its crown that permit estimations of total seed yield. The same relationships were found for the area of a female A. altissima canopy and propagule quantity, implying that if gender is known, delineations of canopy units may be used in place of seed classification. Of note however, seed yield may vary from year to year due to environmental variation (Chmielewski and Rtözer 2001) or local weather events like the limb-removing ice storm of October 2005 in the Morgantown, WV, area. Both the 2005 ice storm and dry summer 
conditions that caused some samara abortions in 2006 may explain the 2.0 -fold lower overall seed quantity at Site II, and the 1.5 -fold reduction within the delineated canopy units.

The cellular automata model projected the propagule pressure of two populations over the 2006-2007 seed dispersal period. Compared to empirical measurements of seed rain, the seed dispersion model based on all classified $A$. altissima samara pixels (model method $i$ ) predicted a mean seed rain total 33.0-fold higher than mean observed seed rain per trap, however the mean predictions using only classified A. altissima samaras within manual delineated canopy units (model method $i$ ) predicted a mean 7.2-fold higher than the mean observed seed rain per trap. This later method demonstrates the advantage of using manually delineated canopy units as a means of discriminating sources of seeds, however, commission error at Sites II and III appear to have increased the apparent seed quantity. For example, it was believed that one canopy unit at Site III overrepresented the number of seeds available for seed rain. If the relationship between observed seed rain $(\mathrm{X})$ and the mean predicted seed rain $(\mathrm{Y})$ at Site III was run using seed traps farther than $200 \mathrm{~m}$ from that canopy unit, there is a trend towards a positive linear relationship using model method $i(\mathrm{y}=03738 \mathrm{x}+1.0398025, \mathrm{p}=0.0830)$ and a strong positive relationship using model method $i i(\mathrm{y}=3.8096 \mathrm{x}+0.6122, \mathrm{p}<0.0001)$.

While the seed rain predicted using model method $i i$ was positively correlated with observed seed rain values, the model greatly overestimated propagule pressure. While the classifications used in this model may still prove useful to the management of this species, it requires greater accuracy of seed quantity and additional seed dispersal curves to accurately reflect seed dispersion patterns under varying landscape conditions (Higgins 
and Richardson 1996). Higher accuracy in seed quantification may be accomplished by increased image resolution and by allowing higher levels of omission error in the supervised classifications. Factors that may affect both seed dispersal and seed trap efficacy include elevation (including slope and aspect), vegetation cover (Landenberger et al. 2007), prevailing wind (Kota 2005, Landenberger et al. 2007), characterization of the primary dispersal tail, and how seeds dehisce from the parent (seed cluster fragments likely have much lower dispersal distances). In future work, we plan to incorporate additional curves parameterized for varying wind direction, slope, and vegetation cover, all of which may improve model predictions. For example, by incorporating vegetation features and propagule pressure in a semimechanistic model, researchers have been able to explain $70 \%$ of range variation for invasive trees in South Africa (Rouget and Richardson 2003).

The ability to accurately project a species' propagule pressure over an environment is valuable in the prevention of invasive spread (Davis et al. 2000, Kota et al. 2007). An invasive is often able to overcome limiting factors (e.g. disturbance) to become established, but is more likely to succeed when propagule input is high (Britton-Simmons and Abbott 2008), thus it can be expected that an area will eventually be invaded if under high propagule pressure, particularly if disturbance is likely (Higgins and Richardson 1996, Davis et al. 2000). This invasion may be preventable with the identification and removal of the invasive propagule sources (Kota et al. 2007, Landenberger et al. 2007).

Within the scope of this study, it was shown that classifications indicating seed location and density can be used to identify sources and quantities of propagule pressure over a landscape with low rates of omission (Figures 2.17-18). Due to the difficulty of 
partitioning highly reflective features, and the subsequent high errors of commission, conservative estimates of yearly A. altissima propagule quantity and location is limited. After spatially-explicit identification of seed sources, seed quantity model parameterization may benefit by reclassifying images with a lower commission tolerance, at the cost of higher omission error. In addition, manual delineation of canopy units permit more accurate identification of invasive propagule pressure sources through remote sensing (Figures 2.19B-20.B), and can be used for parameterization of seed dispersion pattern models across a landscape, providing yearly projections of propagule pressure for threatened communities. 


\section{Literature Cited}

Brandtberg, T., T. Warner, R. Landenberger, J. McGraw, 2003. Detection and analysis of individual leaf-off tree crowns in small footprint, high sampling density LIDAR data from the eastern deciduous forest in North America. Remote Sensing of Environment 85: 290-303.

Britton-Simmons, K.H. and K.C. Abbott, 2008. Short- and long-term effects of disturbance and propagule pressure on a biological invasion. Journal of Ecology 96:68-77.

Byers, J.E., S. Reichard, J.M. Randall, I.M. Parker, C.S. Smith, W.M. Lonsdale, I.A.E. Atkinson, T.R. Seastedt, M. Williamson, E. Chornesky, and D. Hayes, 2002. Directing research to reduce the impacts of nonindigenous species. Conservation Biology 16(3):630-640.

Call, L.J. and E.T. Nilsen, 2003. Analysis of spatial patterns and spatial association between the invasive Tree-of-heaven (Ailanthus altissima) and the native Black locust (Robinia pseudoacacia). American Midland Naturalist. 150: 1-14.

Carson, H.W., L.W. Lass, and R.H. Calliham, 1995. Detection of yellow hawkweed with high resolution digital images. Weed Technology 9:477-483.

Chmielewski, F., T. Rtözer, 2001. Response of tree phenology to climate change across Europe. Agricultural and Forest Meteorology 108:101-112.

Cohen, J., 1960. A Coefficient of agreement for nominal scales. Educational and Psychological Measurement 20:37-46. 
Congalton, R.G., R.G. Oderwald, and R.A. Mead, 1983. Assessing Landsat classification accuracy using discrete multivariate analysis statistical techniques. Photogrammetric Engineering and Remote Sensing 49:1671-1678.

Davis, M.A., J.P. Grime, and K. Thompson, 2000. Fluctuating resources in plant communities: a general theory of invasibility. Journal of Ecology 88:528-534.

DiFazio, S., 2002. Measuring and modeling gene flow from hybrid poplar plantations: Implications for transgenic risk assessment. Ph.D. dissertation, Oregon State University, Corvallis, O.R., U.S.A. 166-171.

Feret, P.P., 1985. Ailanthus: Variation, cultivation, and frustration. J. of Arboriculture 11(12):361-368

Gitelson, A.A., M.N. Merzlak, and O.B. Chivkunova, 2001. Optical properties and nondestructive estimation of anthocyanin content in plant leaves. Photochemistry and Photobiology 74 (1): 38-45.

Gleason, H.A. and A. Cronquist, 1963. Manual of Vascular Plants of Northeastern United

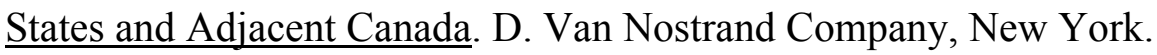

Greene, D.F. and E.A. Johnson, 1994. Estimating the mean annual seed production of trees. Ecology 75(3):642-647.

Grubb, P.J., 1977. The maintenance of species-richness in plant communities: The importance of the regeneration niche. Biol. Rev. 52:107-145.

He, H.S., and D.J. Mladenoff, 1999. The effects of seed dispersal on the simulation of long-term forest landscape change. Ecosystems 2: 308-319.

Higgins, S.I. and D.M. Richardson, 1996. A review of models of alien plant spread. Ecological Modelling 87:249-265. 
Higgins, S.I., and D.M. Richardson, 1998. Pine invasions in the southern hemisphere: Modelling interactions between organism, environment and disturbance. Plant Ecology 135: 79-93.

Joshi, C., J.D. Leeuw, J. van Andel, A.K. Skidmore, H.D. Lekhak, I.C. van Duren, and N. Norbu, 2006. Indirect remote sensing of cryptic forest understorey invasive species. Forest Ecology and Management 225:245-256.

Key, T., T.A. Warner, J.B. McGraw, and M.A. Fajvan, 2001. A comparison of multispectral and multitemporal information in high spatial resolution imagery for classification of individual tree species in a temperate hardwood forest. Remote Sensing of Environment 75: 100-112.

Kolar, C.S. and D.M. Lodge, 2001. Progress in invasion biology: Predicting invaders. TRENDS in Ecology \& Evolution 16(4):1999-204.

Kota, N.L., 2005. Comparative seed dispersal, seedling establishment and growth of exotic, invasive Ailanthus altissima (Mill.) Swingle and native Liriodendron tulipifera (L.). West Virginia University Dept. of Biology, Electronic Thesis.

Kota, N.L., R.E. Landenberger, and J.B. McGraw, 2007. Germination and early growth of Ailanthus and tulip poplar in three levels of forest disturbance. Biological Invasions 9:197-211.

Lamar, W.R., 2003. Censusing and modeling the dynamics of a population of eastern hemlock (Tsuga Canadensis L.) using remote sensing. West Virginia University Dept. of Biology, Electronic Dissertation. 
Lamar, W.R. and J.B. McGraw, 2005. Evaluating the use of remotely sensed data in matrix population modeling for eastern hemlock (Tsuga Canadensis L.). Forest Ecology and Management 212:50-64.

Lamar, W.R., J.B. McGraw, and T.A. Warner, 2005. Multitemporal censusing of a population of eastern hemlock (Tsuga Canadensis L.) from remotely sensed imagery using an automated segmentation and reconciliation procedure. Remote Sensing of the Environment 94:133-143.

Landenberger, R.E., J.B. McGraw, T.A. Warner, and T. Brandtberg, 2003. Potential of digital color imagery for censusing Haleakala silverswords in Hawaii. Photogrammetric Engineering and Remote Sensing 69(8):915-923.

Landenberger, R.E., N.L. Kota, and J.B. McGraw, 2007. Seed dispersal of the non-native invasive tree Ailanthus altissima into contrasting environments. Plant Ecol. 192:55-70.

Landis, J.R. and G.G. Koch, 1977. The measurement of observer agreement for categorical data. Biometrics 33(1):159-174.

Lass, L.W., D.C. Thill, B. Shafii, and T.S. Prather, 2002. Detecting spotted knapweed (Centaurea maculosa) with hyperspectral remote sensing technology. Weed Technology 16:426-432.

Lass, L. W., and T. S. Prather, 2004. Detecting the locations of Brazilian Pepper trees in the Everglades with a hyperspectral sensor. Weed Technology 18: 437-442.

Leung, B., J.M. Drake, and D.M. Lodge, 2004. Predicting invasions: Propagule pressure and the gravity of allee effects. Ecology 85(6):1651-1660. 
Lockwood, J.L., P. Cassey, and T. Blackburn, 2005. The role of propagule pressure in explaining species invasions. TRENDS in Ecology and Evolution 20(5):223-228.

Mack, R.N., D. Simberloff, W.M. Lonsdale, H. Evans, M. Clout, and F.A. Bazzaz, 2000. Biotic invasions: Causes, epidemiology, global consequences, and control. Ecological Applications 10(3):689-710.

Merzlyak, M.N. and O.B. Chivkunova, 2000. Light-stress-induced pigment changes and evidence for anthocyanin photoprotection in apples. J. of Photochemistry and Photobiology 55(2-3):155-163.

McGraw, J.B., T.A. Warner, T. Key, and W.R. Lamar, 1998. High spatial resolution remote sensing of forest trees. Trends in Ecology and Evolution 13(8): 300 - 301.

Molofsky, J. and J.D. Bever, 2004. A new kind of ecology? Bioscience. 54: 440-446.

Nathan, R. and H.C. Muller-Landau, 2000. Spatial patterns of seed dispersal, their determinants and consequences for recruitment. TREE 15(7):278-285.

Pimentel, D., L. Lori, R. Zuniga, and D. Morrison, 2000. Environmental and economic costs of nonindigenous species in the United States. BioScience 50(1):53-65.

Pimentel, D., R. Zuniga, and D. Morrison, 2005. Update on the environmental and economic costs associated with alien-invasive species in the United States. Ecological Economics 52:273-288.

Pinter, P.J.Jr., J.L. Hatfield, J.S. Schepers, E.M. Barnes, M.S. Moran, C.S.T. Daughtry, and D. R. Upchurch, 2003. Remote sensing for crop management. Photogrammetric Engineering \& Remote Sensing 69(9):647-664. 
Ribbens, E., J.A. Silander, Jr., and S.W. Pacala, 1994. Seedling recruitment in forests: calibrating models to predict patterns of seedling dispersion. Ecology 75(6):17941806.

Rouget, M. and D.M. Richardson, 2003. Inferring process from pattern in plant invasions: A semimechanistic model incorporating propagule pressure and environmental factors. American Naturalist 162(6):713-724.

Samson, D.A. and K.S. Werk, 1986. Size-dependant effects in the analysis of reproductive effort in plants. American Naturalist 127(5):667-680.

Shanahan, J.F., J.S. Schepers, D.D. Francis, G.E. Varvel, W.W. Wilhelm, J.M. Tringe, M.R. Schlemmer, and D.J. Major, 2001. Use of remote-sensing imagery to estimate corn grain yield. Agronomy J. 93:583-589.

Sims, D.A. and J.A. Gamon, 2002. Relationships between leaf pigment content and spectral reflectance across a wide range of species, leaf structures and developmental stages. Remote Sensing of Environment 81:337-354.

Swearingen, J., 1999. Tree-of-heaven, Ailanthus altissima (Mill.) Swingle. Plant Conservation Alliance, Alien Plant Working Group.

Travis, J.M.J., and C. Dytham, 1998. The evolution of dispersal in a metapopulation: a spatially explicit, individual-based model. Proc R. Soc. Lond. B 265: 17-23.

Ustin, S.L., D.A. Roberts, J.A. Gamon, G.P. Asner, and R.O. Green, 2004. Using imaging spectroscopy to study ecosystem processes and properties. BioScience 54 (6): $523-534$.

With, K.A., 2002. The landscape ecology of invasive spread. Conservation Biology 16(5):1192-1203. 
With, K.A., 2004. Assessing the risk of invasive spread in fragmented landscapes. Risk Analysis 24(4):803-815.

Wolf, F.T., 1956. Changes in chlorophylls A and B in autumn leaves. American Journal of Botany 43: 714-718. 
Table 2.1: Accuracy assessment of classifications

\begin{tabular}{|c|c|c|c|c|c|c|c|c|c|c|c|c|}
\hline \multirow[b]{2}{*}{$\begin{array}{l}\text { Class } \\
\text { Name }\end{array}$} & \multicolumn{3}{|c|}{ Site I - 2006} & \multicolumn{3}{|c|}{ Site II - 2005} & \multicolumn{3}{|c|}{ Site II - 2006} & \multicolumn{3}{|c|}{ Site III - 2006} \\
\hline & $\begin{array}{l}\text { Producers } \\
\text { Accuracy }\end{array}$ & $\begin{array}{l}\text { Users } \\
\text { Accuracy }\end{array}$ & Kappa & $\begin{array}{c}\text { Producers } \\
\text { Accuracy }\end{array}$ & $\begin{array}{l}\text { Users } \\
\text { Accuracy }\end{array}$ & Kappa & $\begin{array}{l}\text { Producers } \\
\text { Accuracy }\end{array}$ & $\begin{array}{l}\text { Users } \\
\text { Accuracy }\end{array}$ & Kappa & $\begin{array}{c}\text { Producers } \\
\text { Accuracy }\end{array}$ & $\begin{array}{c}\text { Users } \\
\text { Accuracy }\end{array}$ & Карра \\
\hline $\begin{array}{c}\text { Ailanthus } \\
\text { altissima } \\
\text { samara } \\
\text { clusters }\end{array}$ & $100 \%$ & $23 \%$ & 0.1299 & $100 \%$ & $10 \%$ & 0.0526 & $100 \%$ & $8 \%$ & 0.0417 & $83 \%$ & $5 \%$ & 0.0206 \\
\hline $\begin{array}{l}\text { Non } \\
\text { samara } \\
\text { clusters } \\
\text { cover }\end{array}$ & $57 \%$ & $100 \%$ & 1.0000 & $53 \%$ & $100 \%$ & 1.0000 & $52 \%$ & $100 \%$ & 1.0000 & $51 \%$ & $99 \%$ & 0.6667 \\
\hline $\begin{array}{c}\text { Overall } \\
\text { Accuracy }\end{array}$ & \multicolumn{3}{|c|}{$62 \%$} & \multicolumn{3}{|c|}{$55 \%$} & \multicolumn{3}{|c|}{$54 \%$} & \multicolumn{3}{|c|}{$52 \%$} \\
\hline $\begin{array}{l}\text { Overall } \\
\text { Kappa }\end{array}$ & \multicolumn{3}{|c|}{0.2300} & \multicolumn{3}{|c|}{0.1000} & \multicolumn{3}{|c|}{0.0800} & \multicolumn{3}{|c|}{0.0400} \\
\hline
\end{tabular}


Table 2.2: Seed trap arrangement

\begin{tabular}{ccccc} 
Site & Microsite & $\begin{array}{c}\text { Number of } \\
\text { Study Sites }\end{array}$ & $\begin{array}{c}\text { Complete } \\
\text { Record }\end{array}$ & Aspect \\
\hline \hline II & Canopy Gap & 1 & 21 & SSE \\
& Closed Canopy Forest & 1 & 39 & SSE \\
& Forest/Field Edge & 1 & 7 & WSW \\
& Field & 1 & 46 & WSW \\
& Forested Shoreline & 2 & 45 & S, SSE \\
\hline III & Canopy Gap & 1 & 24 & SE \\
& Closed Canopy Forest & 2 & 36 & SE \\
& Forest/Field Edge & 1 & 25 & ENE \\
& Field & 1 & 46 & SSE \\
& Forested Shoreline & 1 & 49 & SE
\end{tabular}




\section{Figure Legends}

2.1: Schematic map of study sites in north-central WV.

2.2: Aerial images of Site I, captured August 23, 2006. Left image was taken $1 \mathrm{~km}$ east of right images.

2.3: Aerial image mosaic of Site II, captured August 3, 2005.

2.4: Aerial image mosaic of Site II, captured August 23, 2006.

2.5: Aerial image mosaic of Site III, captured August 23, 2006.

2.6: Example seed trap with mean seed dispersal, using model method $i$. Cells values represent mean projected seed rain per $\mathrm{m}^{2}$.

2.7: Mean visible wavelength range reflectance factors of canopy vegetation captured in Morgantown, WV, July 10, 2005.

2.8.A: Aerial image of Site I, captured August 23, 2006. A mature A. altissima canopy is located just above arrow.

2.8.B: Supervised classification of August 23, 2006 imagery of Site I.

2.9.A: Aerial image of Site II, captured August 3, 2005. A mature A. altissima canopy is located just above arrow.

2.9.B: Supervised classification of August 3, 2005 imagery of Site II.

2.10.A: Aerial image of Site II, captured August 23, 2006. A mature A. altissima canopy is located just above arrow.

2.10.B: Supervised classification of August 23, 2006 imagery of Site II.

2.11.A: Aerial image of Site III, captured August 23, 2006. A mature A. altissima canopy is located just above black arrow. 
2.11.B: Supervised classification of August 23, 2006 imagery of Site III. A mature $A$. altissima canopy is located just above black arrow.

2.12: Site II (2005). Regression of classified A. altissima samara area on manually delineated canopy unit area showing a positive linear relationship.

2.13: Site II (2006). Regression of classified A. altissima samara area on manually delineated canopy unit area showing a positive linear relationship.

2.14: Site III (2006). Regression of classified A. altissima samara area on manually delineated canopy unit area showing a positive linear relationship.

2.15.A: Site I relationship between total estimated number of seeds and area of classified A. altissima samaras per manually delineated canopy unit. Trend line is constrained through the origin.

2.15.B: Site I relationship between total estimated number of seeds and area of manually delineated canopy unit. Trend line is constrained through the origin.

2.16: Positive log-linear relationship between total estimated seeds per tree and individual dbh.

2.17.A: Mean projected seed dispersion pattern of manually delineated A. altissima at Site II from 2006-2007 using method $i$.

2.17.B: Mean projected seed dispersion pattern of manually delineated A. altissima at Site II from 2006-2007 using method ii.

2.18.A: Mean projected seed dispersion pattern of manually delineated A. altissima at Site III from 2006-2007 using method $i$.

2.18.B: Mean projected seed dispersion pattern of manually delineated A. altissima at Site III from 2006-2007 using method $i$. 
2.19.A: Correspondence of mean projected seed rain predictions and observed seed rain per trap at Site II using model method $i$. 1:1 correspondence is represented by grey trend line.

2.19.B: Positive relationship between mean projected seed rain predictions and observed seed rain per trap at Site II using model method ii. 1:1 correspondence is represented by grey trend line.

2.20.A: Negative correspondence of mean projected seed rain predictions and observed seed rain per trap at Site III using model method $i$. 1:1 correspondence is represented by grey trend line.

2.20.B: Correspondence of mean projected seed rain predictions and observed seed rain per trap at Site III using model method ii. 1:1 correspondence is represented by grey trend line. 
Figure 2.1:

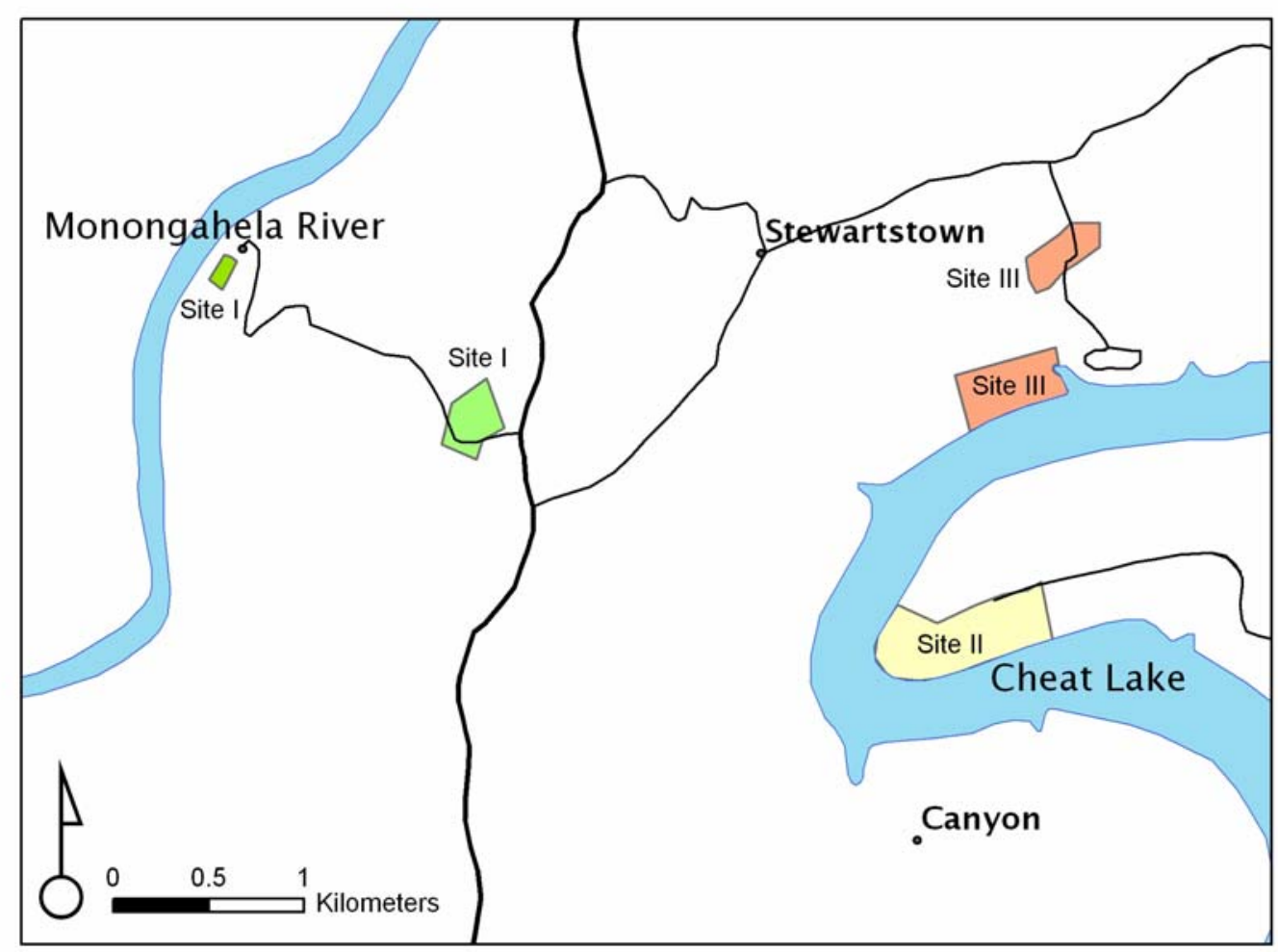


Figure 2.2:
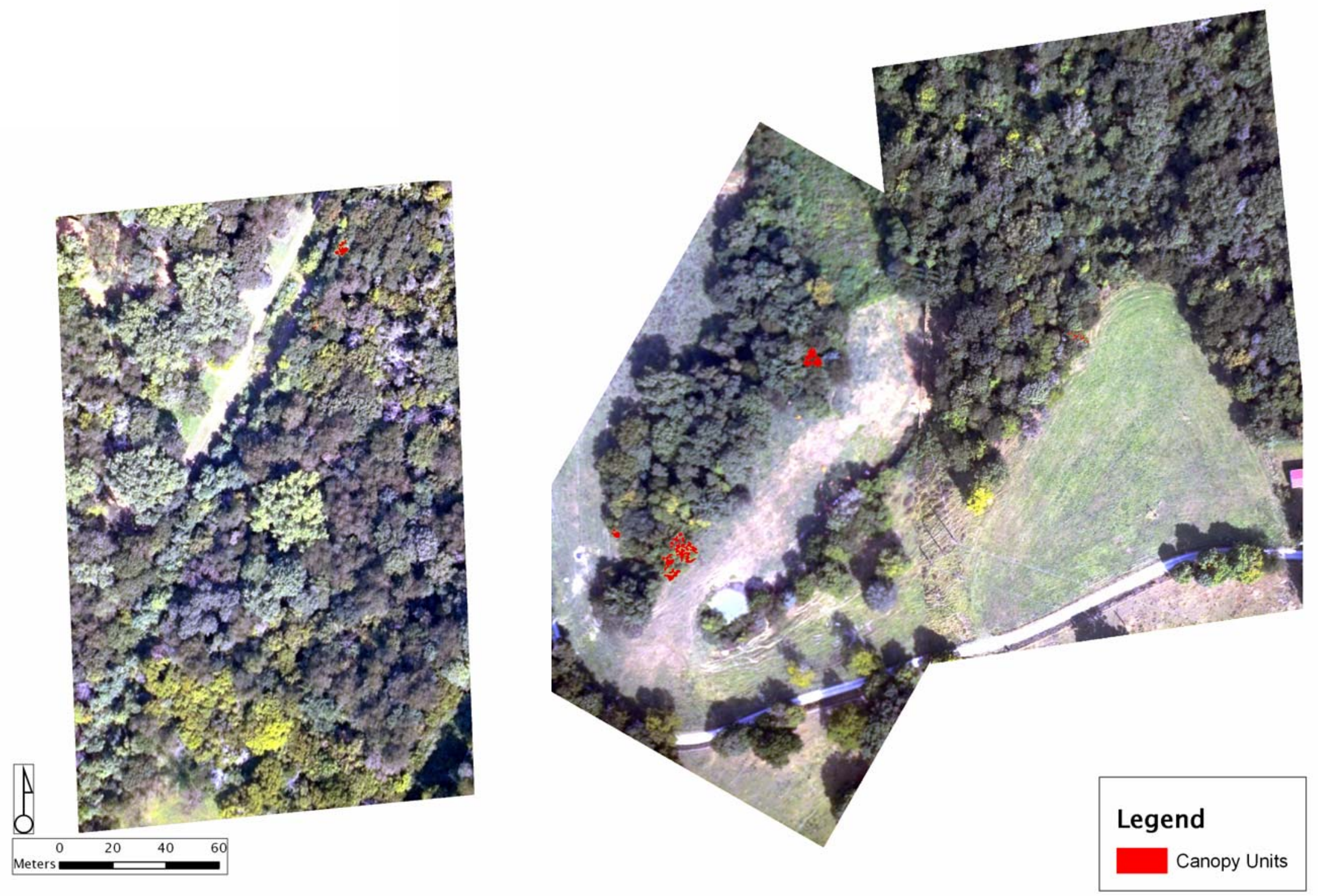
Figure 2.3:

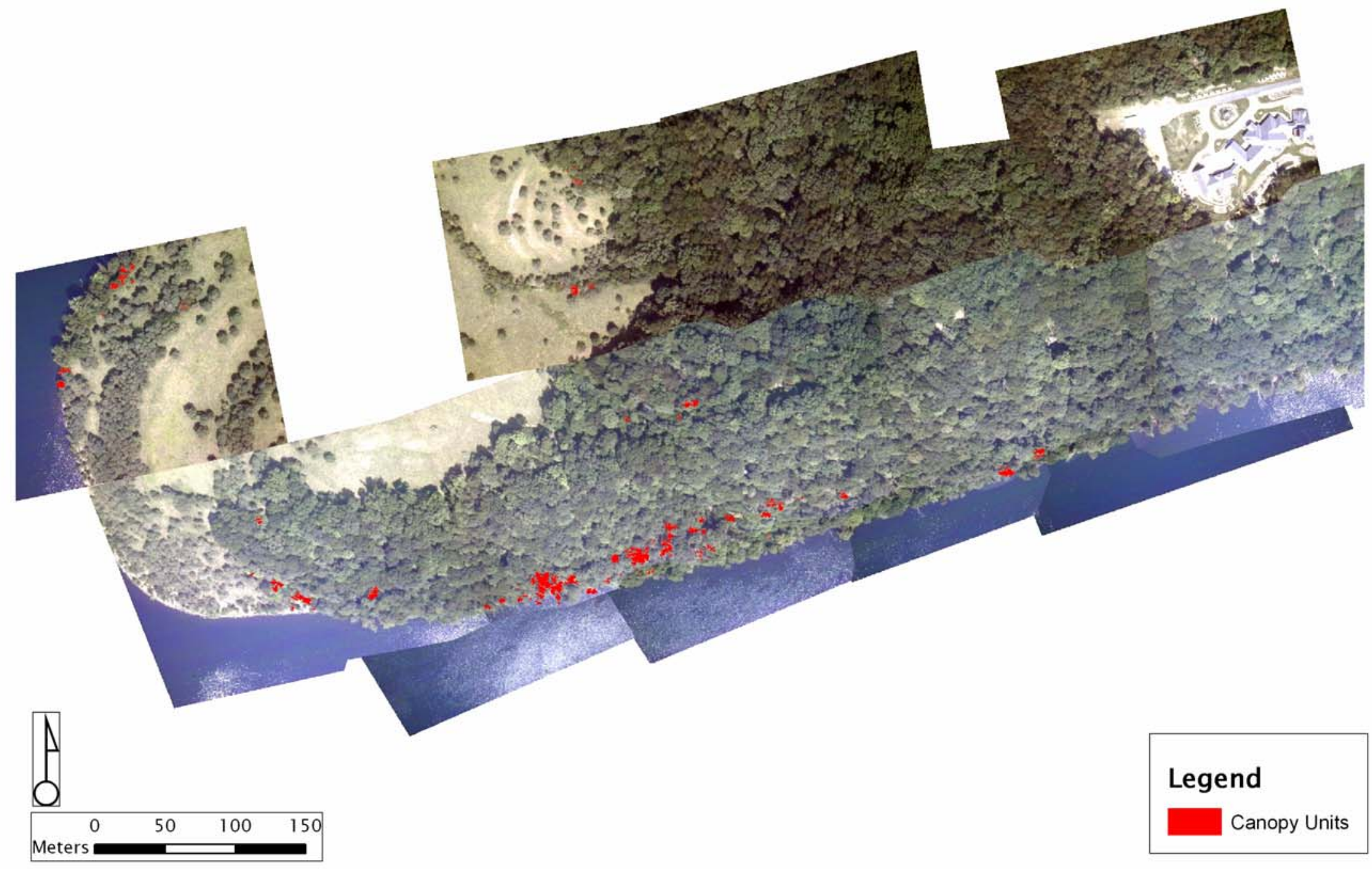


Figure 2.4:

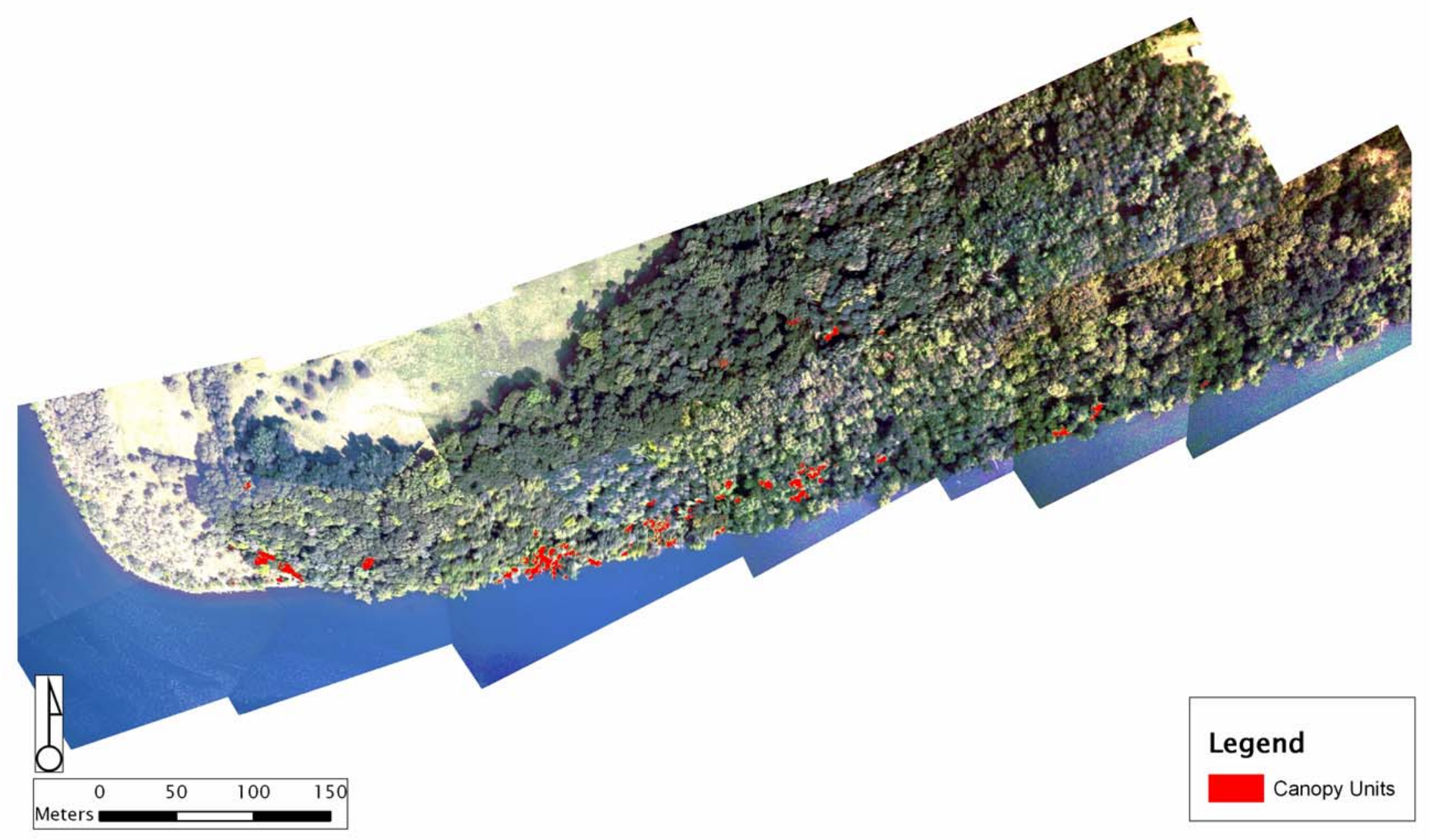




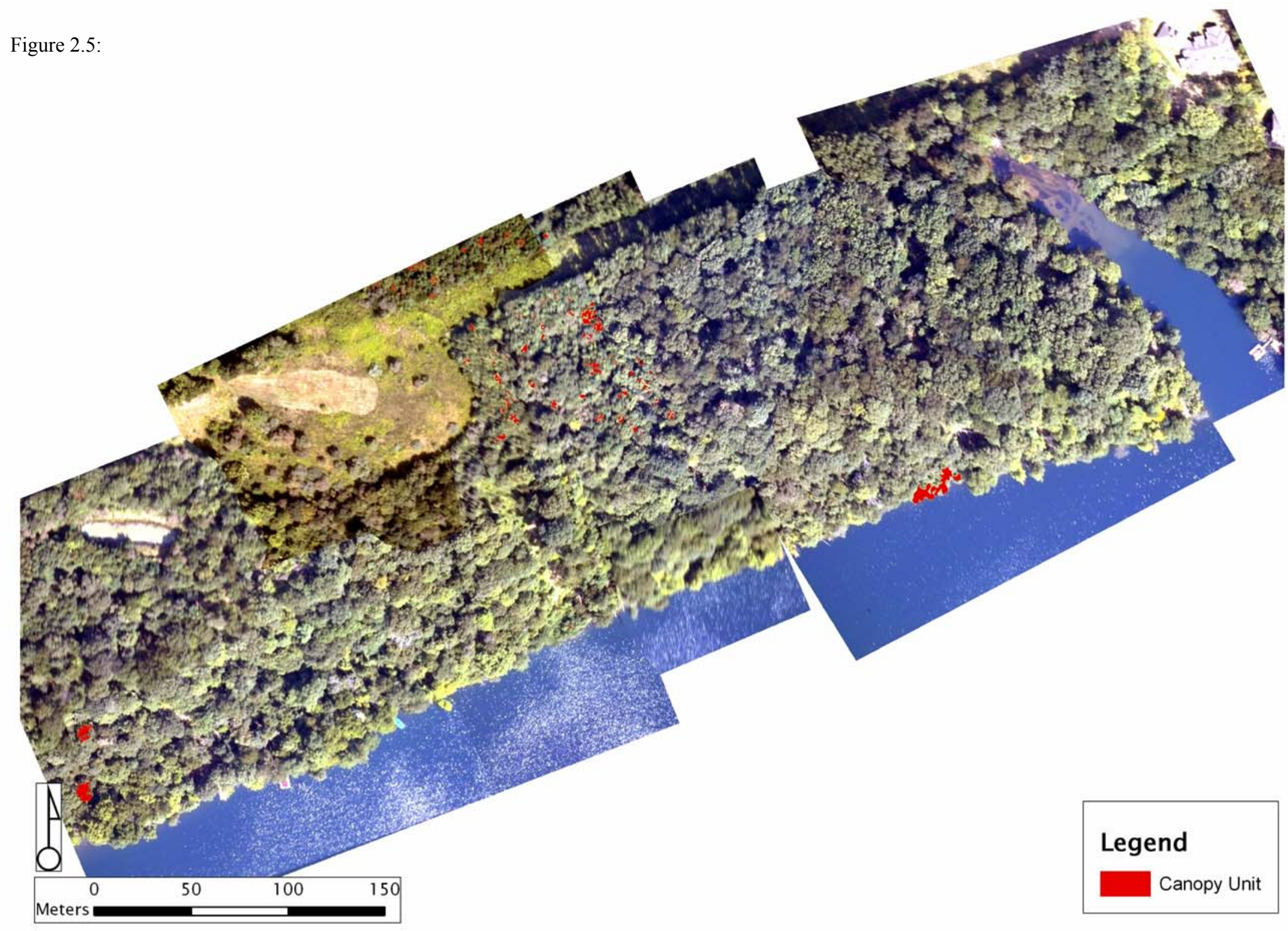


Figure 2.6:

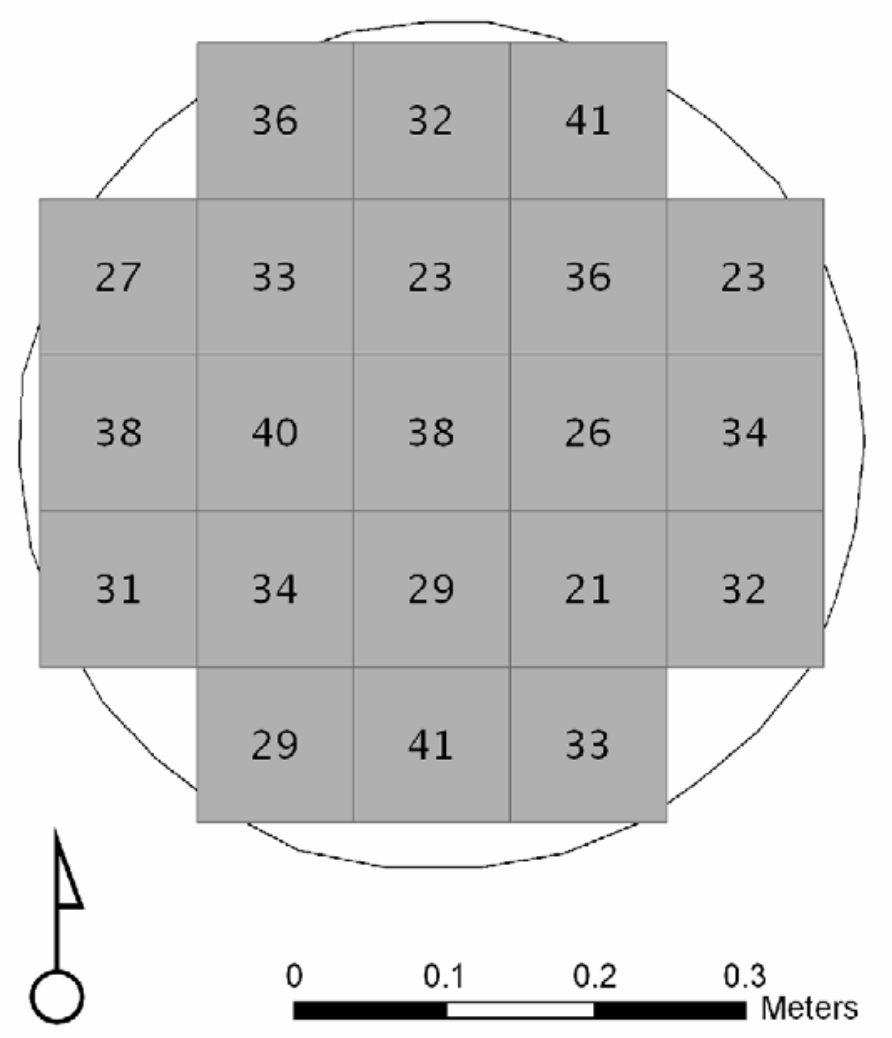


Figure 2.7:

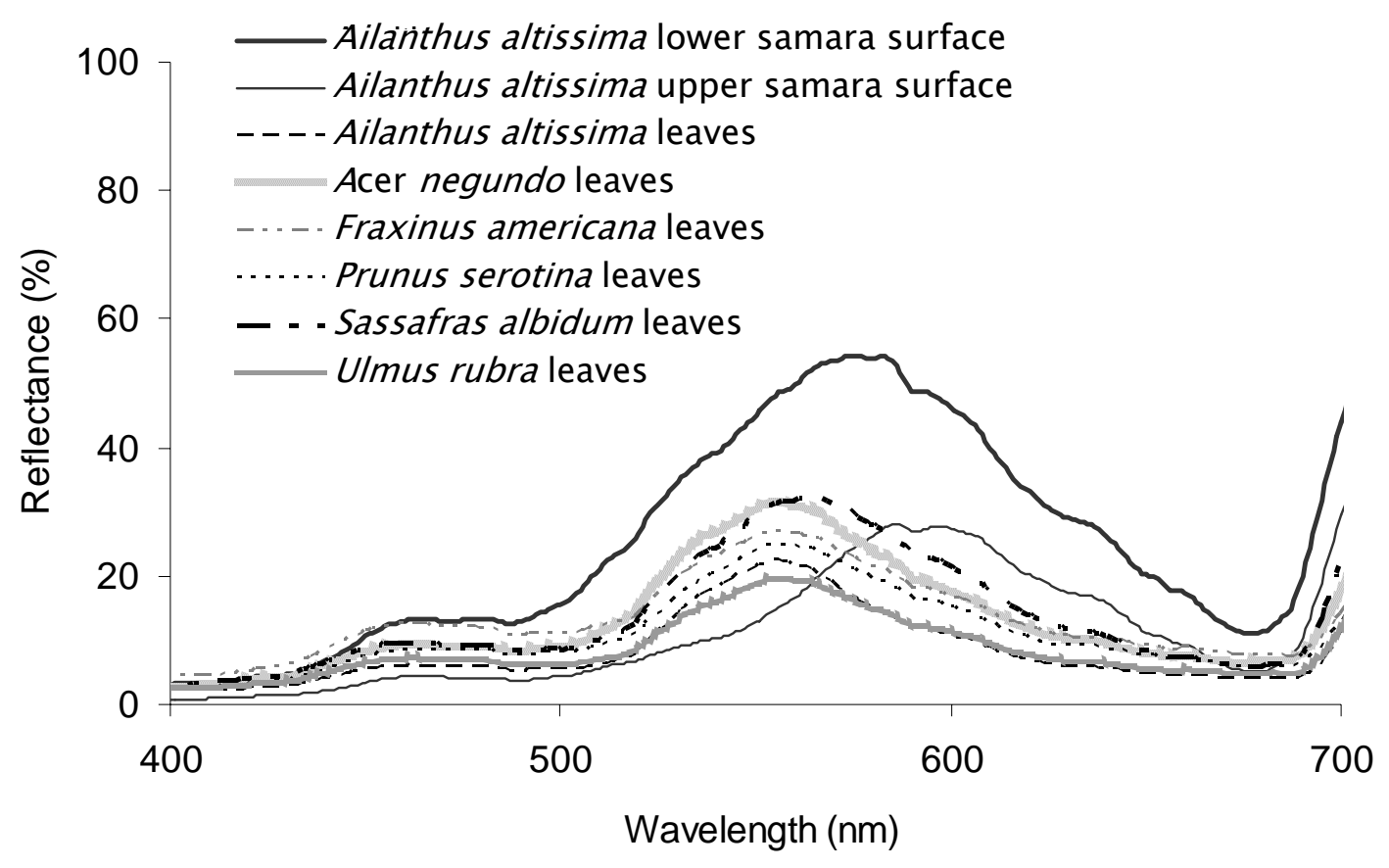


Figure 2.8.A:

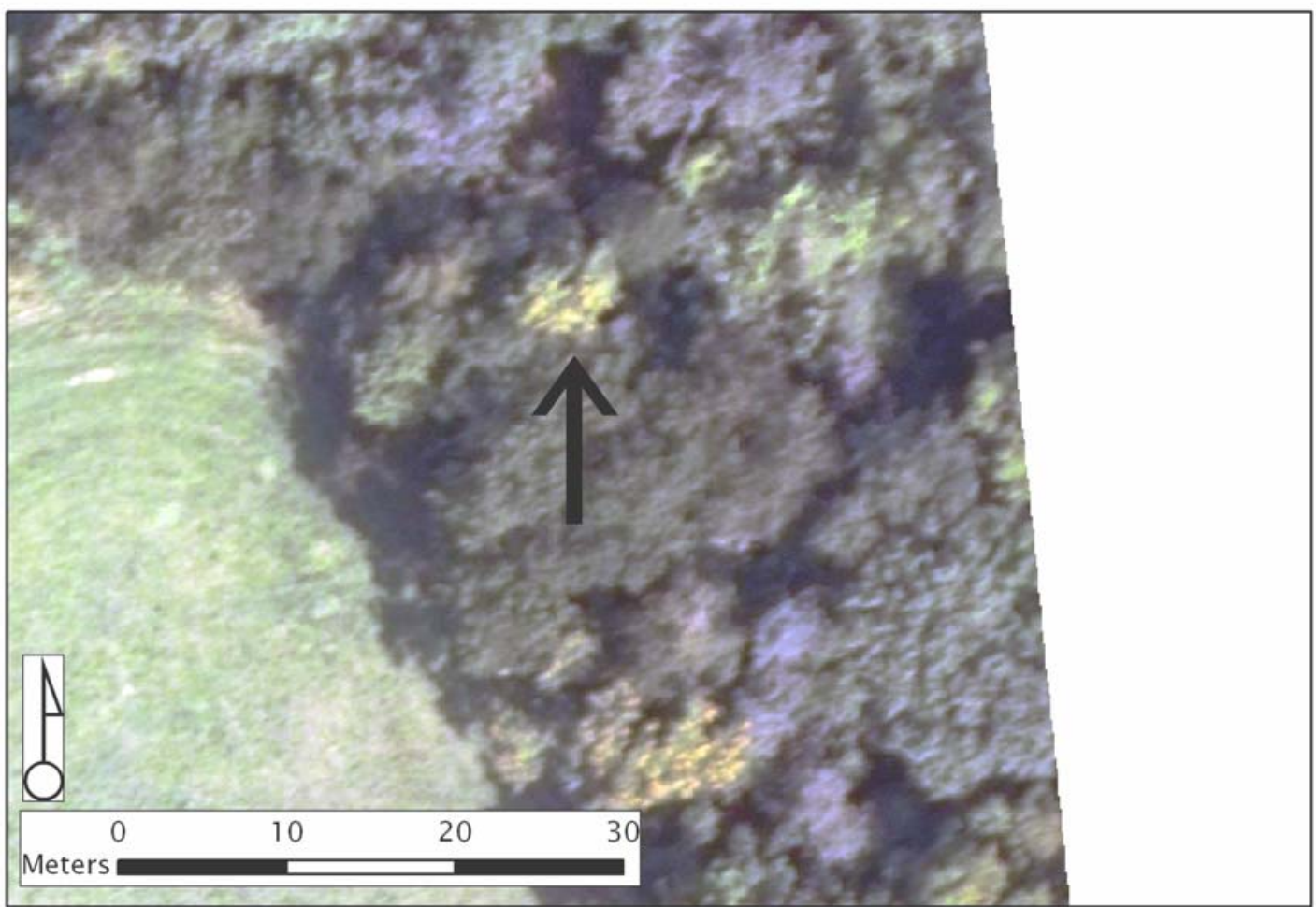

Figure 2.8.B:

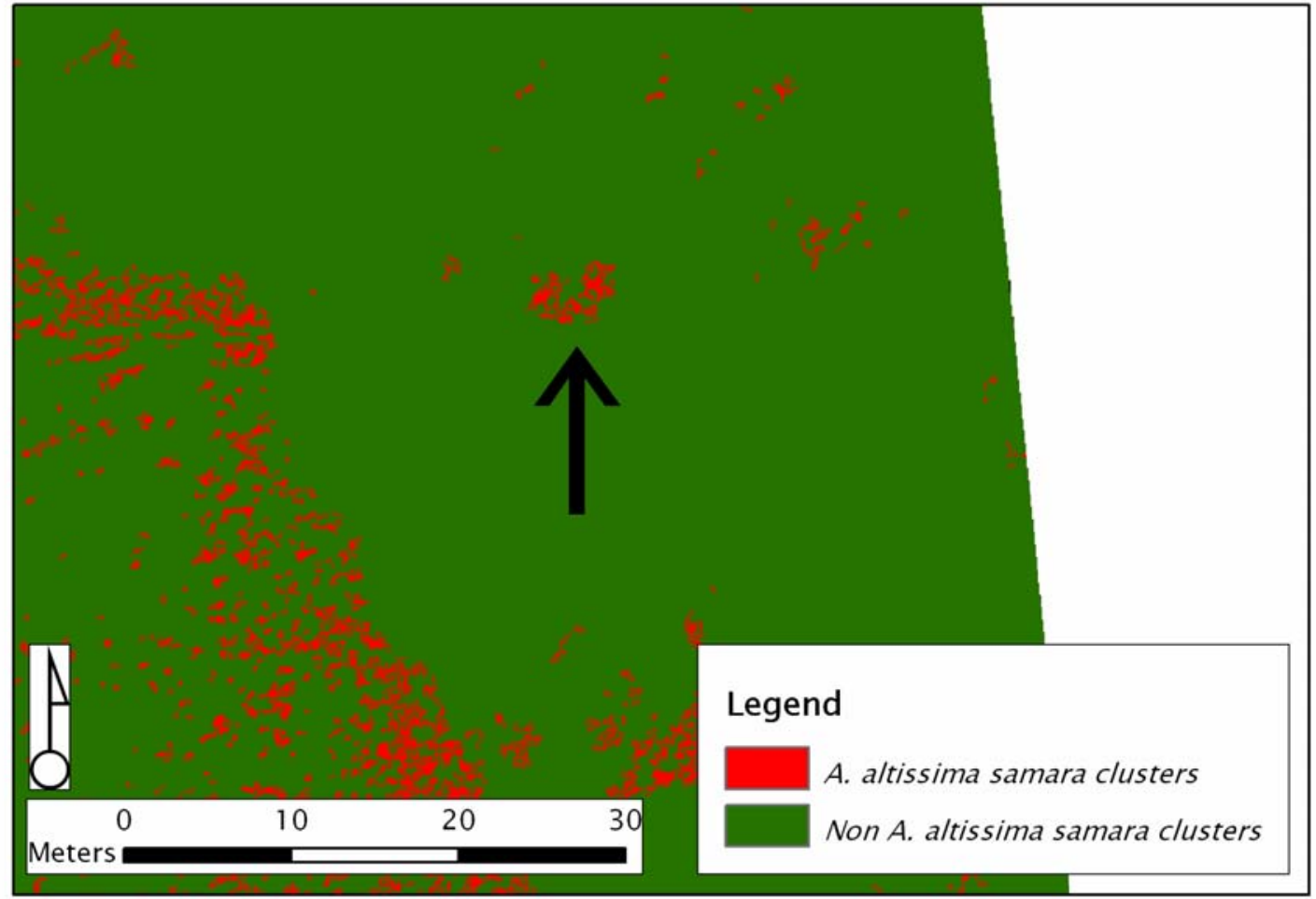


Figure 2.9.A:

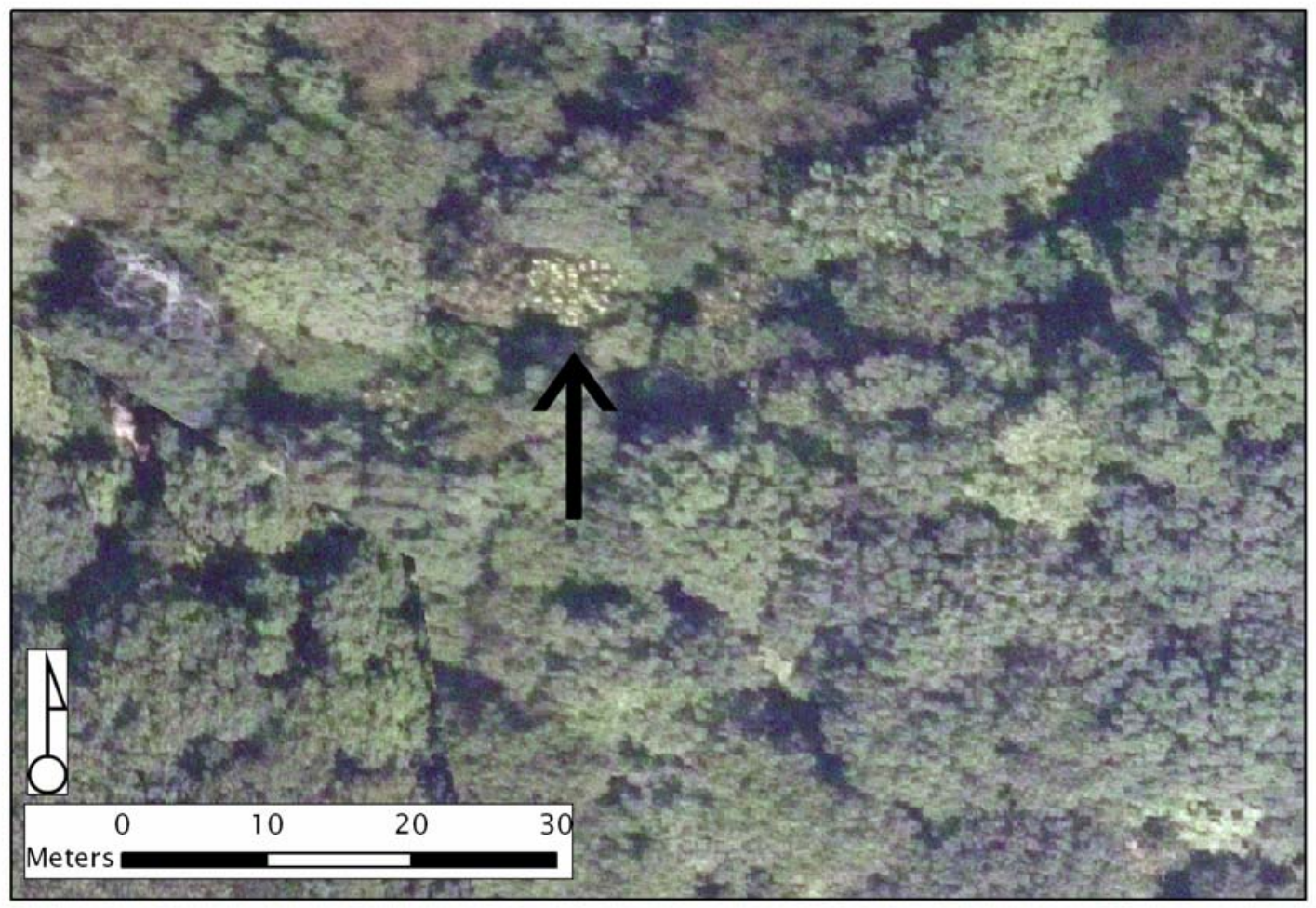

Figure 2.9.B:

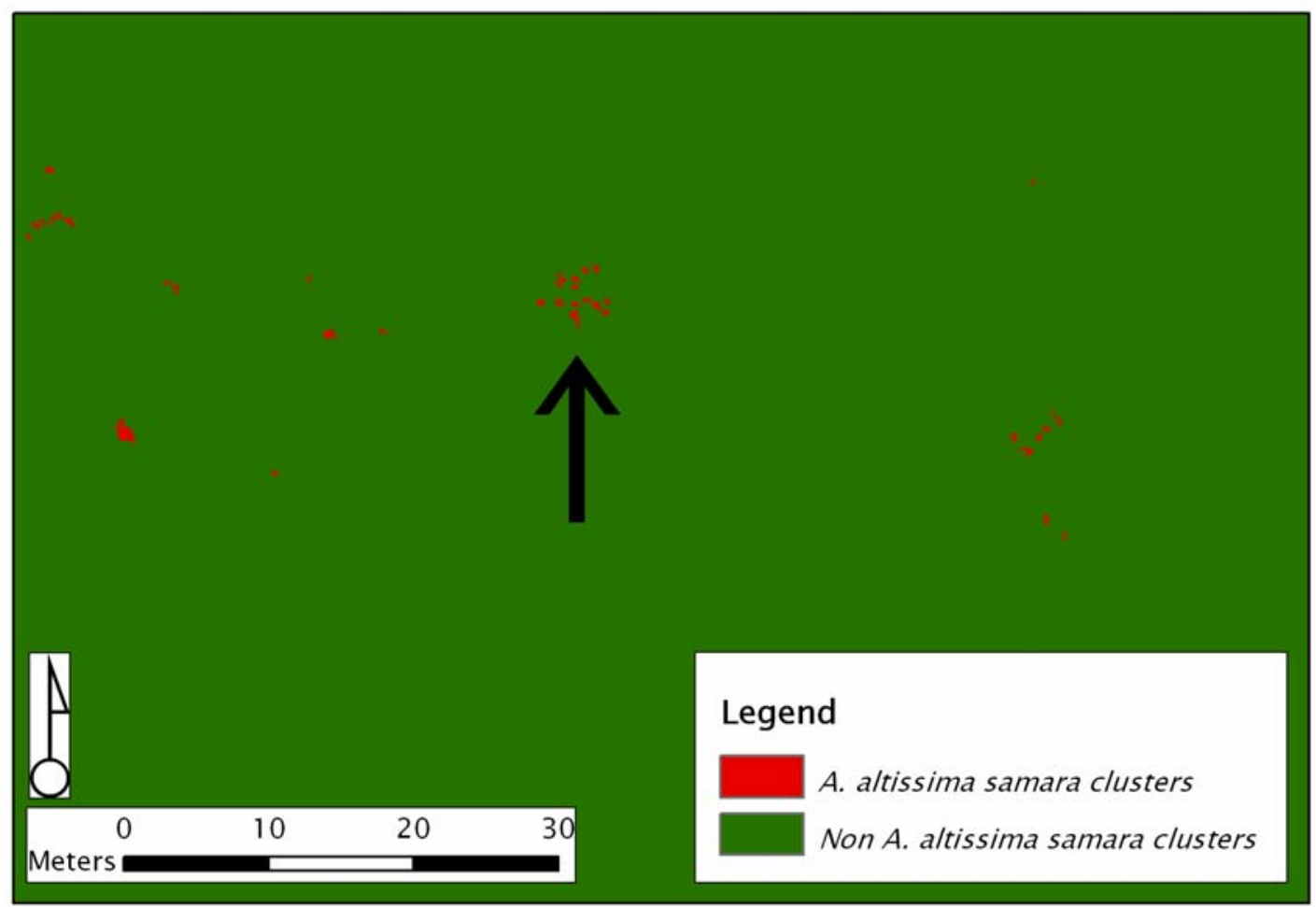


Figure 2.10.A:

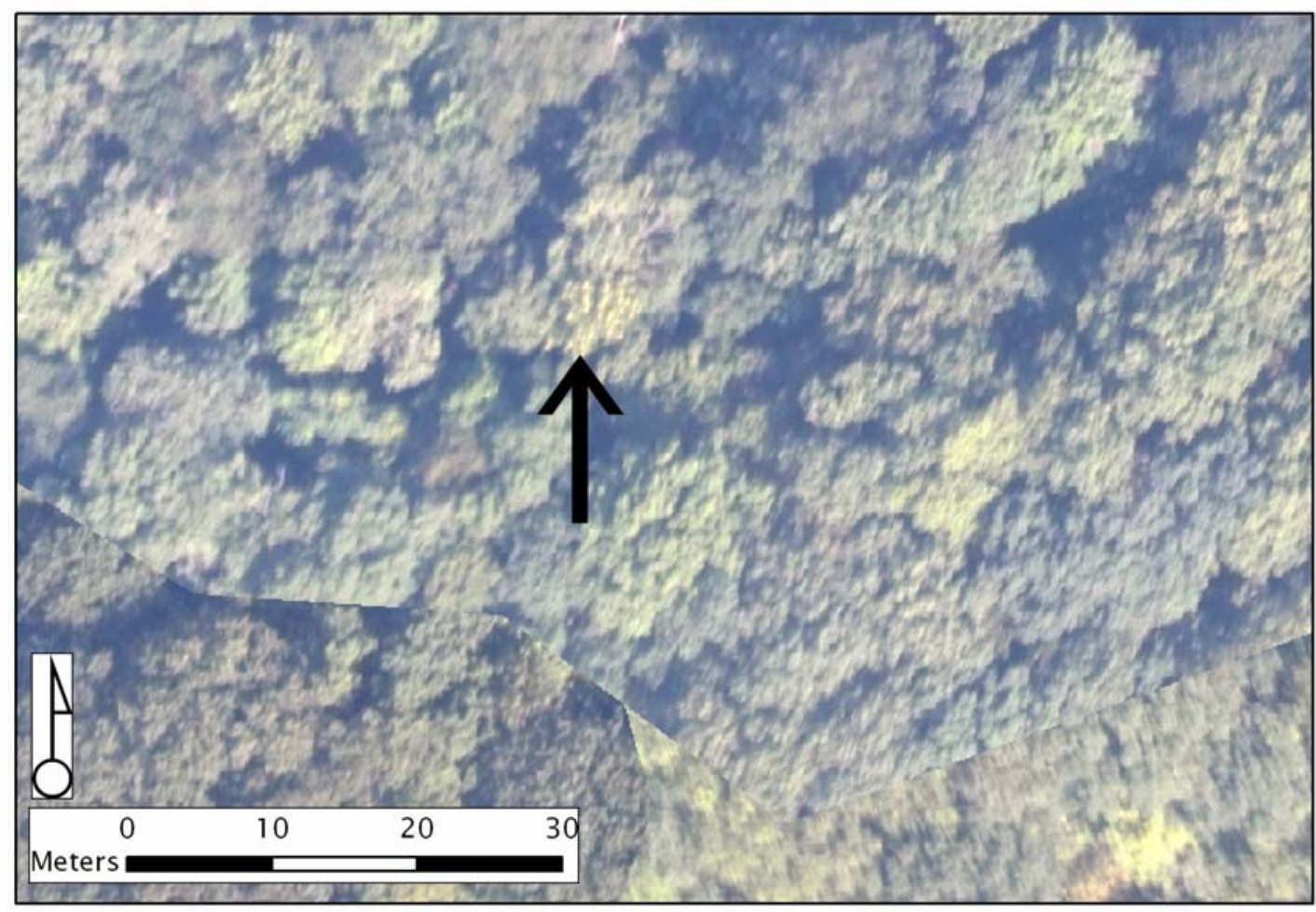

Figure 2.10.B:

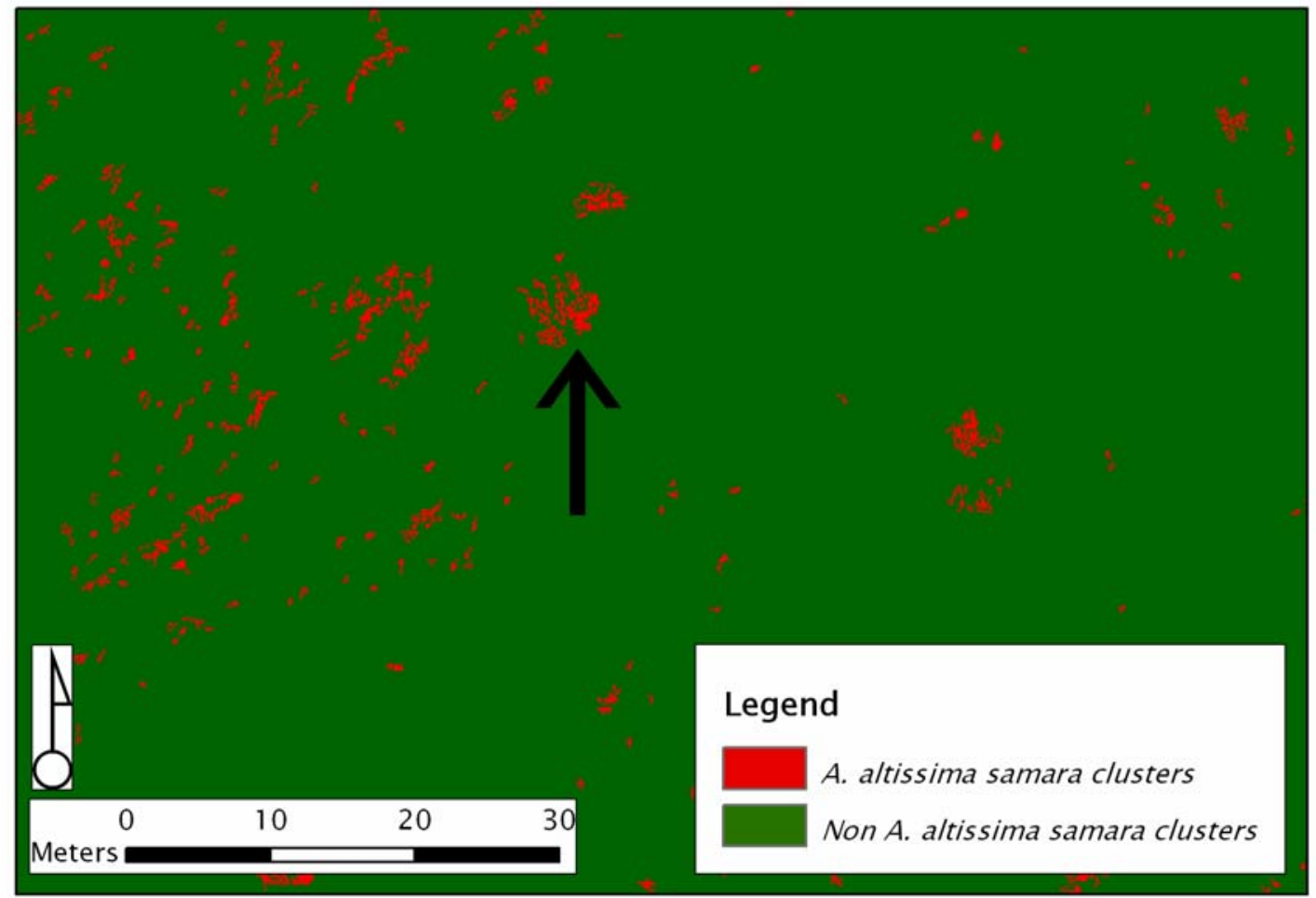


Figure 2.11.A:

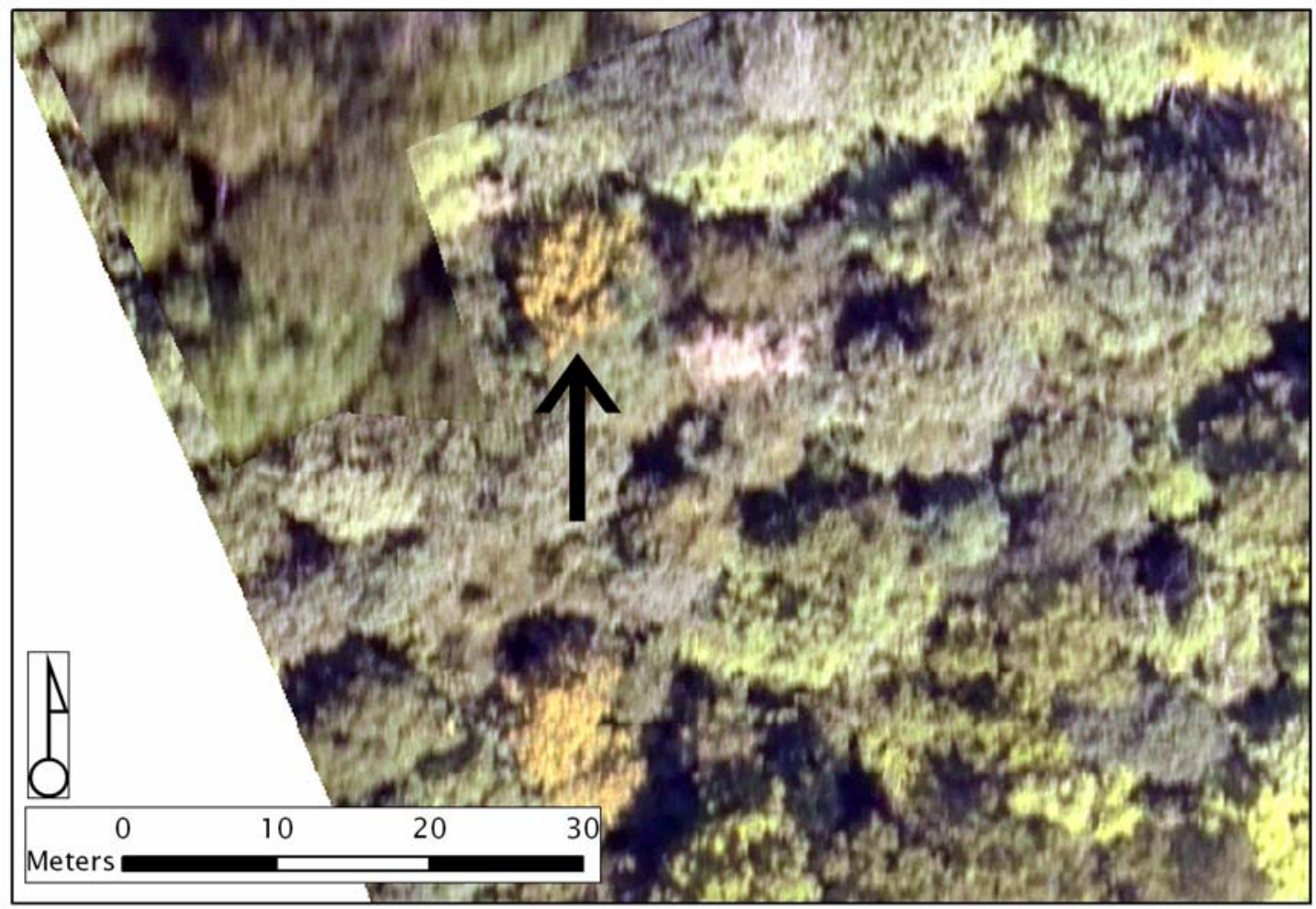

Figure 2.11.B:

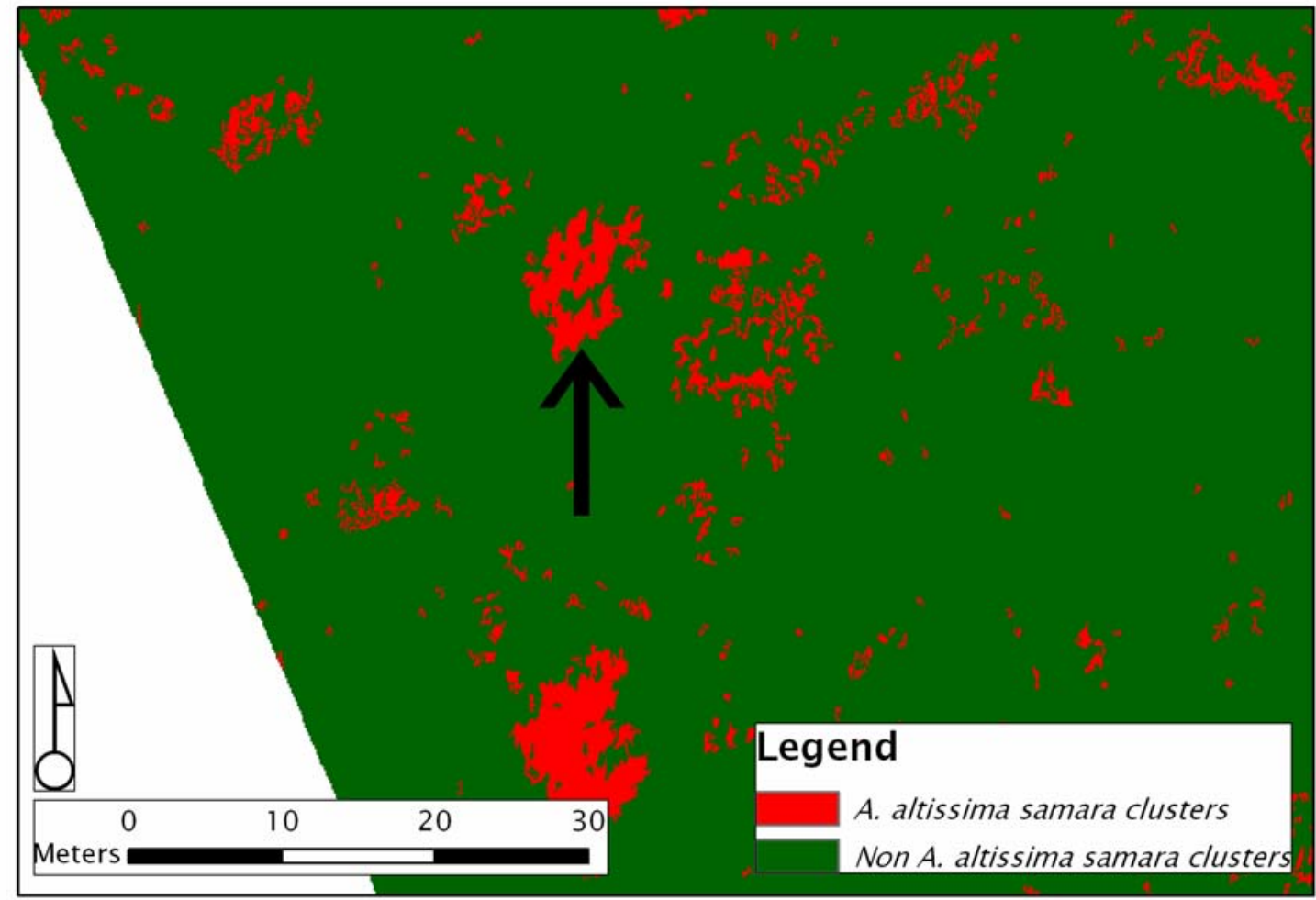


Figure 2.12:

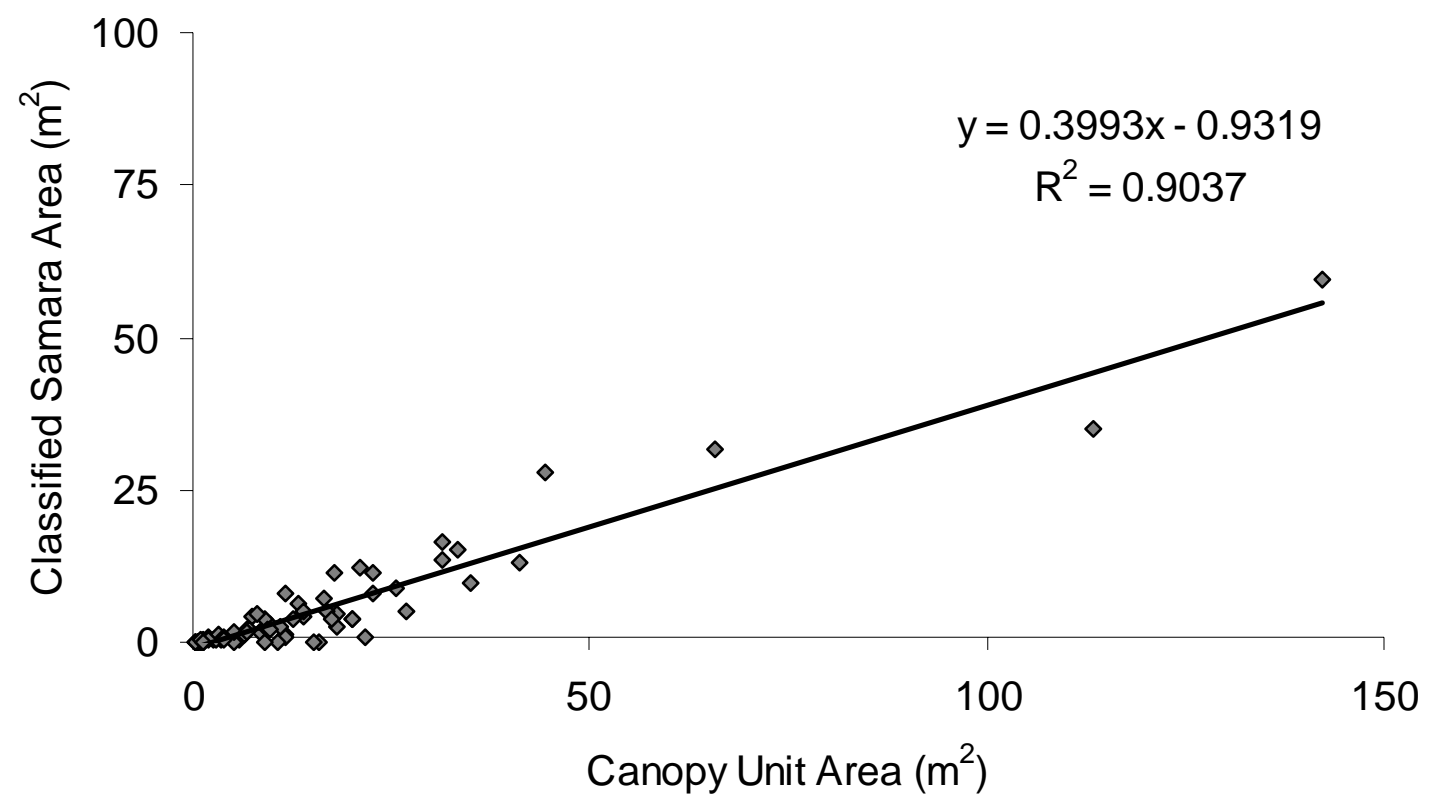

Figure 2.13:

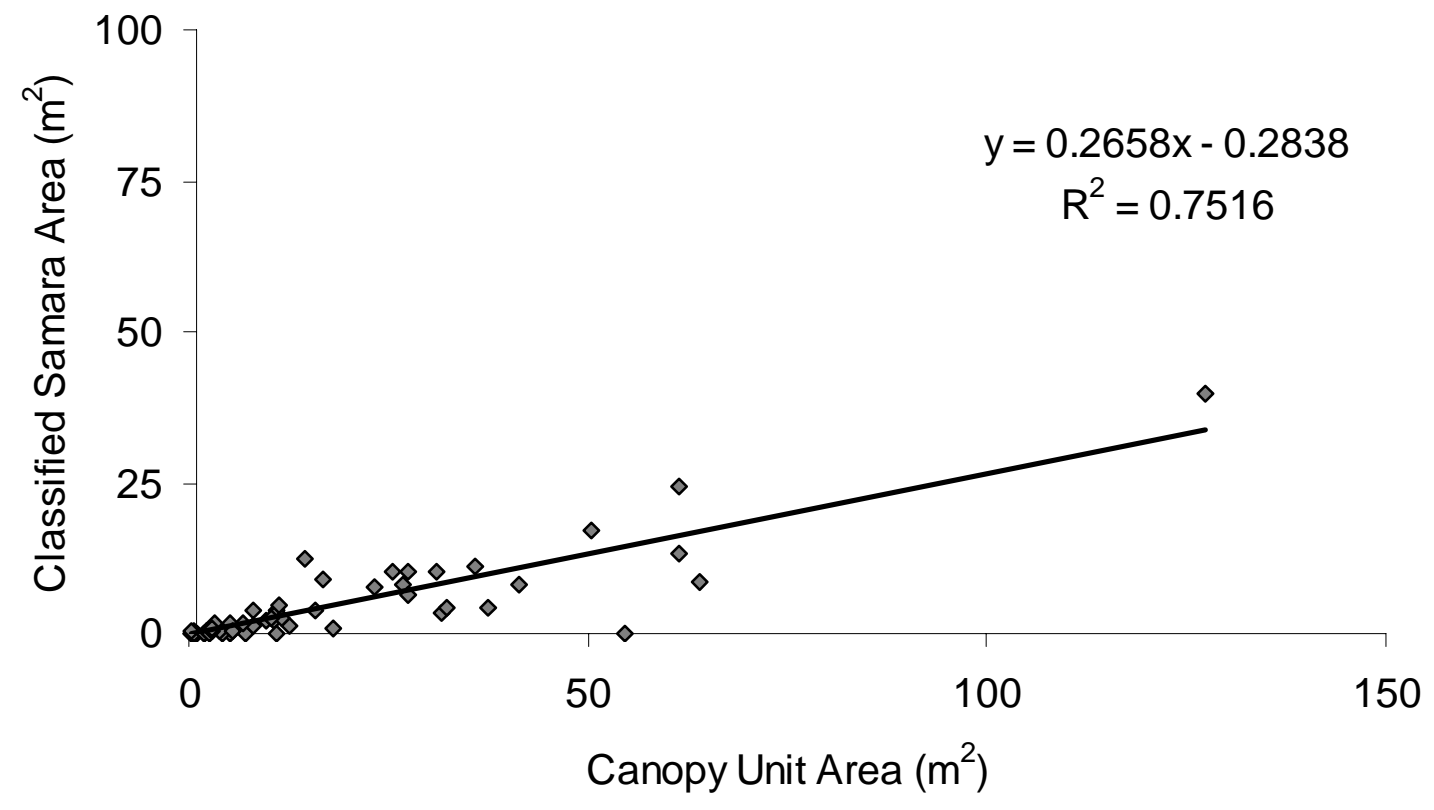


Figure 2.14:

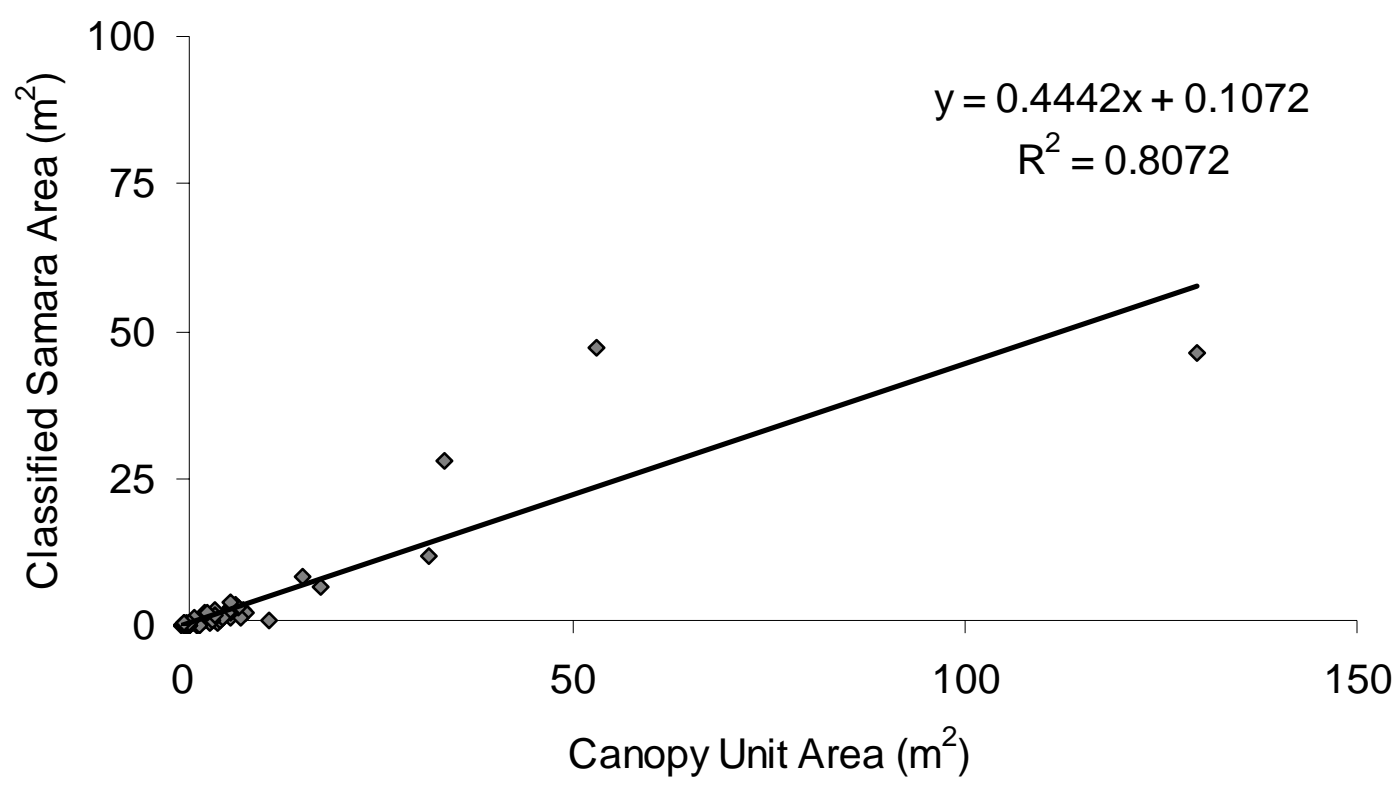


Figure 2.15.A:

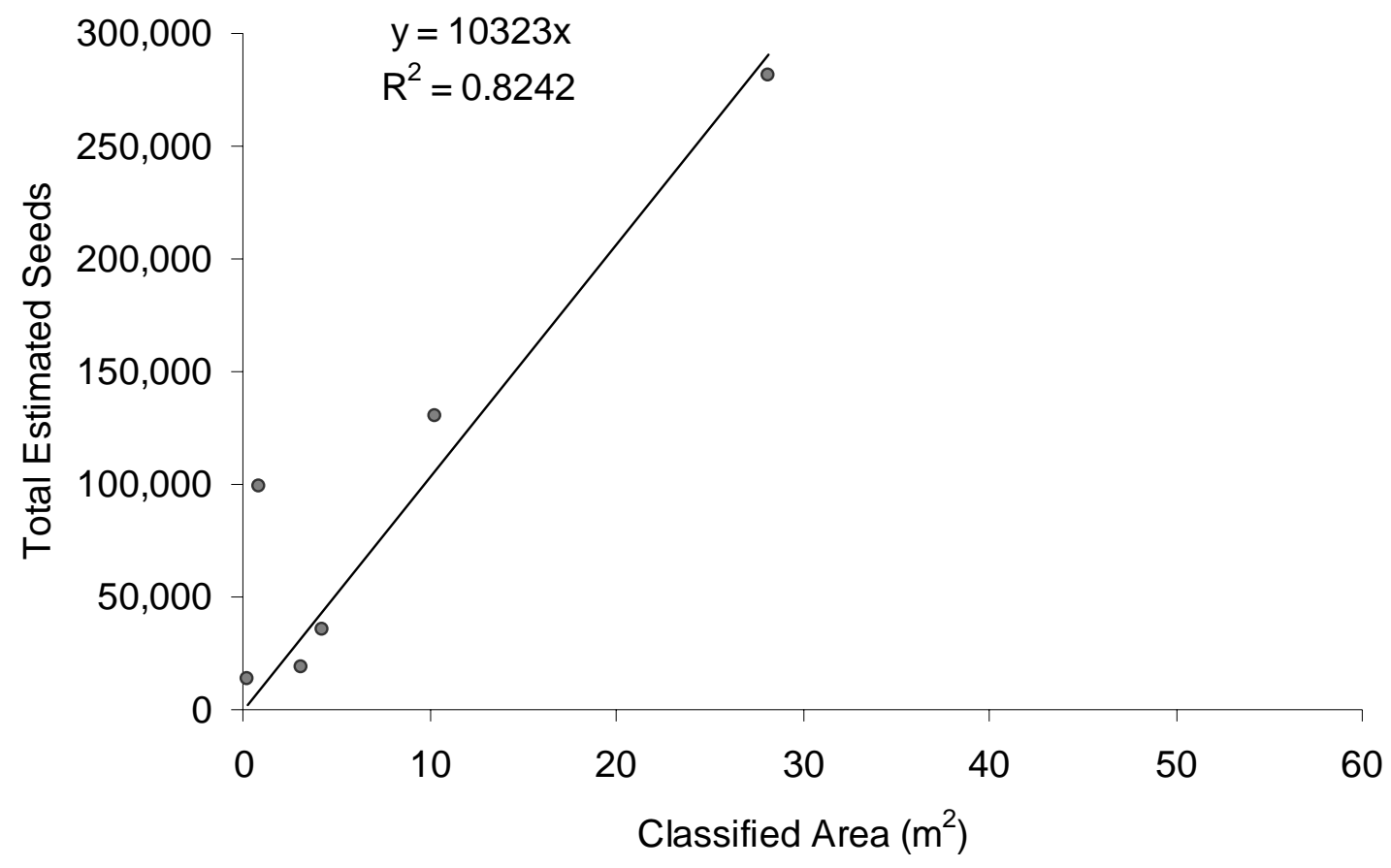

Figure 2.15.B:

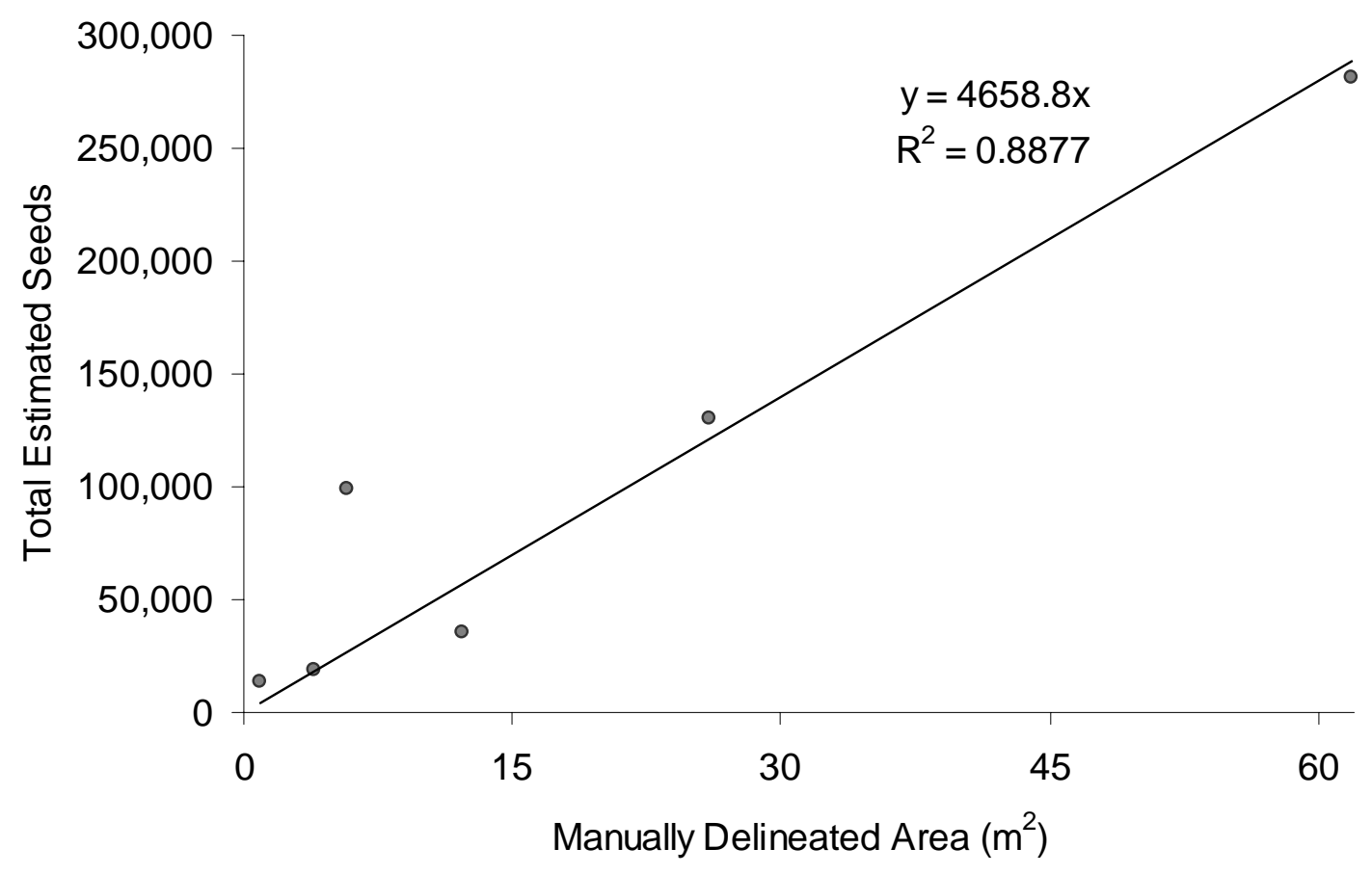


Figure 2.16:

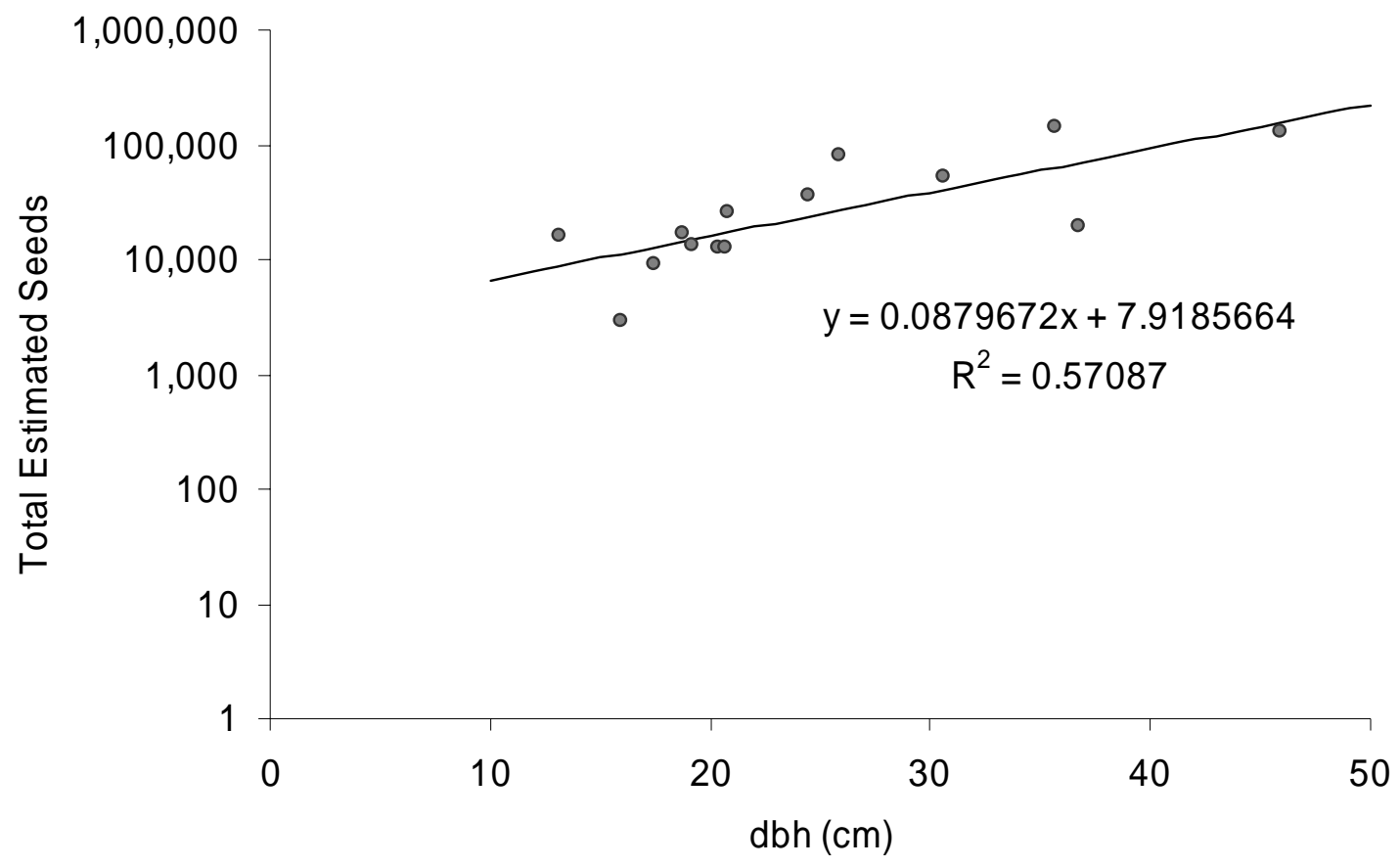


Figure 2.17.A:

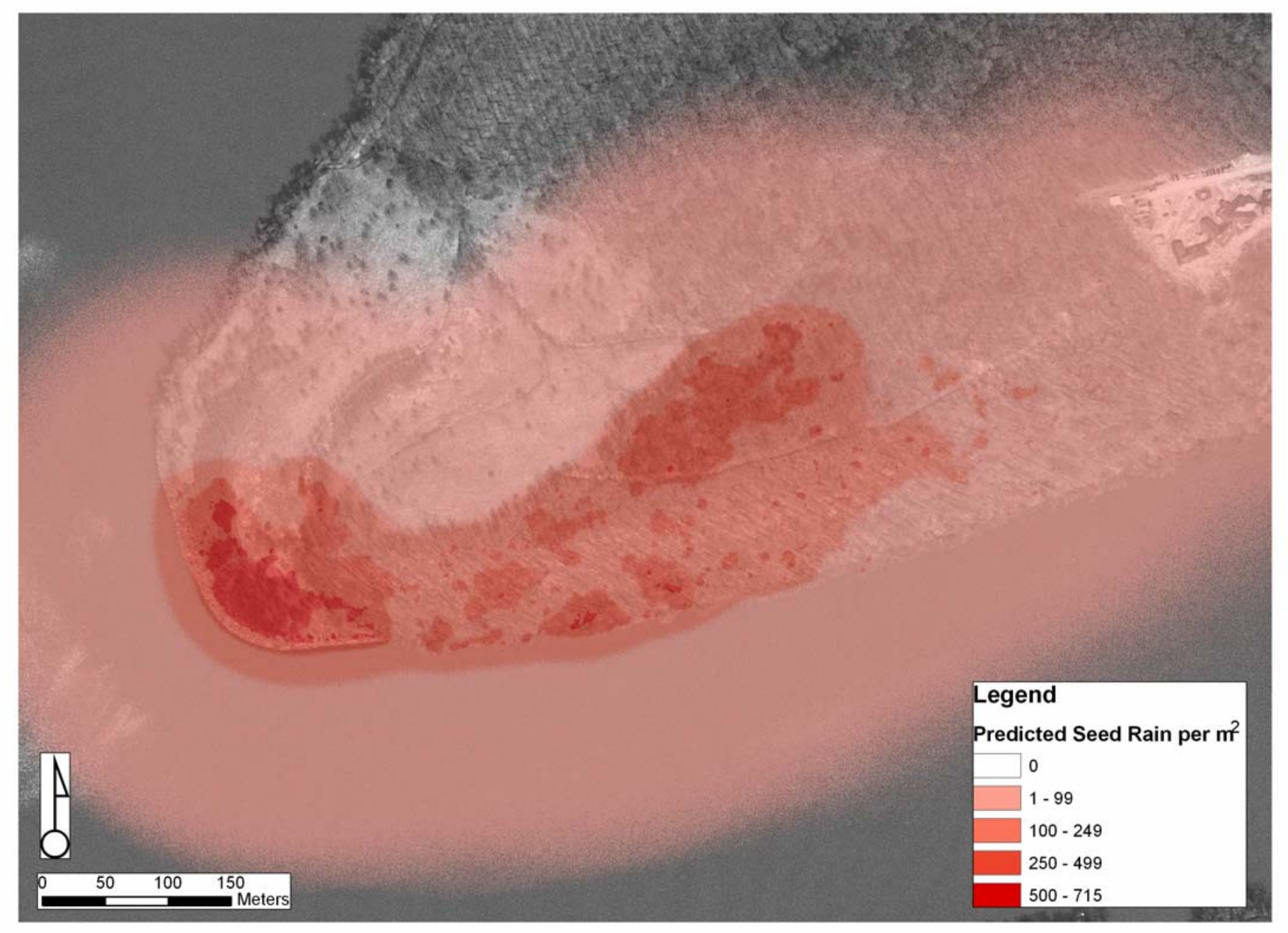


Figure 2.17.B:

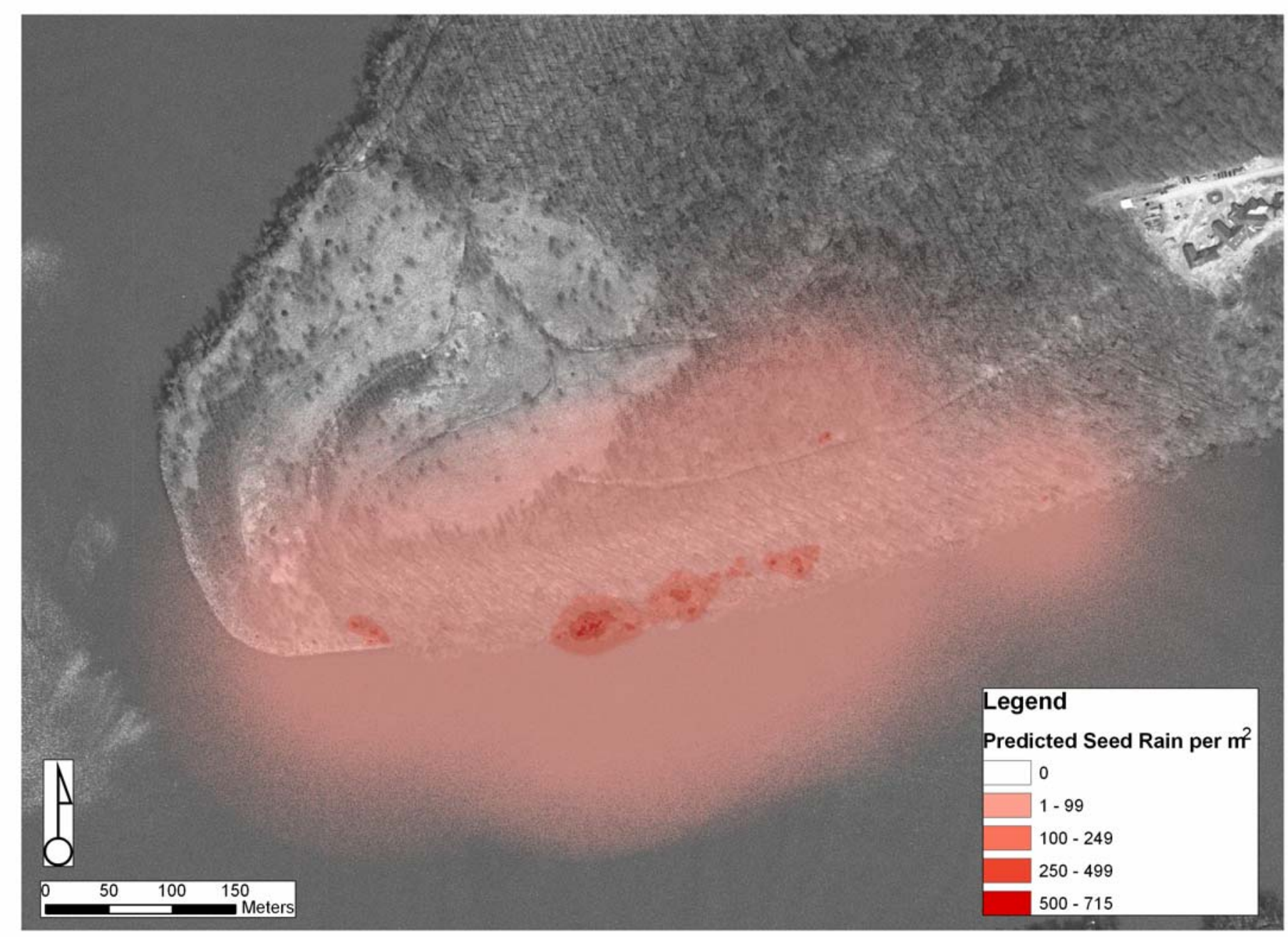


Figure 2.18.A:

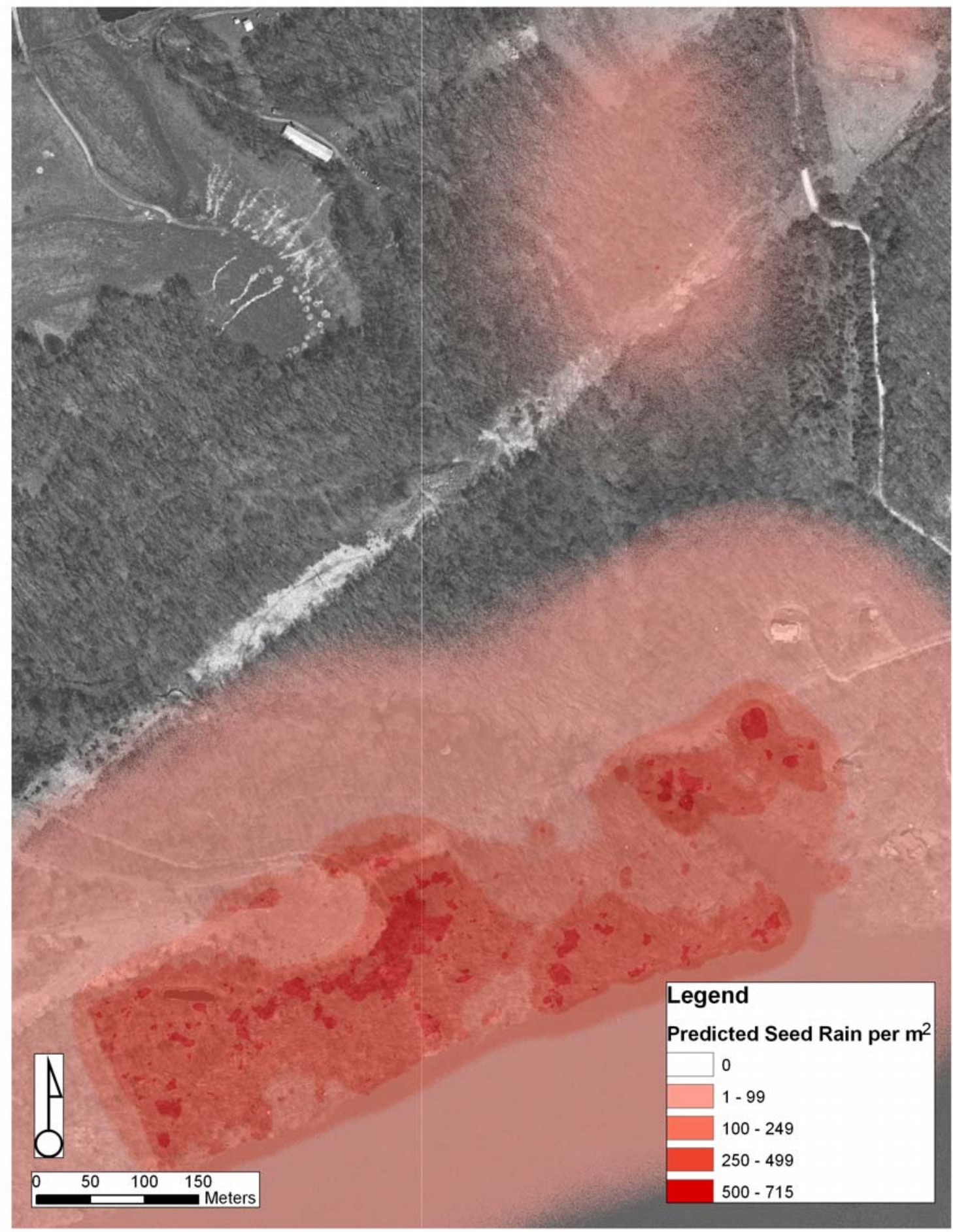


Figure 2.18.B:

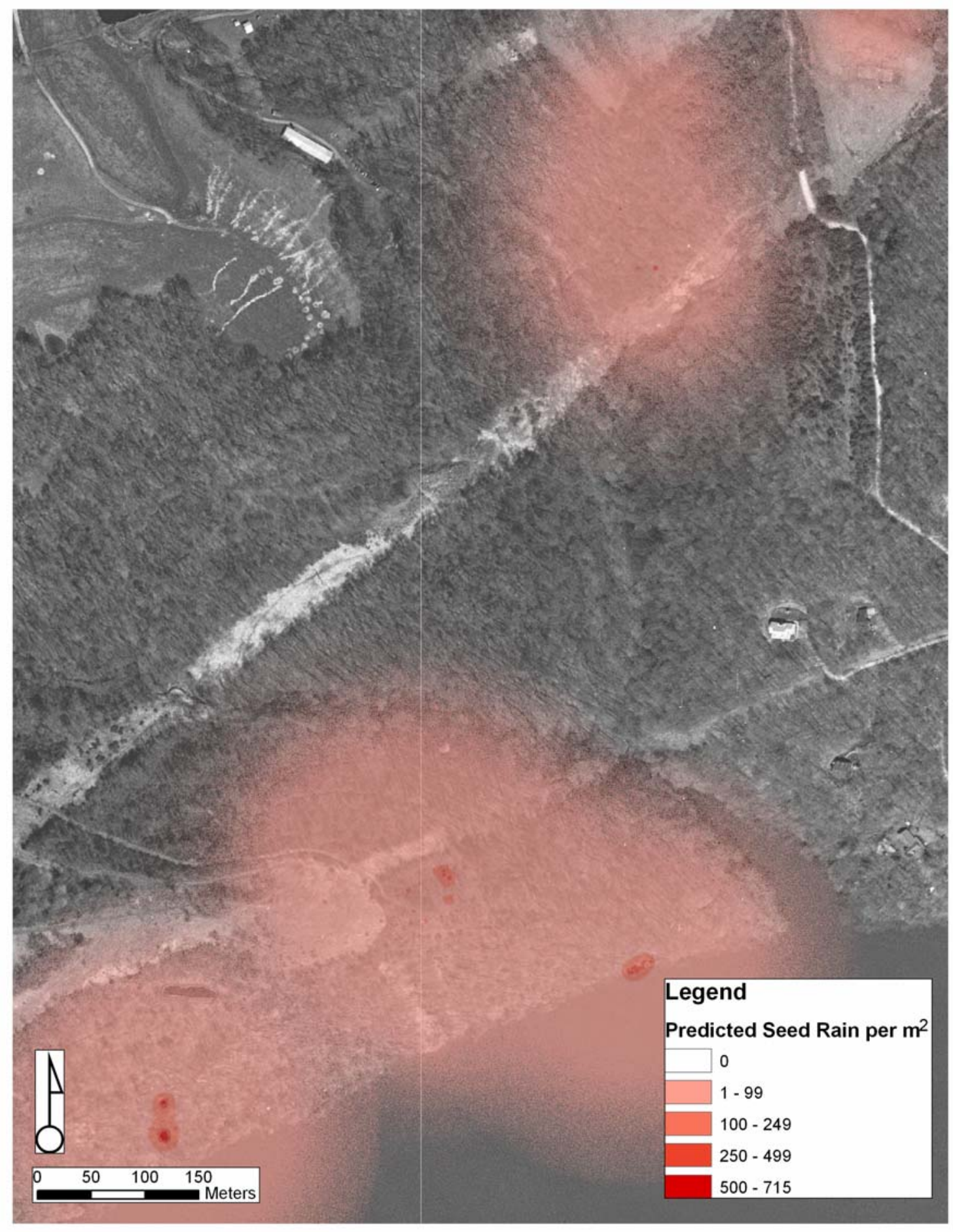


Figure 2.19.A:

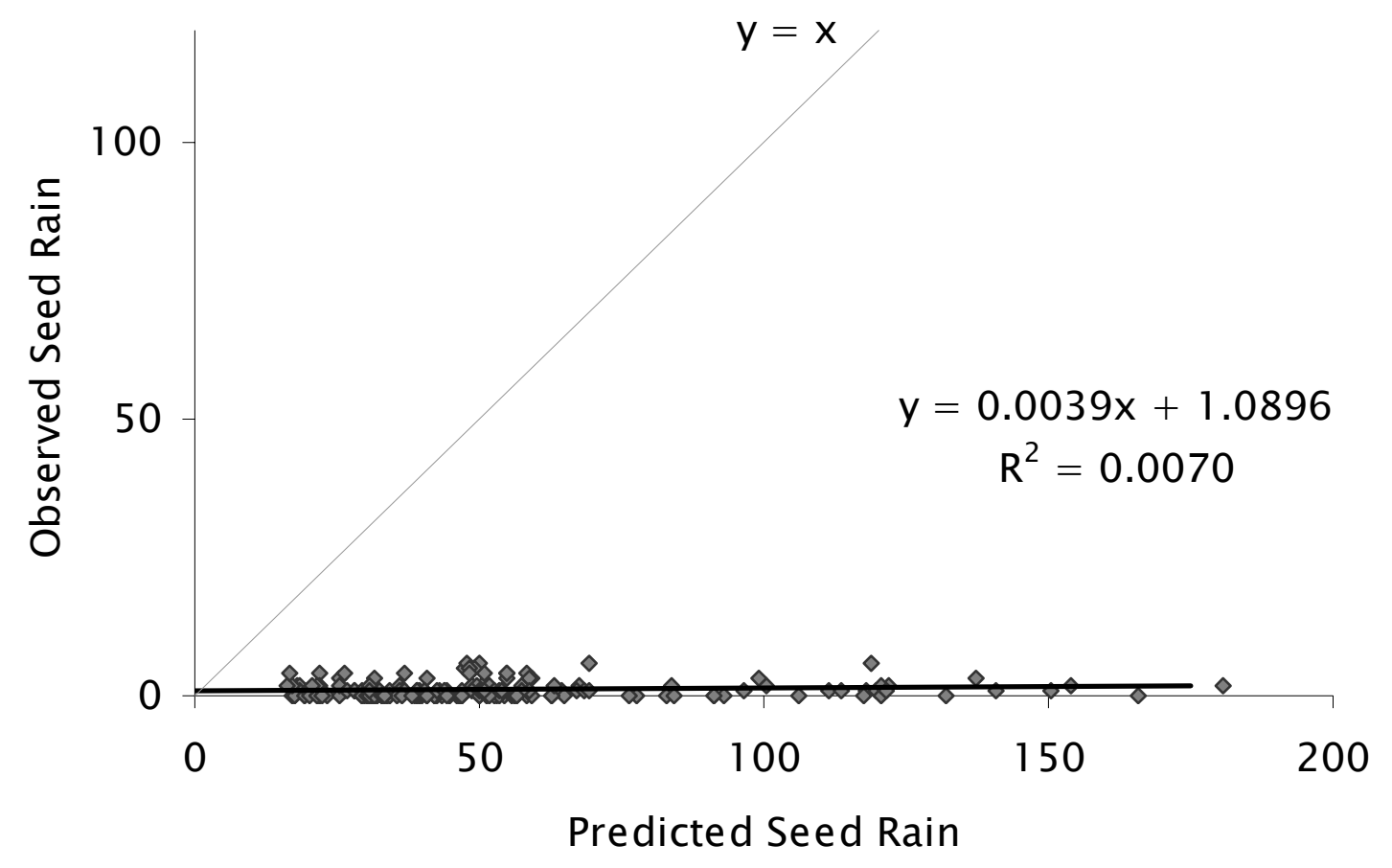

Figure 2.19.B:

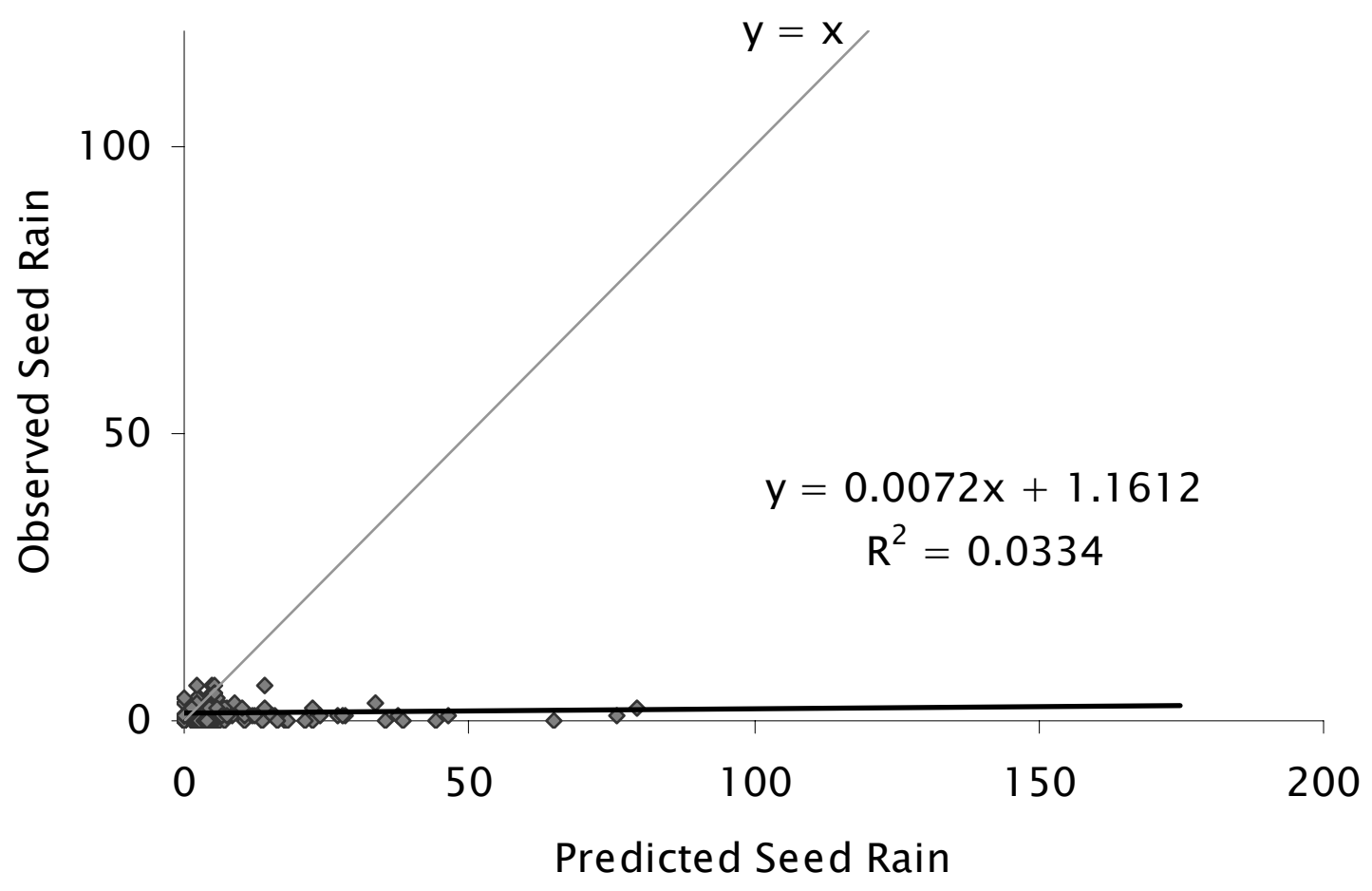


Figure 2.20.A:

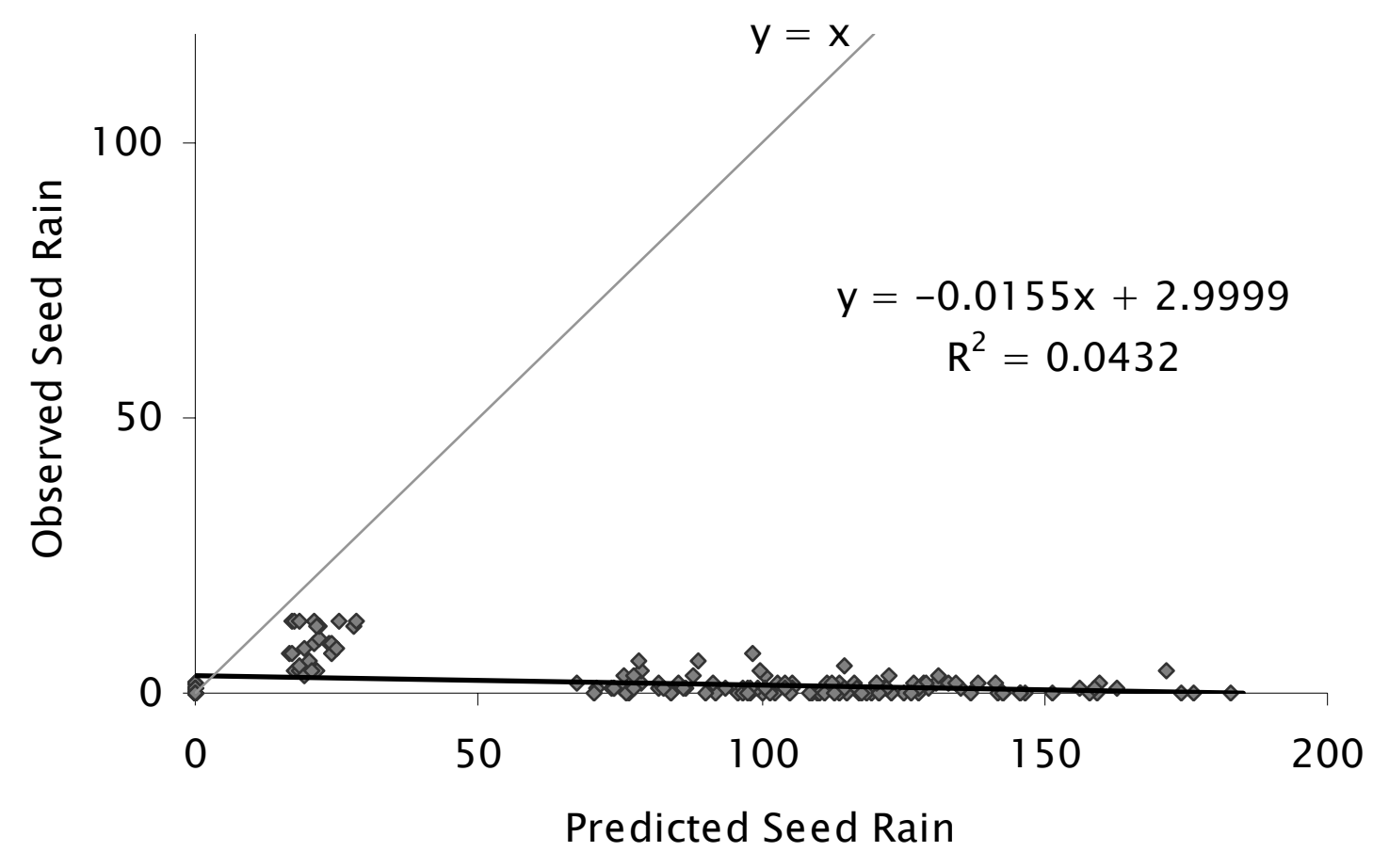

Figure 2.20.B:

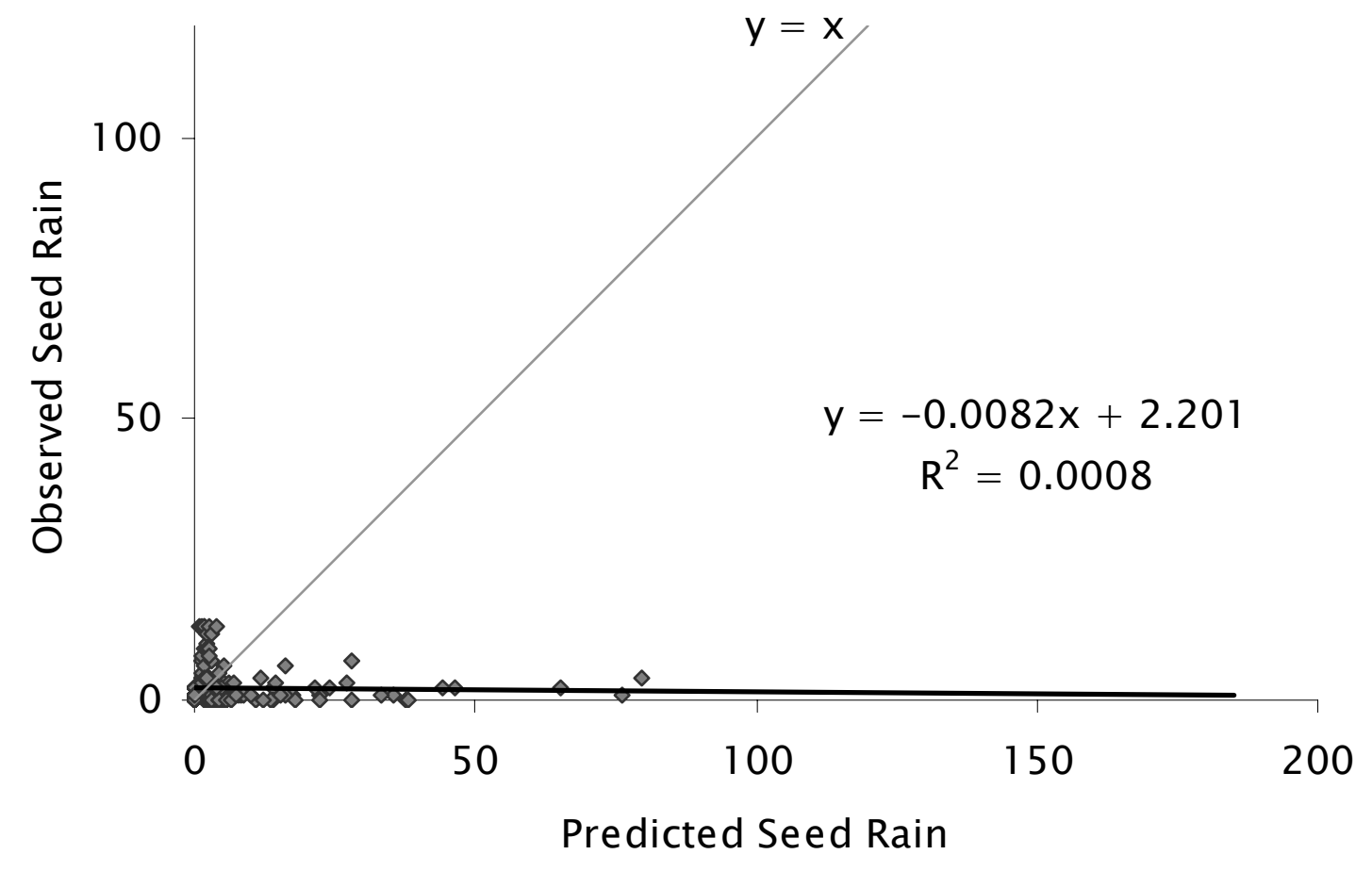




\section{Chapter 3: Ailanthus altissima seed germination and survival in mixed mesophytic forest environments}

\section{Introduction}

Propagule pressure may drive the spread of invasion into a plant community (Lockwood et al. 2005, Von Holle and Simberloff 2005), but the ultimate success of the invasion depends on the characteristics of the environment (Grubb 1977, Alpert et al. 2000 , With 2002, 2004). While the dispersal of progeny will provide an opportunity for recruitment in new locations (Nathan and Muller-Landau 2000), no amount of propagule pressure will lead to invasive success if the available microenvironments do not provide suitable conditions for germination and establishment (Harper et al. 1961).

Numerous studies have shown that seed germination and establishment of some species vary by microsite (i.e. combination of immediate microclimate and vegetation cover) (Grubb 1977, Silvertown 1981, Fowler 1986). For example, for the invasive tree species, Ailanthus altissima (tree of heaven), germination and seedling survival is severely limited in closed canopy forests, but generally more successful in varying levels of forest disturbance (clear cut and selective cut) (Kota et al. 2007). The ability to identify microsites where germination and establishment is likely to be successful will be useful in predictive modeling of species establishment.

This study continues the characterization of A. altissima "safe sites" in environments that are easily classifiable by landscapes covers. Using remote sensing, we know that landscape cover (biotic and abiotic) can be discerned quickly over a large area 
(Lillesand and Kiefer 2000, Kaproth unpublished data). Abiotic cover such as water and vegetative cover such as closed canopy forests or fields provide distinctive microenvironments, along with the transition edges between these features (e.g. forested shoreline, forest/field edge). Do these broadly discernable landscape covers influence seed germination and seedling survival of A. altissima?

\section{Methods}

\section{Study Sites}

A. altissima germination and survival were examined starting in 2006 at two study sites, both located along the river-fed impoundment of Cheat Lake, WV, and ranging in elevation from $271 \mathrm{~m}$ to $354 \mathrm{~m}$. Both sites were bordered by Cheat Lake and predominantly contained south-facing closed canopy forests and fields, as well as at least 100 mature A. altissima females each. Site II (Figure 2.3) was ca. 25 ha in size and located $1.8 \mathrm{~km}$ southeast of Stewartstown, WV. Site III (Figure 2.4), with an area of 18 ha was located $1 \mathrm{~km}$ southeast of Stewartstown, WV. Plants (seeds or seedlings) were placed in one of five microsites (canopy gap, closed canopy forest, field, forest/field edge, and forested shoreline). Each microsite was contained within an environment (closed canopy forest and field) or transition between environments (bare soil canopy gap, forest/field edge, and forested shoreline), which can be classified in remote sensing images (Kaproth unpublished data).

\section{Germination}

To determine the rate of $A$. altissima germination in varying microsites, 399 "arenas" constructed of $8 \mathrm{~cm}$ lengths of $15 \mathrm{~cm}$ diameter sewer and drain PVC piping were evenly divided among the two study sites, into one of five microsites (Table 3.1). 
On April 9, 2006, after natural A. altissima seed rain was complete, the arenas were secured to the soil surface (with two $15 \mathrm{~cm}$ insulated wire hooks) in random locations within each microenvironment . Any naturally occurring A. altissima seeds were cleared before inoculating each arena with 25 A. altissima seeds (method of Kota et al. 2007), for a total of 9,975 seeds. Naturally stratified seeds were obtained from five trees two km northeast of Morgantown, WV on March 11, 2006, then mixed and stored in cold stratification. Previous work (Kota 2005, Kota et al. 2007) showed no significant variation in A. altissima germination between seed sources, so maternal families were not tracked.

Arenas were censused for germinated seeds every month through August 25, 2006. Germinated seeds were removed during each census so they could not be counted twice. Previous studies found that experimental A. altissima seed movement in or out of an arena was negligible (Kota et al. 2007). Due to low rates of germination and a preponderance of zeroes in the data, residuals of germination data were not normally distributed and could not be transformed in all cases, in which case the independent variables were converted to a nominal data type (arena either contained germinated seeds or did not) and analyzed using loglikelihood (Kota 2005, Kota et al. 2007).

Differences in the frequency of "safe sites", defined as an arena in which one or more seeds germinated $(\mathrm{Y})$, were analyzed with sites $\left(\mathrm{X}_{1}\right)$ and microsites $\left(\mathrm{X}_{2}\right)$ as main effects, and their interaction (sites * microsites) using loglikelihood (SAS JMP v. 5.1.2) (Kota 2005, Kota et al. 2007). Statistical significance for all tests was recognized when p $<\alpha=0.05$. 
Differences in the percent germinated within "safe site" arenas $(\mathrm{Y})$ between sites $\left(\mathrm{X}_{1}\right)$ and microsites $\left(\mathrm{X}_{2}\right)$ could not be analyzed using a formal ANOVA. No transformation compensated for the non-normally distributed data.

\section{Seedling Survival}

To determine the rate of $A$. altissima seedling survival in varying microsites, 400 "phytometers" were planted in Sites I and II (Antonovics and Primack 1982, McGraw and Antonovics 1983, Kota 2005). On July 7, 2006, cold stratified A. altissima seeds from the same sources used in the Germination study were placed in moist vermiculite for nine days to germinate. Germinated seeds were then transplanted in pairs into $6 \times 7.5$ x $5.5 \mathrm{~cm}$ cell containers, which were divided in half with a Parafilm ${ }^{\circledR}$ strip, to increase the number of replicates and reduce the soil volume for root growth. Each container was filled with a low nutrient containing medium (1:1 volume ratio of Turface ${ }^{\circledR}$ arcillite clay chips and vermiculite) and kept moist until transplanting into the field. Seedlings were allowed to grow under shaded indoor greenhouse conditions $\left(18-29.5^{\circ} \mathrm{C}\right)$ for two weeks, then placed in full sun starting July 31, to "harden off" (Rogers and Siemann 2002).

On August 24 and August 25, the eight week-old phytometers were planted in Site III and Site II, respectively. One phytometer was planted within $0.5 \mathrm{~m}$ from each seed germination arena (Table 3.1). For the following three days, all transplanted phytometers were kept moist through daily watering or rainfall, after which, rainfall occurred at least every three days for one month.

Phytometer survival was surveyed on June 13, 2007. Differences in survival (Y) between sites were analyzed with sites (X) or microsites (X) as main effects using loglikelihood (SAS JMP v. 5.1.2). 


\section{Results}

\section{Germination}

The frequency of safe sites varied by site (Figure 3.1, Likelihood Ratio, $X^{2}=14.1035, p=0.0002$ ) and microsite (Figure 3.2, Likelihood Ratio, $X^{2}=54.5118$, $p<0.0001)$. The effect of microsite on the frequency of safe sites was dependent on site (Figure 3.3, Likelihood Ratio, $\mathrm{X}^{2}=27.4081, \mathrm{p}<0.0001$ ). Overall, less than $20 \%$ of all arenas contained germinated seeds: $26 \%$ at Site III, and $13 \%$ at Site II. Overall, canopy gap safe site frequency was highest, with a mean rate of $57 \%, 3.6$ to 5.7 times greater than other microsites. The lowest frequency of safe sites occurred in field microsites overall, however, no safe sites were found within the closed canopy microsite at Site III.

The mean seed germination percent within safe sites at Site III's canopy gap was 23.5\%, 4.4 to 5.9 times greater than other Site III rates (Table 3.2). At Site II, forest/field edge mean seed germination percent within safe sites was 1.9 to 3.1 times greater than other Site II rates. The mean seed germination percent within safe sites at Site III's canopy gap was 1.7 times greater than the Site II's forest/field edge germination rate.

\section{Seedling Survival}

Phytometer survival was very low. After ten months, only one phytometer remained alive. Site III's forested shoreline single living phytometer had an above ground height of $3.0 \mathrm{~cm}$ and a root to tip length of $7.5 \mathrm{~cm}$. There were no significant differences in survival between sites (Likelihood Ratio, $\mathrm{X}^{2}=1.389, \mathrm{p}=0.2386$ ) and microsite (Likelihood Ratio, $\mathrm{X}^{2}=2.780, \mathrm{p}=0.5953$ ).

\section{Discussion}

Like Kota et al. (2007), differences between frequencies of safe sites were present. In 2004, Kota et al. (2007) found A. altissima seed germination occurred in 47\% 
of arenas, nearly twice the rate for a native competitor, Liriodendron tulipifera (tulip poplar). This study found the frequency of safe sites was $20 \%$ overall. When adjusting for the inoculum quantity per arena for each study (Kota et al. 2007 $=50$ seeds, this study $=25$ ), the overall probability of individual seeds not germinating was $98.7 \%$ and $99.1 \%$, respectively, i.e., the studies had very similar rates.

Differences in safe site frequency between sites may be explained in part by variation in aspect (Kota et al. 2007). Differences in safe site frequency between microsites may also be explained by variation in aspect between similar microsites, but also by the percent germination within safe sites (Table 3.2). The high rate of germination found at canopy gap microenvironments correspond with research showing higher degrees of invasive success in disturbed sites (Knapp and Canham 2000, Call and Nilsen 2003, Vilá et al. 2007). The low germination rate in open field environments was surprising. However, grass and herbaceous canopies were dense in this cover class, so from the perspective of a seedling, the environment may not have been "open".

The low phytometer survival was surprising. Although the timing of the transplanting was one month later than the peak of germination (Kaproth unpublished data), the phytometers were of comparable size and age of some natural seedlings. Many transplants (ca. 50\%) were alive as late as October 25, 2006, but did not survive the winter (Kaproth field observations). Although low survival rates were found in previous studies, e.g. 15.7\% survival rate after two growing seasons (Kota et al. 2007), our phytometer results show minimal seedling survival occurring over only one year. Variation in A. altissima seed germination and survival was expected. The species is known for shade intolerance and success in disturbed habitats (Call and Nilsen 
2003). In addition, the species' prolific rates of seed production (Chapter 2) and germination do not correspond with the total number of individuals unless seedling survival is very low. However, improvements to this study's experimental design may yield more effective predictions of establishment probability. For example, increasing the number of arena locations within a site, increasing the number of seeds per arena, transplanting phytometers earlier, in higher quantity, and after hardening off under varying light levels that correspond with its future microsite.

In future work, one can prioritize A. altissima management to areas of highest success through ecological modeling (the interaction of a species with its immediate environment, providing a prediction of invasion into a plant community) (Guisan and Zimmermann 2000). Ecological models can be built with fine resolution to distinguish whether the species is limited by its dispersal of propagules or the availability of safe sites (DiFazio 2002, Moore and Elmendorf 2006, Satterthwaite 2007). For example Rouget and Richardson (2003) explained at most $49.4 \%$ of variation in S. Africa for three invasive tree species using geology, climate, land use and topography to explain distribution. When the semi-mechanistic models incorporated greater amounts of interactions of spread rate and environmental factors on propagule pressure, however, they were able to account for $70.6 \%$ of each species' canopy cover differences.

Using this and previous characterizations of $A$. altissima, ecological model predictions could be produced. For example, in Chapter 2, I demonstrated the ability to identify A. altissima rough propagule location and quantity using remote sensing. With classifications indicating propagule pressure sources, along with the surrounding environment, cellular automata dispersal models could predict seed dispersion patterns 
over the neighboring landscape (Chapter 2). With the identification of surrounding landscape covers that contain important microenvironments shown to affect seed germination rates in this species, prediction of species establishment could be predicted though ecological modeling, creating a powerful management tool. The greatest challenge in obtaining empirical data to parameterize these models will be the enormous sample size required to detect seedling survival rates as different from zero, given the low rates of seedling success that naturally occur in this species. 


\section{Literature Cited}

Alpert, P., E. Bone, and C. Holzapfel, 2000. Invasiveness, invasibility and the role of environmental stress in the spread of non-native plants. Perspectives in Plant Ecology, Evolution and Systematics 3(1):52-66.

Antonovics, J. and R.B. Primack, 1982. Experimental ecological genetics in Plantago. VI. The demography of seedling transplants of P. lanceolata L. Journal of Ecology 70:55-71.

Call, L.J. and E.T. Nilsen, 2003. Analysis of spatial patterns and spatial association between the invasive Tree-of-heaven (Ailanthus altissima) and the native Black locust (Robinia pseudoacacia). American Midland Naturalist. 150: 1-14.

DiFazio, S., 2002. Measuring and modeling gene flow from hybrid poplar plantations: Implications for transgenic risk assessment. Ph.D. dissertation, Oregon State University, Corvallis, O.R., U.S.A. 166-171.

Fowler, N.L., 1986. Microsite requirements for germination and establishment of three grass species. American Midland Naturalist 115(1):131-145.

Grubb, P.J. 1977. The maintenance of species-richness in plant communities: The importance of the regeneration niche. Biol. Rev. 52:107-145.

Guisan, A. and N.E. Zimmermann, 2000. Predictive habitat distribution models in ecology. Ecological Modelling 135(2-3):147-186.

Harper, J.L., J.N. Clatworthy, I.H. McHaughton, and G.R. Sagar, 1961. The evolution and ecology of closely related species living in the same area. Evolution 15:209227. 
Knapp, L.B. and C.D. Canham, 2000. Invasion of an old-growth forest in New York by Ailanthus altissima: sapling growth and recruitment in canopy gaps. Journal of the Torrey Botanical Society 127(4): 307-315.

Kota, N.L., 2005. Comparative seed dispersal, seedling establishment and growth of exotic, invasive Ailanthus altissima (Mill.) Swingle and native Liriodendron tulipifera (L.). West Virginia University Dept. of Biology, Electronic Thesis.

Kota, N.L., R.E. Landenberger, and J.B. McGraw, 2007. Germination and early growth of Ailanthus and tulip poplar in three levels of forest disturbance. Biological Invasions 9:197-211.

Lillesand, T.M and R.W. Kiefer, 2000. Remote sensing and image interpretation. Wiley, New York, 4th edition, 246-247, 267-277.

Lockwood, J.L., P. Cassey, and T. Blackburn, 2005. The role of propagule pressure in explaining species invasions. TRENDS in Ecology and Evolution 20(5):223-228.

McGraw, J.B. and J. Antonovics, 1983. Experimental ecology of Dryas octopetala ecotypes. I. Ecotypic differentiation and life-cycle stages of selection. Journal of Ecology 71:879-897.

Moore, K.A. and S.C. Elmendorf, 2006. Propagule vs. niche limitation: untangling the mechanisms behind plant species' distributions. Ecology Letters 9:797-804.

Nathan, R. and H.C. Muller-Landau, 2000. Spatial patterns of seed dispersal, their determinants and consequences for recruitment. TREE 15(7):278-285.

Rogers, W.E. and E. Siemann, 2002. Effects of simulated herbivory and resource availability on native and invasive exotic tree seedlings. Basic and Applied Ecology 3:297-307. 
Rouget, M. and D.M. Richardson, 2003. Inferring process from pattern in plant invasions: A semimechanistic model incorporating propagule pressure and environmental factors. American Naturalist 162(6):713-724.

Satterthwaite, W. H. 2007. The importance of dispersal in determining seed versus safe site limitation in plant populations. Plant Ecology 193(1): 113-130.

Silvertown, J.W., 1981. Micro-spatial heterogeneity and seedling demography in speciesrich grassland. NewPhytologist 88:117-128.

Vilá, M., J. Pino, and X. Font, 2007. Regional assessment of plant invasions across different habitat types. J. of Vegetation Science 18:35-42.

Von Holle, B. and D. Simberloff, 2005. Ecological resistance to biological invasion overwhelmed by propagule pressure. Ecology 86(12):3212-3218.

With, K.A., 2002. The landscape ecology of invasive spread. Conservation Biology 16(5):1192-1203.

With, K.A., 2004. Assessing the risk of invasive spread in fragmented landscapes. Risk Analysis 24(4):803-815. 
Table 3.1: Seed germination arena and phytometer deployment

\begin{tabular}{cccccc} 
Site & Microsite & $\begin{array}{c}\text { Number of } \\
\text { Locations }\end{array}$ & $\begin{array}{c}\text { Number of } \\
\text { Arenas }\end{array}$ & $\begin{array}{c}\text { Number of } \\
\text { Phytometers }\end{array}$ & Aspect \\
\hline \hline \multirow{4}{*}{ II } & Canopy Gap & 1 & 25 & 25 & SSE \\
& Closed Canopy Forest & 1 & 48 & 50 & SSE \\
& Forest/Field Edge & 1 & 26 & 25 & WSW \\
& Field & 1 & 50 & 50 & WSW \\
& Forested Shoreline & 2 & 50 & 50 & S, SSE \\
\hline \multirow{2}{*}{ III } & Canopy Gap & 1 & 25 & 25 & SE \\
& Fosed Canopy Forest & 2 & 50 & 50 & SE \\
& Forest/Field Edge & 1 & 25 & 25 & ENE \\
& Field & 1 & 50 & 50 & SSE \\
& Forested Shoreline & 1 & 50 & 50 & SE
\end{tabular}


Table 3.2: Mean percent seed germination within safe site arenas

\begin{tabular}{cccc} 
Site & Microsite & $\begin{array}{c}\text { Mean Germination } \\
\text { Rate }(\%)\end{array}$ & $\begin{array}{c}\text { Standard } \\
\text { Error * } 2\end{array}$ \\
\hline \hline & Canopy Gap & 7.3 & 2.2 \\
II $\quad$ Closed Canopy Forest & 6.9 & 2.1 \\
& Forest/Field Edge & 14.0 & 7.7 \\
& Field & 4.6 & 1.1 \\
& Forested Shoreline & 6.8 & 2.5 \\
\hline & Canopy Gap & 23.5 & 4.7 \\
III $\quad$ Closed Canopy Forest & 0 & - \\
& Forest/Field Edge & 4.0 & 0 \\
& Field & 5.3 & 1.3 \\
& Forested Shoreline & 4.0 & 0
\end{tabular}




\section{Figure Legends}

Figure 3.1: Effect of location on percentage of germination safe sites.

Figure 3.2: Effect of microsite on percentage of germination safe sites.

Figure 3.3: Effect of microsite and site on percentage of germination safe sites. 
Figure 3.1:

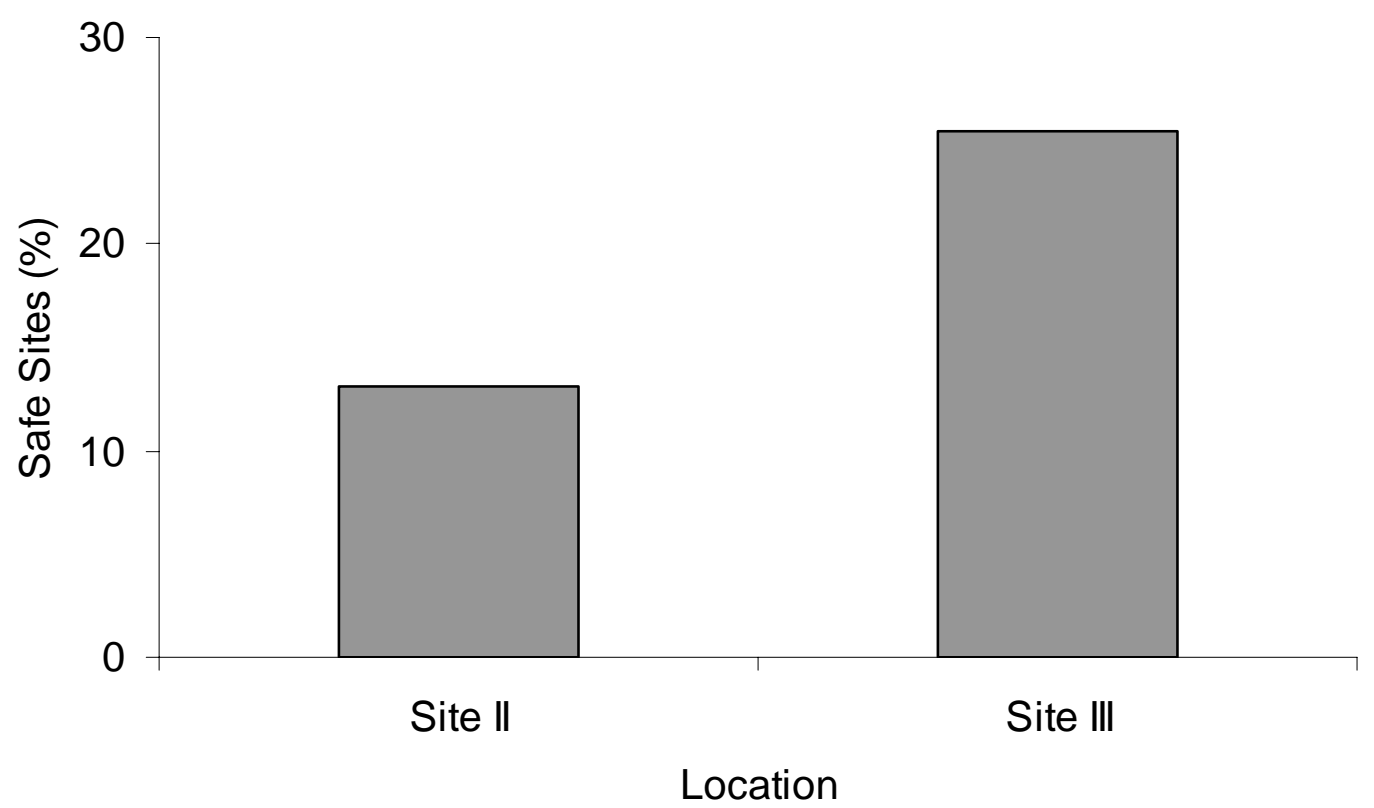


Figure 3.2:

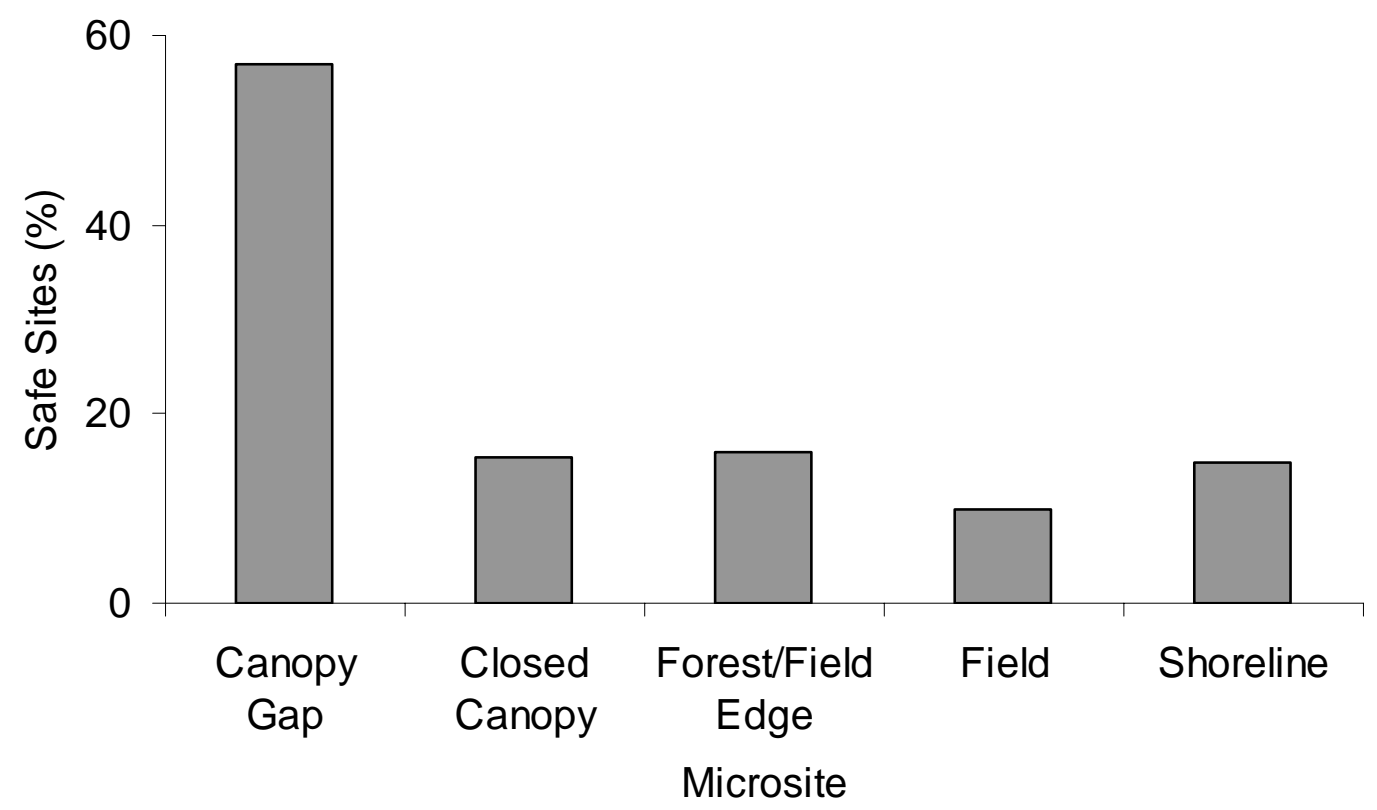


Figure 3.3:

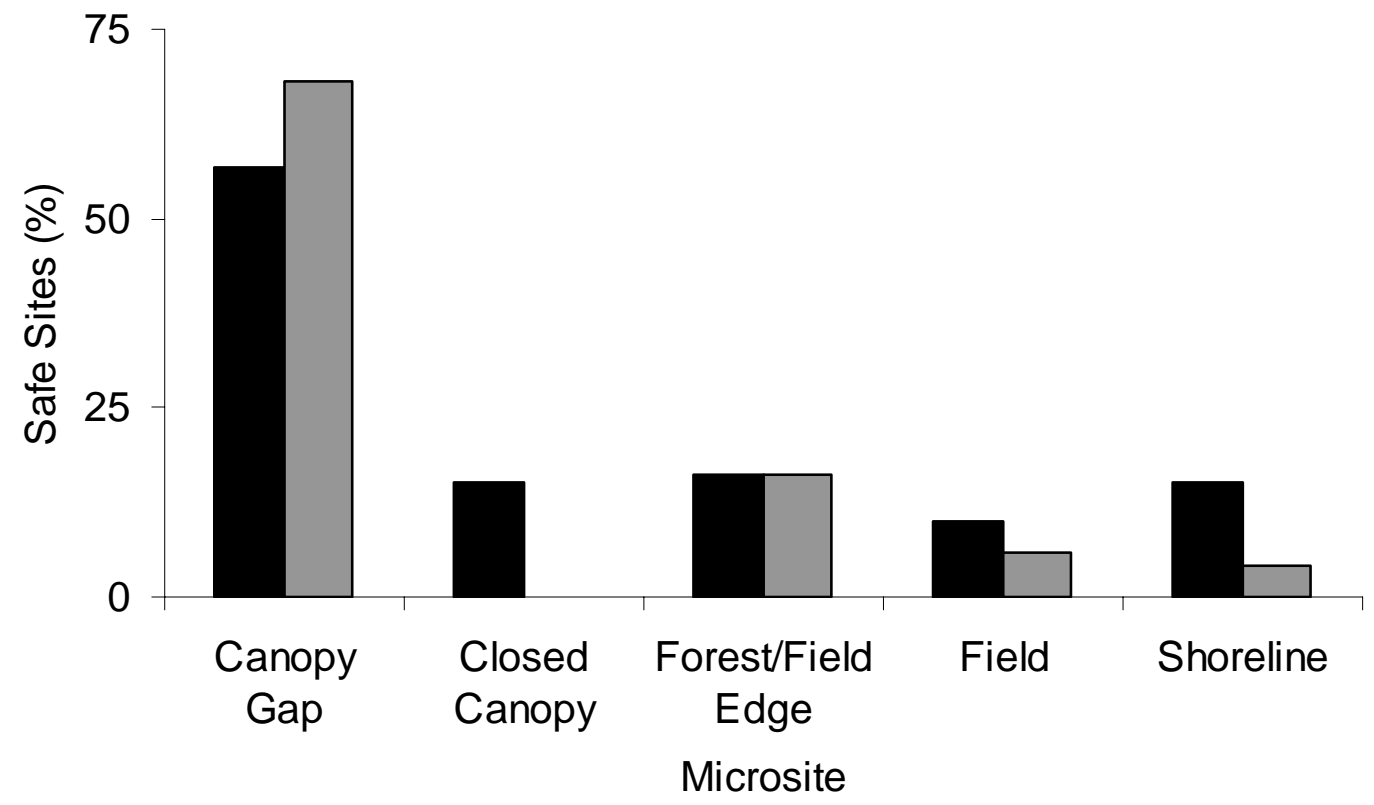




\section{Chapter 4: Seed viability and dispersal of the wind-dispersed invasive Ailanthus altissima in aqueous environments}

\section{Introduction}

The low rate of plant spread predicted by measures of primary dispersal is insufficient to explain observed rates (Reid 1899, Skellman 1951, Clark et al. 1998). Many studies have investigated dispersal distances and suggest that the rapid rates of spread, often observed in invasive species, may require rare long-distance dispersal events (e.g. Ritchie and MacDonald 1986, Lonsdale 1993, Cain et al. 1998), but these events are difficult to observe (Clark 1998, Higgins and Richardson 1999). The inability to accurately sample and subsequently predict how a species will disperse into and colonize new environments has hampered the parameterization of migration rate modeling in a constantly disturbed and dynamic environment (Higgins and Richardson 1999).

How a community responds to disturbance (e.g. flooding, timbering) depends largely on what species arrive and colonize the open niches (Grubb 1977, He and Mladenoff 1999, Lockwood et al. 2005). The 'regeneration niche' concept posits that early-established species have a greater chance to preempt resources than species establishing at a later time (Belyea and Lancaster 1999). Understanding the ability of a species to disperse to these open environments becomes essential, and in many cases species with long dispersal distance and high propagule pressure will have the greatest opportunity for establishment (Lockwood et al. 2005). Species with these characteristics, many of which are invasive, are increasingly being recognized as a threat to biodiversity (Rejmánek and Richardson 1996, Mack et al. 2000), and the prevalence of invasives in 
disturbed environments continues to grow at alarming rates (Higgins et al. 1999, Parendes and Jones 2000, Hutchinson et al. 2004). Many invasive species such as the widespread terrestrial tree, tree of heaven (Ailanthus altissima (Mill.) Swingle), are poised to expand into new locations throughout the United States (Kota 2005, Kota et al. 2007, Landenberger et al. 2007). The ability to predict where and how quickly the establishment of an invasive species will occur can improve the effectiveness of conservation management (Mack et al. 2000, Rejmánek 2000), but requires quantification of the dispersal tail (Bullock and Clarke 2000).

The difficulty of quantifying long-distance dispersal empirically is two-fold; the frequency of long-distance dispersal is low (Bullock and Clarke 2000, Clark et al. 2005, Kota 2005), and the mechanism of dispersal may not be the obvious 'primary' mode (Pakeman 2001). Multiple studies have shown that seeds can be dispersed by more than one mechanism (e.g. Darwin 1859, Welch 1985, Myers et al. 2004, Couvreur et al. 2005). These secondary dispersal mechanisms such as animals (both internal and external) and water may be able to transport propagules greater distances than the primary vector, as shown by Imbert and Lefévre (2003) in their genetic marker study of riparian black poplar (Populus nigra L.) in which anemochorous propagules were dispersed by hydrochory.

Hydrochory has long been proposed as an important mechanism explaining the global distribution of plants (Darwin 1856). However, little experimental work has been published on dispersion in aquatic environments (Barrat-Segretain 1996). Water could be an important vector because it flows long distances in a single season via connected corridors and can carry debris with little friction. Seeds accumulate in aqueous 
environments through primary dispersal directly into water or by secondary movement spurred by animals, wind, or rain wash, often assisted by gravity. In essence, for hydrochory to occur, three conditions must be met; (I) seeds must be able to reach water, (II) seeds must retain viability while in the water, and (III) seeds must be able to be deposited in a suitable habitat.

This study focuses on whether hydrochory occurs for A. altissima, an invasive terrestrial 'wind-dispersed' species. In particular, this study hypothesized that the first two requirements of hydrochory occur at measurable levels. We assume if these requirements are met, on at least some occasions the third will also be met, i.e., seeds will occasionally be deposited (e.g., by flooding events) in suitable habitat.

\section{Methods}

\section{Study Species and Area}

A. altissima grows rapidly in a wide variety of environments in the eastern United States (Feret 1985), limited primarily by shade intolerance, low water availability, and severe low temperatures (Feret 1985, Kowarik and Säumel 2007). Copious amounts of seeds borne by mature females ripen, desiccate, and start to disperse starting in October (Landenberger et al. 2007). Desiccated seeds used for the following experiments were collected from multiple locations in Monongalia County, WV, were mixed and kept at room temperature.

Investigations of A. altissima hydrochory occurred at two study sites, one located in and along the Monongahela River neighboring the Core Arboretum of Morgantown, $\mathrm{WV}$, at an elevation of $238 \mathrm{~m}$ and the other $10 \mathrm{~km}$ to the northeast in and along the riverfed impoundment of Cheat Lake, WV, at an elevation of $271 \mathrm{~m}$. Temperatures of both 
water bodies ranged from $1{ }^{\circ} \mathrm{C}$ to $19{ }^{\circ} \mathrm{C}$ during November to April, 2006, although Cheat Lake water temperature averaged one degree lower than the Monongahela River, $5^{\circ} \mathrm{C}$ and $6{ }^{\circ} \mathrm{C}$ respectively. Mean low monthly air temperatures for Morgantown, $\mathrm{WV}$, range from $-6^{\circ} \mathrm{C}$ to $4{ }^{\circ} \mathrm{C}$ during November to April, and three degrees lower at Cheat Lake, WV (personal observation).

\section{Estimating Direct Primary Dispersal into Nearby Water}

Knowing the primary seed dispersal curve function of A. altissima derived from a log-linear curve fit of the well-characterized primary dispersal curve out to $100 \mathrm{~m}$ (Landenberger et al. 2007; Figure 4.1), we estimated the expected proportion of seeds landing directly in water as a function of distance from the water's edge:

$$
\frac{2\left[\int_{\theta=0}^{\theta=\cos ^{-1} \frac{d}{100}} \int_{r=\frac{d}{\cos \theta}}^{r=100} \frac{2.0079 e^{-0.0427 r}}{2 \pi r} r d r d \theta\right]}{\int_{r=0}^{r=0} 2.0779 e^{-0.0427 r} d r}
$$

In the calculation of this estimate (Equation 4.1), cylindrical coordinates were used in an assumed environment where all seeds came from a point source, the shoreline was straight, the water extended out $100 \mathrm{~m}$, and the seed shadow was equal in all directions (Figure 4.2). In Equation 1, $d$ is the shortest distance from the point source to the water's edge, $\theta$ is the angle between the perpendicular dispersal vector and the seed dispersal vector, and $r$ is the radius along which seeds disperse (Figure 4.2). The constants were derived from the previously published regression equation (Landenberger et al. 2007). The numerator of the equation determines the seed rain falling directly into 
the water body as a function of $d$ and the denominator estimates total seed rain, within a $100 \mathrm{~m}$ radius.

In an effort to derive an empirical estimate of the number of seeds that could be deposited in water from the primary dispersal estimate (Equation 4.1), a single $100 \mathrm{~m}$ wide survey was conducted on February 24, 2007, along the east shore of a one $\mathrm{km}$ stretch of the Monongahela River near Morgantown, WV. The location and dbh of each reproducing $A$. altissima female present was recorded. Distance of each tree from water was determined using a global positioning system (GPS) and mapped using geographic information systems (ESRI ArcView ${ }^{\circledR}$ 9.1). An estimate of each individual's total seed count was determined from a linear relationship (Equation 4.2) between $\mathrm{dbh}(x$ in $\mathrm{cm})$ and the natural log of total tree seed count (y) for 14 varying-sized A. altissima females in September 2006 (Chapter 2, Figure 2.16):

$$
y=0.08797 x+7.91856
$$

\section{Buoyancy Studies}

In order to determine the period of potential buoyancy of $A$. altissima seeds in moving water, 400 intact seeds were divided evenly into four covered $100 \mathrm{~L}$ containers filled to a depth of $30 \mathrm{~cm}$ with tap water and stirred once daily for five-seconds to break surface tension (adapted from Boedeltje et al. 2003). After stirring, the number of buoyant propagules was recorded every day for the first week and thereafter once a week for a month. The containers were kept in an unheated greenhouse in which water temperatures were similar to outdoor aqueous environment temperatures during November, February-April $\left(6-19^{\circ} \mathrm{C}\right)$. Differences in buoyancy over time were analyzed using logistic regression (SAS JMP v. 5.1.2). Statistical significance for all tests was 
recognized when $\mathrm{p}<\alpha=0.05$. After one month, 25 randomly sampled seeds were harvested from each container, bisected across the endosperm, and exposed to $0.1 \mathrm{M}$ triphenyl tetrazolium chloride for 24 hours to test if viability was retained (Watkinson 1978).

In a parallel study, seed buoyancy was tested after being marked with fluorescent spray paint, to determine whether it would be possible to do a realistic mark-recapture study in a calm water body. A total of 600 intact $A$. altissima seeds were divided evenly into three marking treatments: yellow-fluorescent Rust-Oleum ${ }^{\circledR}$ paint, orange-fluorescent Rust-Oleum ${ }^{\circledR}$ paint or unmarked. The intact seeds of each painted treatment were lightly sprayed and dried, adding $<0.1 \mathrm{~g}$ per seed. Seed treatments were divided, exposed to water, measured and analyzed using similar methods previously described for the potential buoyancy study in moving water, however the containers were not stirred.

\section{Observing Hydrochory}

In order to determine the potential movement of $A$. altissima propagules through hydrochory, a mark-recapture study was used (Schneider 1999). A weight-estimated total of 10,000 yellow-painted seeds were scattered at one location on the water's surface in the center of the Monongahela River along Morgantown, WV, on June 29, 2006. After 24 hours, the banks of the river were surveyed downstream for a distance of $8.1 \mathrm{~km}$. The position of any marked seeds was noted using GPS.

\section{Measuring Secondary Dispersal on Land}

In northern $\mathrm{WV}$, the majority of mature A. altissima seeds dehisce from October through April (Landenberger et al. 2007, Chapter 2), with a peak of $40 \%$ of total seed rain occurring in November (Kota 2005). A. altissima germination does not begin before 
late May (Kota 2007, Chapter 3), allowing up to seven months of secondary dispersal events. In order to determine the rate at which seeds landing in terrestrial environments might move downhill into streams, rivers, or lakes, a short-term study was conducted on a closed canopy floor of Morgantown, WV's Core Arboretum, by evenly placing 6,000 painted seeds over six $5 \mathrm{~cm}$ wide $\mathrm{x} 4 \mathrm{~m}$ long transects on January 16, 2007. Transects were placed in pairs oriented along three continuous contours ( 9,33 and $48 \%$ slope). After one month, seed positions were recorded. Differences in dispersal distances among slopes were analyzed using a non-parametric nested analysis of variance (ANOVA) (SAS JMP v. 5.1.2), with the effect of transect nested within slope class.

\section{Germinability after Dispersal in Water}

To determine if $A$. altissima seed germinability was affected by continuous exposure to an aqueous environment, a seed cage study was set up using 60 buoyant cages on November 1, 2005. Each cage was made from a $3.8 \mathrm{~L}$ plastic container, kept buoyant by two $5 \mathrm{~cm} \times 5 \mathrm{~cm} \times 10 \mathrm{~cm}$ foam pieces (Dow ${ }^{\circledR}$ STYROFOAM), and covered in nylon mesh bags (adapted from Edwards et al. 1994). This design kept seeds near the water's surface, as would occur when the seeds were floating, driven by current or wind, and when they washed up to the shoreline strand, along the water's edge. Twenty-six containers were deployed in the Monongahela River, Morgantown, WV, while another 26 were tethered in Cheat Lake, WV. An additional four containers per site were packed with leaf litter and placed under the neighboring forest canopy to serve as terrestrial controls. Each container included 50 mature $A$. altissima seeds harvested from three Morgantown, WV, sources one week prior to deployment, providing 50 seeds $\mathrm{x} 60$ cages $=3,000$ seeds total. 
Every two weeks thereafter, two submerged containers were removed from each site until April 4, 2006. Two terrestrial controls were removed after two and 22 weeks from each site. The seeds remaining in each container were transferred into trays of moist sand and allowed to stratify for five weeks at $4^{\circ} \mathrm{C}$. After stratification, trays were placed under fluorescent lights at room temperature $\left(22-25^{\circ} \mathrm{C}\right)$ and allowed to germinate for at least four weeks. Differences in germination rates between environment (aquatic vs. terrestrial) and incubation site (Cheat vs. Monongahela) were determined through a 2way ANOVA, with harvest date as a 'covariate' and observations weighted by sample size. In addition, differences in germination among the aqueous sites as a function of harvest date were analyzed using a 2-way ANOVA (SAS JMP v. 5.1.2).

\section{Results}

\section{Estimating Direct Primary Dispersal into Nearby Water}

The proportion of a plant's seed shadow predicted to be deposited in a neighboring water body decreased exponentially with distance from the water body (Figure 4.3). The proportion of an individual's seeds primarily dispersed into water dropped to $18.2 \%$ at a distance of $20 \mathrm{~m}$.

In a single $100 \mathrm{~m}$ wide, one $\mathrm{km}$ long survey along the one side of the Monongahela River, 33 female A. altissima trees were found at a mean distance of 26.9 $\mathrm{m}$ from water. Provided the assumptions of the primary dispersal model are met (Equation 4.1; Figure 4.2), varying seed totals (Equation 4.2) and distances from water for each tree (Figure 4.4), an estimated population total of 62,124 seeds (17.8\%) would be deposited into the water through primary dispersal in one year along this one $\mathrm{km}$ stretch of urban/suburban riparian forest along the river. 


\section{Buoyancy Studies}

Buoyancy of unmarked A. altissima seeds in stirred water decreased with the number of days exposed (Likelihood Ratio, $\mathrm{X}^{2}=1767.911, \mathrm{p}<0.0001$ ), with a predicted $50 \%$ of seeds remaining buoyant after 1.5 days. After 7.0 days, only $2 \%$ of seeds remain buoyant. All seeds exposed to triphenyl tetrazolium chloride were viable, regardless of buoyancy retention. In contrast, when in still water, buoyancy was retained in all seeds after one day, regardless of paint treatment.

\section{Observing Hydrochory}

Of the 10,000 seeds released, 565 were recovered over a distance of $8.1 \mathrm{~km}$ of shoreline after 24 hours. Retrieved propagules traveled a mean distance of $4.05 \mathrm{~km}$, however the first group found ( $88.5 \%$ of recovered seeds) were $3.95 \mathrm{~km}$ downstream (Figure 4.5). An additional 65 seeds were recovered at six locations with a maximum dispersal distance of $6.8 \mathrm{~km}$. The seeds retained buoyancy and were found in caches of debris only on the western (outer) edge of the river. Wind was negligible during the study period. The surface flow rate (ca. $0.5 \mathrm{~m} / \mathrm{sec})$ and discharge $\left(650 \mathrm{~m}^{3} / \mathrm{sec}\right)$ of the Monongahela River during seed release was above average for summer conditions, but within the normal range of conditions for winter (USGS National Water Information System), and could have carried seeds $7.2 \mathrm{~km}$ in ca. four hours.

\section{Measuring Secondary Dispersal on Land}

After 27 days, secondary seed dispersal of A. altissima on land varied by slope $(\mathrm{F}=108.6699, \mathrm{p}<0.0001)$. The greatest seed movement occurred along the steepest slopes, with $5.7 \%$ of all seeds traveling $>0.25 \mathrm{~m}$, including the maximum distance traveled for one seed at $10 \mathrm{~m}$ (Figure 4.6.A). Only $3.4 \%$ of all seeds on a $33 \%$ slope traveled $>0.25 \mathrm{~m}$ (Figure 4.6.B), while no seeds on a 9\% slope traveled $>0.25 \mathrm{~m}$ (Figure 
4.6.C). Secondary dispersal distance varied by transect within slope class ( $\mathrm{F}=71.9895$, $\mathrm{p}<0.0001$ ). While normal precipitation levels occurred throughout the study period (totaling $70 \mathrm{~mm}$ ), leaf litter and seed movement appeared highest where surface water moved ephemerally during snow melting events.

\section{Germinability after Dispersal in Water}

Seeds recovered from submerged cages retained high germinability $(94.4 \pm 1.1 \%)$ showing no significant decline over a five-month period (Figure 4.7). On dates when terrestrial controls were sampled, seeds that had been exposed to aqueous environments germinated at a $15.5 \%$ higher rate than those in terrestrial environments $(\mathrm{F}=10.94$, $\mathrm{p}=0.0057)$. Furthermore, the effect of environment on seed germinability depended on site $(\mathrm{F}=6.88, \mathrm{p}=0.0210$, Figure 4.8$)$. Seeds germinated at a lower rate if incubated on land (relative to those in water) at Cheat Lake, but this pattern was not observed at the Monongahela River site.

\section{Discussion}

The results of our dispersal and germination studies suggest that the prerequisites for dispersal of A. altissima by water are present as hypothesized. Within $20 \mathrm{~m}$ of the shoreline, high proportions of an individual's seeds were estimated to disperse directly into water $(18.2 \%$ at $20 \mathrm{~m}, 3.5 \%$ at $50 \mathrm{~m})$. Overall, an A. altissima population will contribute a considerable number of seeds due to overall high fecundity. Although we found minimal secondary dispersal on land in our short-term study, some additional seeds are likely to reach aquatic environments by this route. The population's estimated seed rain into the water along just one km of the Monongahela River suggests a high likelihood that this secondary mechanism of dispersal is frequent. Similar relationships 
between the number of collected diaspores downstream and stand distance from water (negative) or seed production (positive) were found for riparian species (Boedeltje 2003).

Secondly, A. altissima seeds submerged in water retained consistently high rates of germinability over five months and may retain viability in aqueous environments for longer periods, even if submerged (Lazenby 1955). In addition, seeds can float on still water under controlled conditions for one month and retain buoyancy in moving-water under controlled and riverine conditions at least 24 hours.

Given that seeds can reach aqueous environments and retain viability, the only sine qua non of hydrochory is deposition into a suitable habitat. Provided that a species has high propagule pressure, like A. altissima, it appears that the opportunity for safe site deposition and germination along riparian zones is possible (Barrat-Segretain 1996, Von Holle and Simberloff 2005). In addition, successful hydrochory would likely enhance with flooding conditions as increased flow rate and volume would transport seeds farther and permit deposition at high-water elevations in newly disturbed habitat. Since $A$. altissima is not typically a riparian species, deposition during high water, or movement to higher ground by wind or animals would increase the probability of successful establishment. Individual A. altissima have been observed at sites that have periodic flooding.

Within the estimates and observations presented in this study, buoyant propagules of A. altissima can be dispersed long distances at greater frequencies than primary dispersal. While we know A. altissima seeds can disperse at least $200 \mathrm{~m}$ through primary dispersal (Kota 2005), hydrochory can carry seeds distances two orders of magnitude farther over a short time. These long distance dispersal events may be occurring at 
similar rates throughout much of the United States and other countries, as disturbances (e.g. flooding, railroads, anthropogenic activity) are typically created along river gradients and are frequently dominated by invasive species (Parendes and Jones 2000).

The observed variation in seed germination rates was unexpected. Seeds incubated in aqueous environments did not differ in germination rates, while seeds kept at one terrestrial site germinated at lower rates. Low temperature limitations have been previously noted for A. altissima (Kowarik and Säumel 2007) and the Cheat Lake terrestrial treatment also experienced lower temperatures than any other site. Due in part to the temperature buffering ability of water, the submerged seeds in Cheat Lake may have experienced limited temperature variation and had restricted exposure to severe low temperatures compared to the terrestrial controls. These results indicate aqueous bodies may provide large, temperature-insulating transient seed banks that can disperse propagules long distances throughout mesic environments.

While A. altissima is described as a 'wind-dispersed' invasive species; the description can be misleading. Although its seed structure initially facilitates wind dispersal, the structure should not be assumed to imply that primary dispersal is the only, let alone most important, means of long-distance dispersal. This study provides evidence that hydrochory may be an important mechanism for migration of A. altissima and we expect these findings may apply to other wind-dispersed, native and non-native species as well. Previous studies have shown that parameterization of a species' seed dispersal curve tail is vital to forecasting range movement and establishment with changing environmental conditions (Lyford et al. 2003, Higgins et al. 2003). These models of spread are particularly sensitive to how long a dispersal tail is (Clark 1998), and 
hydrochory secondary-dispersal may provide the mechanism for the majority of longdistance dispersal in some terrestrial wind-dispersed species. 


\section{Literature Cited}

Barrat-Segretain, M.H. 1996. Strategies of reproduction, dispersion, and competition in river plants: A review. Vegetatio 123:13-37.

Belyea, L.R. and J. Lancaster. 1999. Assembly rules within a contingent ecology. Oikos 86(3):402-416.

Boedeltje, G., J.P. Bakker, R. M. Bekker, J.M. Van Groenendael, and M. Soesbergen. 2003. Plant dispersal in a lowland stream in relation to occurrence and three specific life-history traits of the species in the species pool. J. of Ecol. 91:855866.

Bullock, J.M. and R.T. Clarke. 2000. Long distance seed dispersal by wind: Measuring and modelling the tail of the curve. Oecologia 124:506-521.

Cain, M.L., H. Damman, and A. Muir. 1998. Seed dispersal and the Holocene migration of woodland herbs. Ecol. Monogr. 68(3):325-347.

Clark, J.S. 1998. Why trees migrate so fast: confronting theory with dispersal biology and the paleo record. Am. Nat. 152:204-224.

Clark, J.S., C. Fastie, G. Hurtt, S.T. Jackson, C. Johnson, S.A. King, M. Lewis, J. Lynch, S, Pacala, C. Prentice, E.W. Schupp, T. Webb, and P. Wycoff. 1998. Reid's paradox of rapid plant migration: dispersal theory and interpretation of paleoecolocial records. Bioscience 48(1):13-24.

Clark, C.J., J.R. Poulsen, B.M. Bolker, E.F. Connor, and V.T. Parker. 2005. Comparative seed shadows of bird-, monkey-, and wind-dispersed trees. Ecology 86(10):26842694. 
Couvreur, M., E. Cosyns, M. Hermy, and M. Huffmann. 2005. Complementarity of epiand endozoochory of plant seeds by free ranging donkeys. Ecography 28:37-48.

Darwin, C. 1856. On the action of sea-water on the germination of seeds. P. 264-273 in The collected papers of C. Darwin, Vol. 1, D.H. Barrett (ed.). 1977. University of Chicago Press, Chicageo, IL.

Darwin, C. 1859. The origins of species. Murray, London.

Edwards, A.L., R. Wyatt, and R.R. Sharitz. 1994. Seed buoyancy and viability of the wetland milkweed Asclepias perennis and upland milkweed, Asclepias exaltata. Bull. of the Torr. Bot. Club 121(2):160-169.

Feret, P.P. 1985. Ailanthus: Variation, cultivation, and frustration. J. of Arboriculture 11(12):361-368

Grubb, P.J. 1977. The maintenance of species-richness in plant communities: The importance of the regeneration niche. Biol. Rev. 52:107-145.

He, H.S., and D.J. Mladenoff, 1999. The effects of seed dispersal on the simulation of long-term forest landscape change. Ecosystems 2: 308-319.

Higgins, S.I. and D.M. Richardson. 1999. Predicting plant migration rates in a changing world: The role of long-distance dispersal. Am. Nat. 153(5):464-475.

Higgins, S.I., D.M. Richardson, R.M. Cowling, and T.H. Trinder-Smith. 1999. Predicting the landscape-scale distribution of alien plants and their threat to plant diversity. Cons. Biol. 13(2):303-313.

Higgins, S.I., J.S. Clark, R. Nathan, T. Hovestadt, F. Schurr, J.M.V. Fragoso, M.R. Aguiar, E. Ribbens, and S. Lavorel. 2003. Forecasting plant migration rates: Managing uncertainty for risk assessment. J. of Ecol. 91:341-347. 
Hutchinson, T. J. Rebbeck, and R. Long. 2004. Abundant establishment of Ailanthus altissima (Tree-of-heaven) after restoration treatments in an upland oak forest. P. 514 in Proc. $14^{\text {th }}$ Central Hardwood Forest Conference GTR-NE-316.

Imbert, E. and F. Lefévre. 2003. Dispersal and gene flow of Populus nigra (Salicaceae) along a dynamic river system. J. of Ecol. 91:447-456.

Kota, N.L. 2005. Comparative seed dispersal, seedling establishment and growth of exotic, invasive Ailanthus altissima (Mill.) Swingle and native Liriodendron tulipifera (L.). M.S. thesis, West Virginia Univ., Morgantown, W.V., U.S.A.

Kota, N.L., R.E. Landenberger, and J.B. McGraw. 2007. Germination and early growth of Ailanthus and tulip poplar in three levels of forest disturbance. Biol. Inv. 9:197211.

Kowarik, I. and I. Säumel, 2007. Biological flora of central Europe: Ailanthus altissima (Mill.) Swingle. Persp. in Plant Ecol., Evol. and Syst. 8(4)207-237.

Landenberger, R.E., N.L. Kota, and J.B. McGraw. 2007. Seed dispersal of the non-native invasive tree Ailanthus altissima into contrasting environments. Plant Ecol. 192:55-70.

Lazenby, A. 1955. Germination and establishment of Juncus effuses L.: II. The interaction effects of moisture and competition. J. of Ecol. 43(2):595-605.

Lockwood, J.L., P. Cassey, and T. Blackburn, 2005. The role of propagule pressure in explaining species invasions. TR. Ecol. and Evol. 20(5):223-228.

Lonsdale, W.M. 1993. Rates of spread of an invading species - Mimosa pigra in northern Australia. J. of Ecol. 81:513-521. 
Lyford, M.E., S.T. Jackson, J.L. Betancourt, and S.T. Gray. 2003. Influence of landscape structure and climate variability on a late Holocene plant migration. Ecol. Monogr. 73(4):567-583.

Mack, R.N., D. Simberloff, W.M. Lonsdale, H. Evans, M. Clout, and F.A. Bazzaz. 2000. Biotic invasions: Causes, epidemiology, global consequences, and control. Ecol. Applications 10(3):689-710.

Myers, J.A., M. Vellend, S. Gardescu, and P.L. Marks. 2004. Seed dispersal by whitetailed deer: Implications for long distance dispersal, invasion, and migration of plants in eastern North America. Oecologia 139:35-44.

Pakeman, R.J. 2001. Plant migration rates and seed dispersal mechanisms. J. of Biogeog. 28:795-800.

Parendes, L.A. and J.A. Jones. 2000. Role of light availability and dispersal in exotic plant invasion along roads and streams in the H. J. Andrews Experimental Forest, Oregon. Cons. Biol. 14(1):64-75.

Rejmánek, M. and D.M. Richardson. 1996. What attributes make some plant species more invasive? Ecology 77(6):1651-1661.

Rejmánek, M. 2000. Invasive plants: Approaches and predictions. Aust.Ecol. 25:297506.

Reid, C. 1899. The origin of the British flora. Dulau, London, UK.

Ritchie, J.C. and G.M. MacDonald. 1986. The patterns of post-glacial spread of white spruce. J. of Biogeog. 13:527-540.

Schneider, J.C. 1999. Dispersal of a highly vagile insect in a heterogeneous environment. Ecology 80(8):2740-2749. 
Skellman, J.G. 1951. Random dispersal in theoretical populations. Biometrika 38:196218.

USGS National Water Information System. 2007. Surface-water daily statistics for the nation: USGS 03072655 Monongahela River near Masontown, PA. Available online at http://waterdata.usgs.gov/nwis/sw; last accessed Sept. 9, 2007.

Von Holle, B. and D. Simberloff. 2005. Ecological resistance to biological invasion overwhelmed by propagule pressure. Ecology 86(12):3212-3218.

Watkinson, A.R. 1978. The demography of sand dune annual: Vulpia fasciculata. J. of Ecol. 66:35-44.

Welch, D. 1985. Studies in the grazing of heather moorland in north-east Scotland. IV. Seed dispersal and plant establishment in dung. J. of Appl. Ecol. 22:461-472. 


\section{Figure Legends}

Figure 4.1: Log-linear curve fit to observed primary dispersal of $A$. altissima, relative to densities found at parent $(0 \mathrm{~m})$ to $100 \mathrm{~m}$ in an open field environment; adapted from Landenberger et al. 2007.

Figure 4.2: Primary dispersal into water, assuming equal dispersal in all directions. Figure 4.3: Percent (left axis) and estimated number (right axis) of seeds dispersing into water as a function of tree distance from water's edge, based upon a tree of $25 \mathrm{dbh}(\mathrm{cm})$. Figure 4.4: Relationship between observed individual A. altissima $\mathrm{dbh}(\mathrm{cm})$ and distance from water on the projected number of seeds deposited directly into water as a function of Equation 1.

Figure 4.5: Number of recovered A. altissima seeds at varying distances along the Monongahela River after 24 hours.

Figure 4.6: Percent of seeds traveling a certain distance downhill through secondary dispersal events in a terrestrial environment over one-month on a (A) $48 \%$, (B) $33 \%$, or (C) $9 \%$ slope. Axis slant corresponds to slope.

Figure 4.7: Mean ( \pm 2 s.e.) germination rate of A. altissima seeds incubated in aqueous conditions over five months.

Figure 4.8: The effect of environment and location on the mean germination ( 2 s.e.) of $A$. altissima seeds near Morgantown, WV. Columns with different letters are significantly different from one another (Tukey-Kramer HSD a posteriori test). 
Figure 4.1:

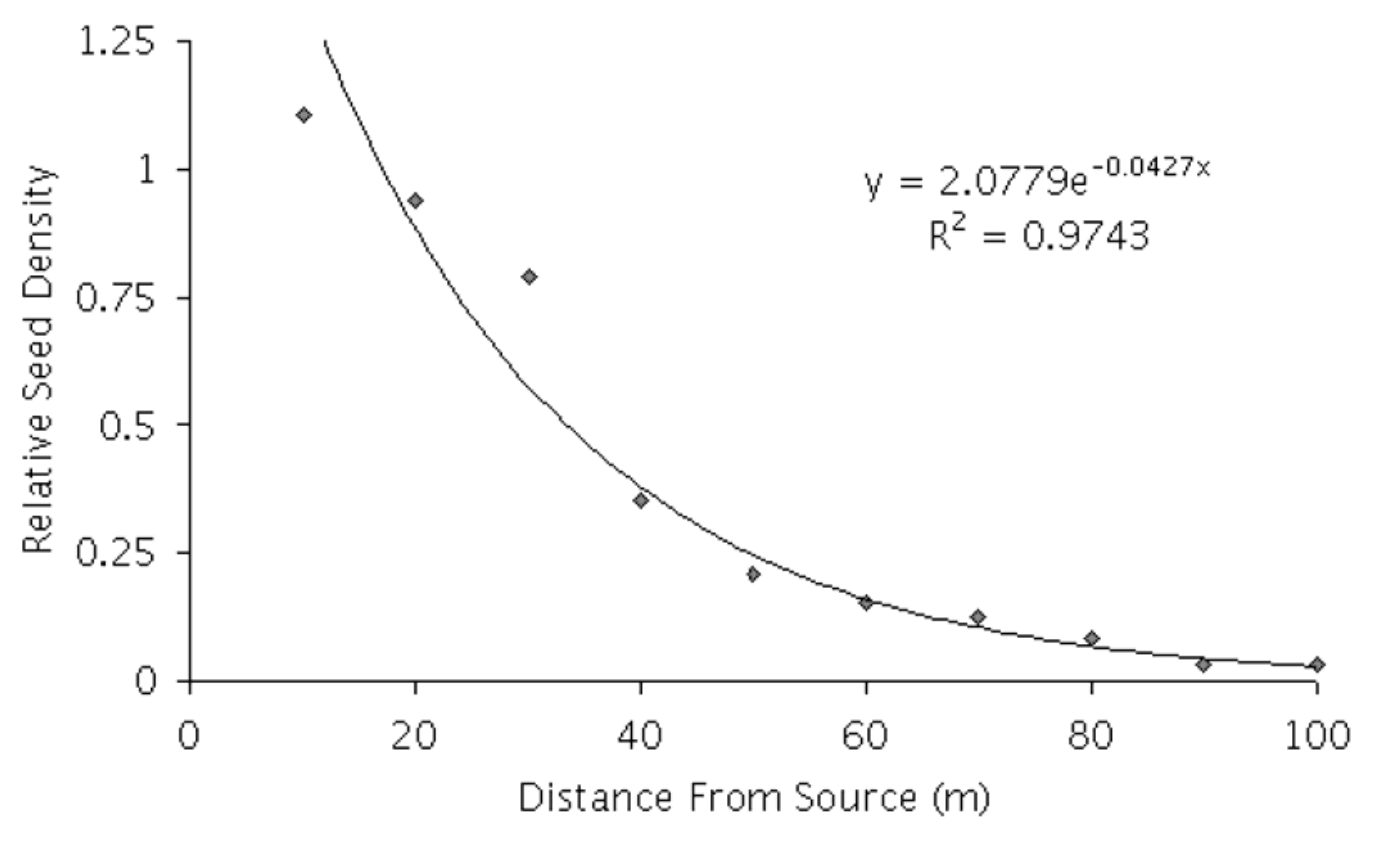


Figure 4.2:

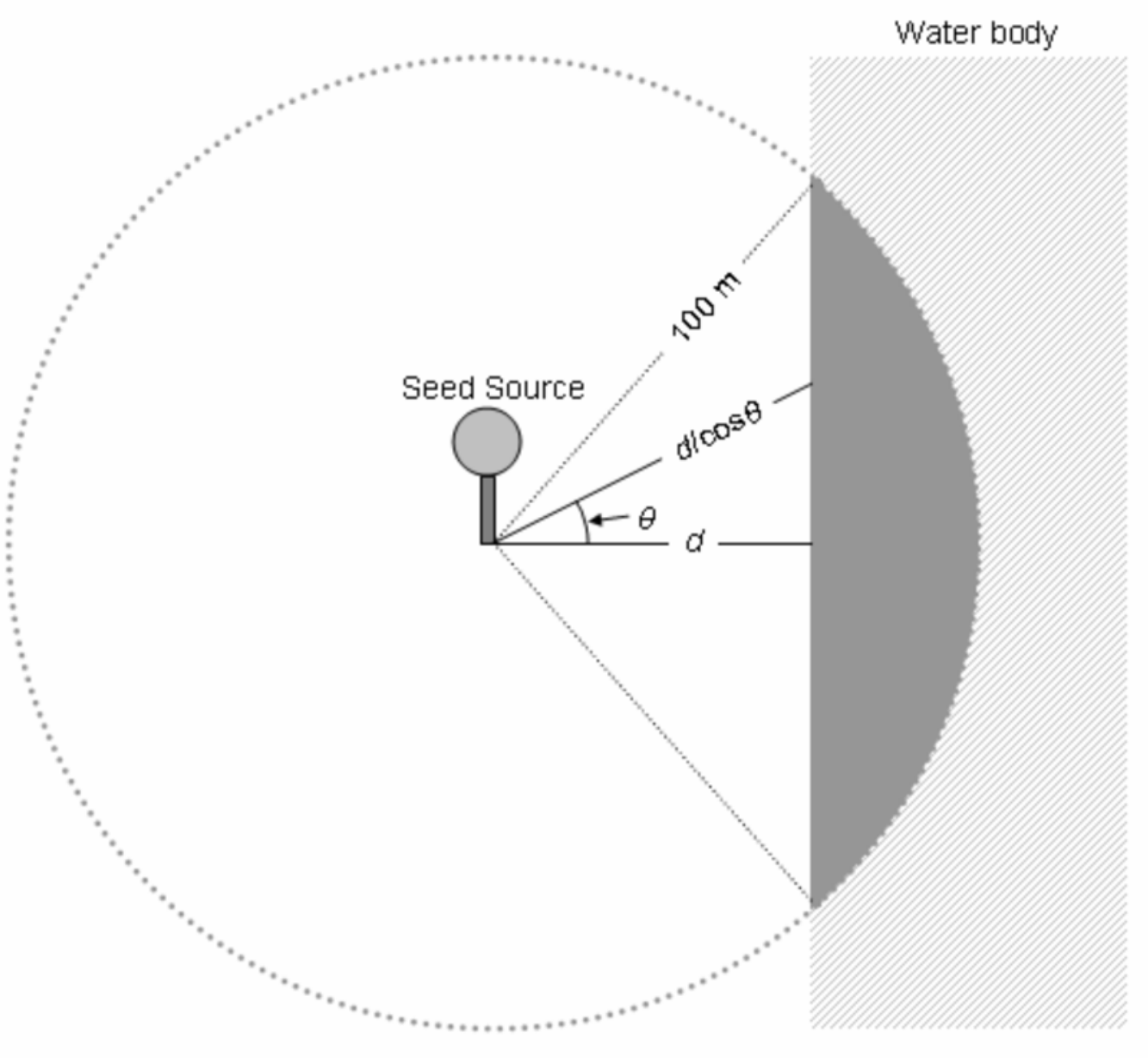


Figure 4.3:

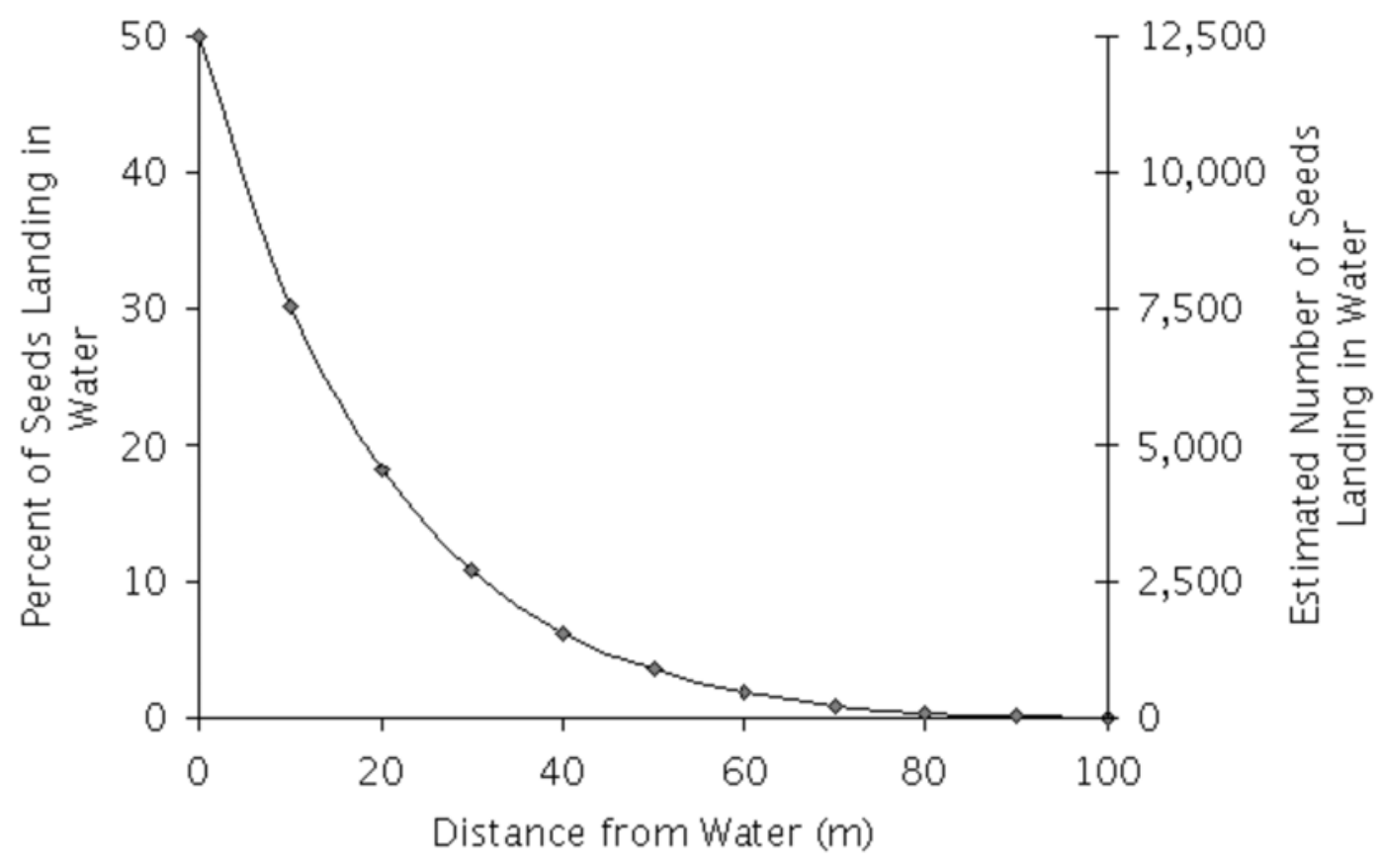


Figure 4.4:

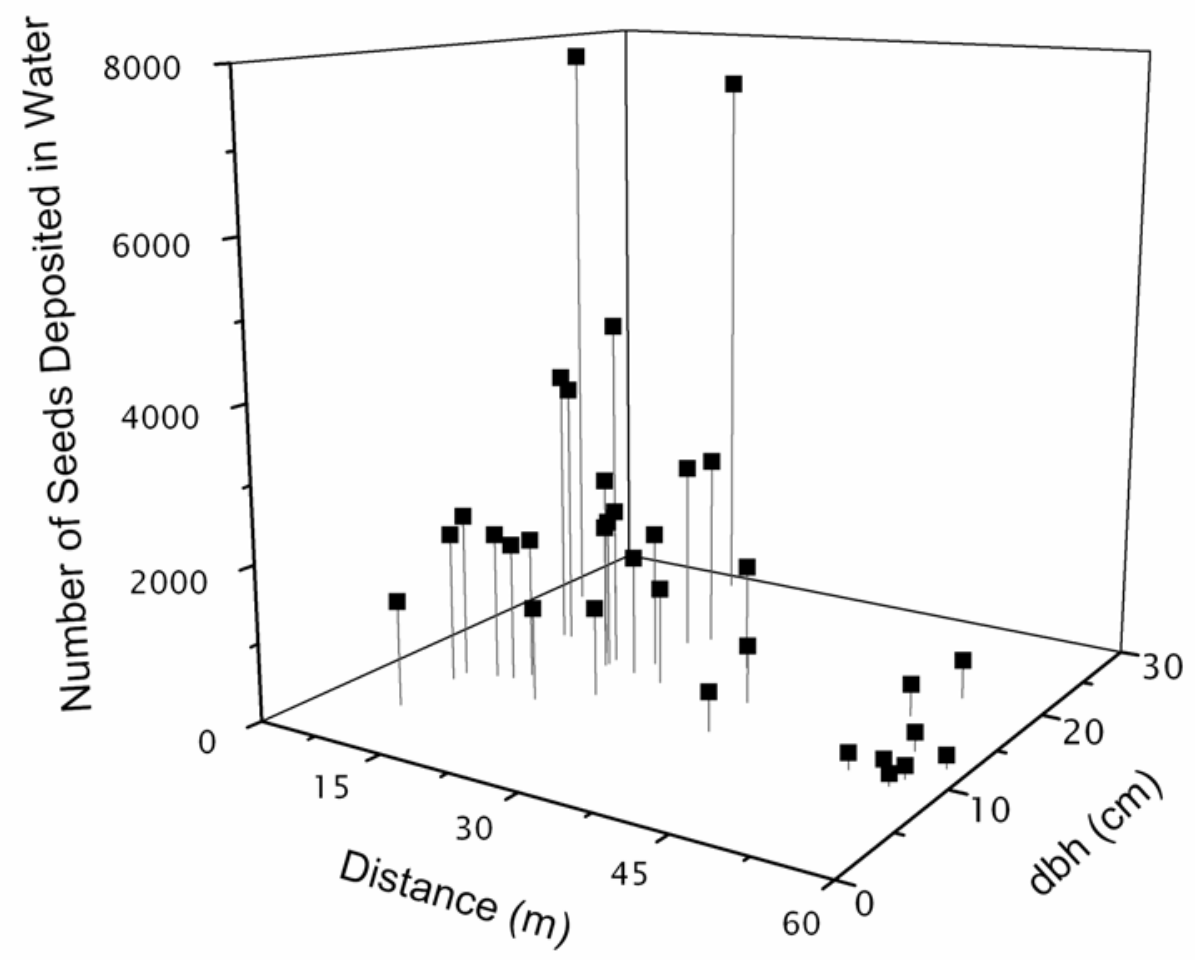


Figure 4.5:

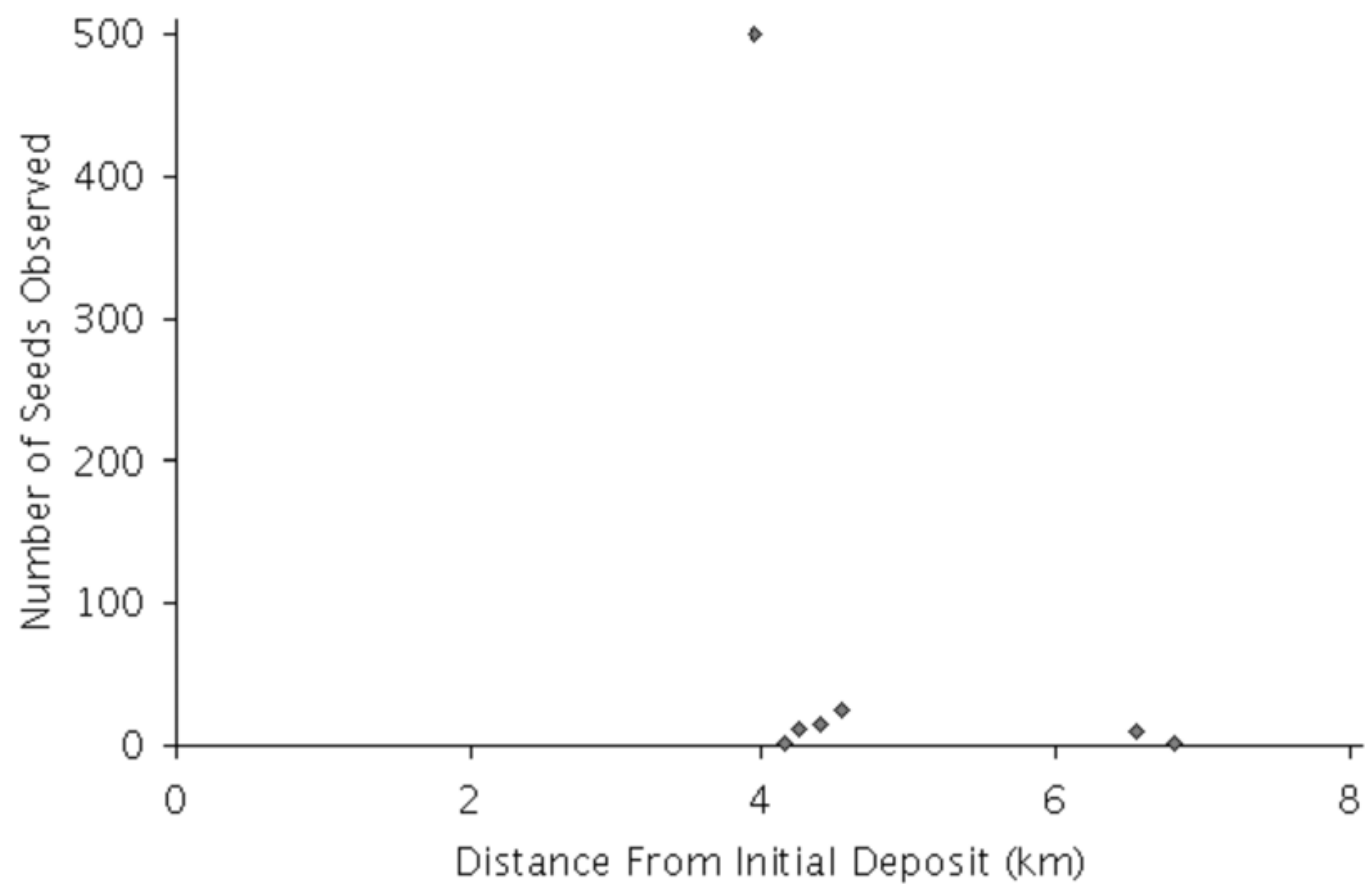


Figure 4.6:

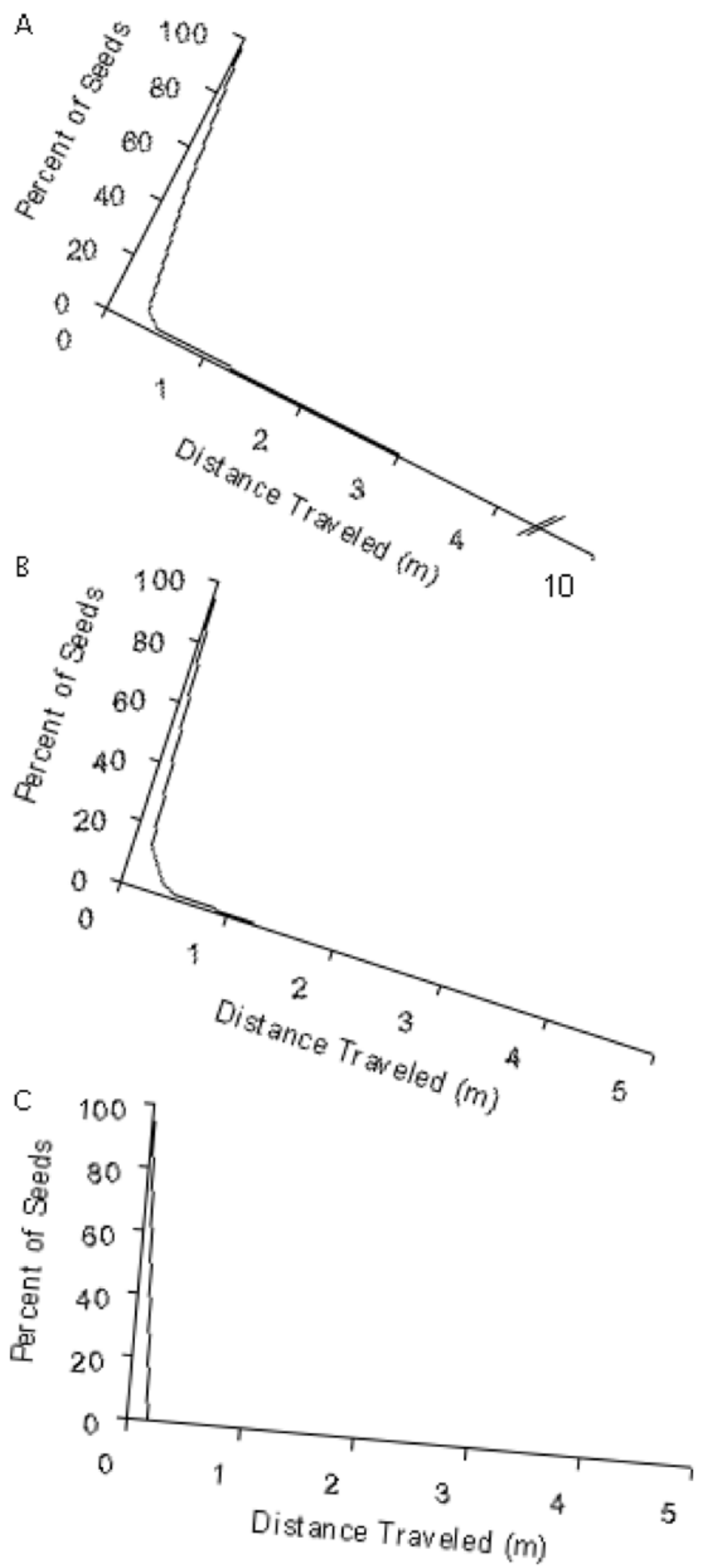


Figure 4.7:

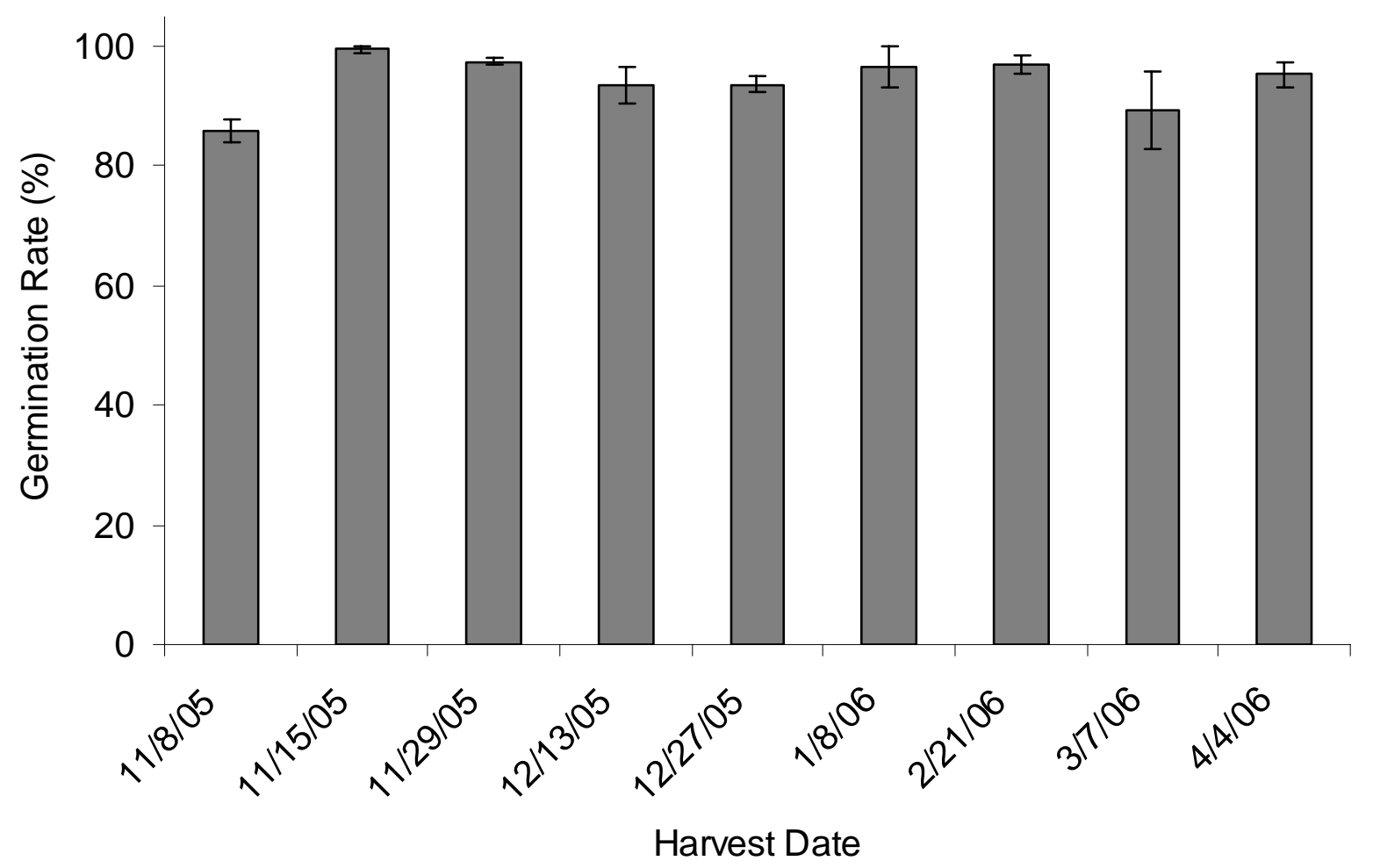


Figure 4.8:

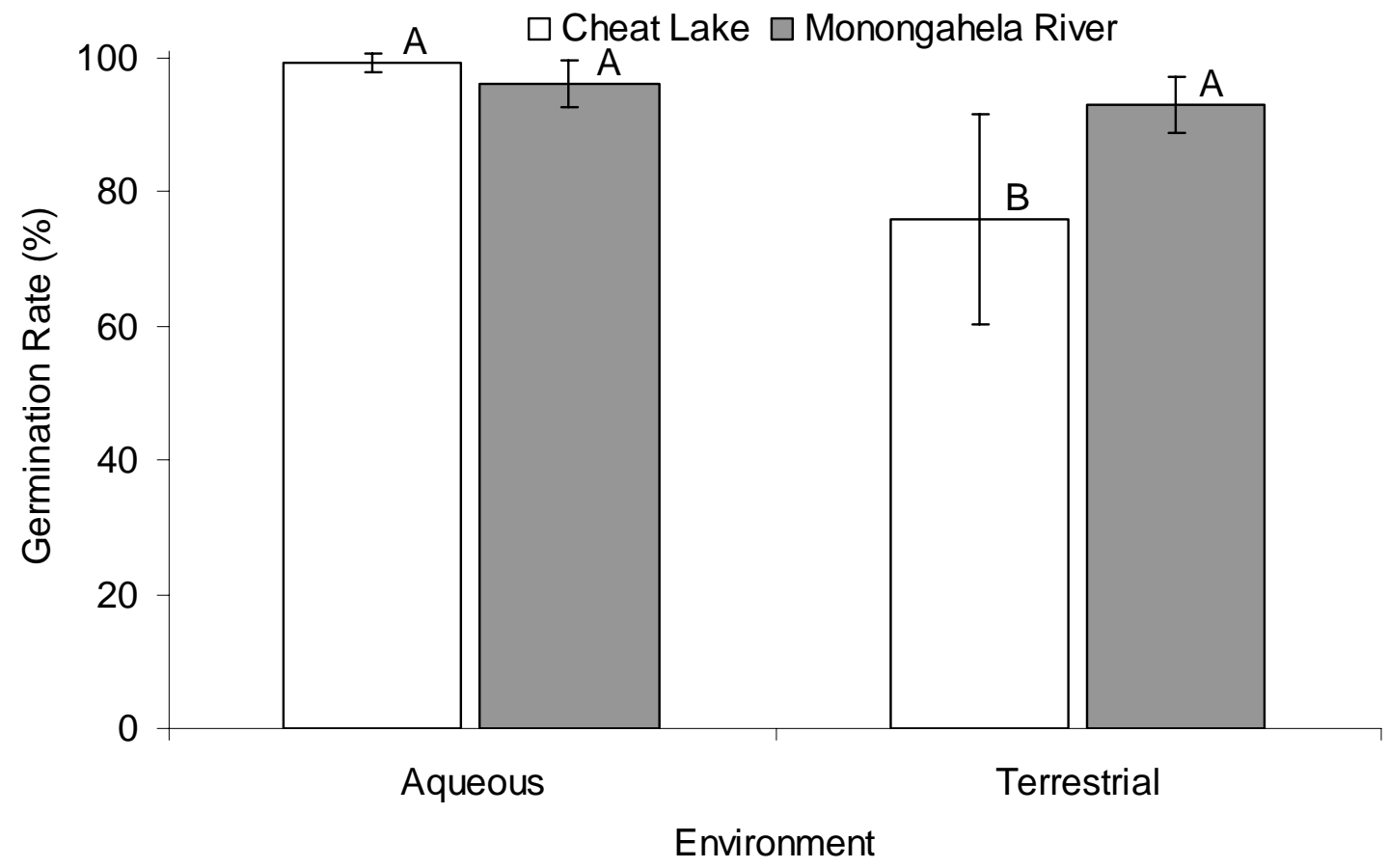




\section{Chapter 5: General Conclusions}

John Harper described plants as good research subjects because they sit still and "wait to be counted" (Harper 1972). Of course an adult plant is inherently capable of only relatively slow movement once it has rooted. By remaining in one position, an individual is unable to escape stresses put upon it. Plant progeny (seeds) are not so constrained and represent a phase of rapid exploration of the environment (Bohrer et al. 2005). Thus, the brief opportunity for plant mobility is integral to species perpetuation,

spread, and if in high frequency, permit the species to grow invasively (Lockwood 2005, Eppstein and Molofsky 2007).

Focusing on the propagules and early stages of $A$. altissima, this study indicates that remote sensing can be used to survey mixed mesophytic forests for the identification of $A$. altissima samara clusters, although high levels of commission occur on bright features. Further improvements to the image acquisition and classification process may ensure higher accuracy, which would be advantageous in the parameterization of the propagule quantity. Manual delineation of canopy units simplifies classification errors, and improves quantification of propagules in the canopy for primary seed dispersal models. The seed dispersal model suggests the single mean Landenberger et al. (2007) dispersal curve may inadequately reflect the various forces acting on seed dispersal in a landscape (Figures 2.19-20). The scope of this trial was constrained, however, and was not parameterized to account for differences in seed dispersal due to varying landscapes (e.g. slope, wind direction) and vegetative cover (Landenberger et al. 2007). 
Field studies of germination and early growth demonstrated that $A$. altissima is safe site limited. Germination rates were generally far lower than were observed in "ideal" conditions and responded to microsite variation (Kota et al. 2007). Establishment rates of seedling phytometers were near zero in all sites. A prolific invasive plant produces far more propagules than can germinate and become established (Rejmánek and Richardson 1996). Like many other plant species with low maternal investment in each seed, the seeds are unlikely to become established unless they arrive in a favorable site. The frequency of safe sites for seed germination occurred at a high rate (57\%) in a disturbed environment (canopy gaps, Figure 3.2), similar to findings of Call and Nilsen (2003), and Kota et al. (2007). The frequency of safe sites for seed germination in the field microsite was only $1 / 5^{\text {th }}$ the rate of that seen in canopy gaps, possibly due to high competition for soil moisture (Davis et al. 1998), indicating that fallow fields are at a low risk of A. altissima invasion compared to canopy gaps.

Overall dispersal of a propagule depends greatly on the environment surrounding it (Schurr et al. 2005). My experimental and modeling studies showed that propagules of A. altissima not only reach nearby bodies of water (Figure 4.3), but can remain viable for long periods of time in water (Figure 4.7), providing the species with an opportunity of long distance dispersal two orders of magnitude greater than recorded primary dispersal in a short amount of time. Deposition along frequently disturbed riparian habitats or high water levels may allow for successful hydrochory (Barrat-Segretain 1996), and would only be augmented with flooding conditions. This was the first demonstration of hydrochory in this species. While establishment of new seedlings via this route may be 
infrequent, hydrochory may nonetheless be important for explaining rare long-distance dispersal along aquatic corridors.

Plants with long distance dispersal, compared to poor dispersers, have high rates of success when disturbed environments are infrequent (With 2004). The propagules of A. altissima are produced in high quantity and can be dispersed by multiple agents, enabling the species to be a good disperser capable of invading disturbed environments. Overall, it is difficult to characterize the pattern of response of a species over a wide variety of conditions present in a landscape. Rarity of seedling survival was shown under the methodology and year we tested, but it is abundantly clear that some establishment occurs in this species (Figures 2.2-2.5). Modeling seed dispersal and subsequent seed germination may ultimately predict locations of invasive success, with some degree of stochasticity. On the whole, active management of A. altissima is recommended (Kota 2005, Landenberger et al. 2007), especially along water bodies and in canopy gaps. These management efforts can be aided through remote sensing identification and discrete seed dispersal modeling. 


\section{Literature Cited}

Barrat-Segretain, M.H. 1996. Strategies of reproduction, dispersion, and competition in river plants: A review. Vegetatio 123:13-37.

Bohrer, G., R. Nathan, and S. Volis, 2005. Effects of long-distance dispersal for metapopulation survival and genetic structure at ecological time and spatial scales. Journal of Ecology 1029-1040.

Call, L.J. and E.T. Nilsen, 2003. Analysis of spatial patterns and spatial association between the invasive Tree-of-heaven (Ailanthus altissima) and the native Black locust (Robinia pseudoacacia). American Midland Naturalist. 150: 1-14.

Davis, M.A., K.J. Wrage, and P.B. Reich, 1998. Competition between tree seedlings and herbaceous vegetation: support for a theory of resource supply and demand. Journal of Ecology 86(4):652-661.

Eppstein, M.J. and J. Molofsky, 2007. Invasiveness in plant communities with feedbacks. Ecology Letters 10:253-263.

Harper, J. L., 1972. The population biology of plants. Academic Press, London.

Kota, N.L., 2005. Comparative seed dispersal, seedling establishment and growth of exotic, invasive Ailanthus altissima (Mill.) Swingle and native Liriodendron tulipifera (L.). West Virginia University Dept. of Biology, Electronic Thesis.

Kota, N.L., R.E. Landenberger, and J.B. McGraw, 2007. Germination and early growth of Ailanthus and tulip poplar in three levels of forest disturbance. Biological Invasions 9:197-211. 
Landenberger, R.E., N.L. Kota, and J.B. McGraw. 2007. Seed dispersal of the non-native invasive tree Ailanthus altissima into contrasting environments. Plant Ecol. 192:55-70.

Lockwood, J.L., P. Cassey, and T. Blackburn, 2005. The role of propagule pressure in explaining species invasions. TR. Ecol. and Evol. 20(5):223-228.

Rejmánek, M. and D.M. Richardson, 1996. What attributes make some plant species more invasive? Ecology 77(6):1651-1661.

Schurr, F.M., W.J. Bond, G.F. Midgley, and S.I. Higgins, 2005. A mechanistic model for secondary seed dispersal by wind and its experimental validation. Journal of Ecology 93:1017-1028.

With, K.A., 2004. Assessing the risk of invasive spread in fragmented landscapes. Risk Analysis 24(4):803-815. 


\section{Appendix}

\section{Primary Dispersal Model Code}

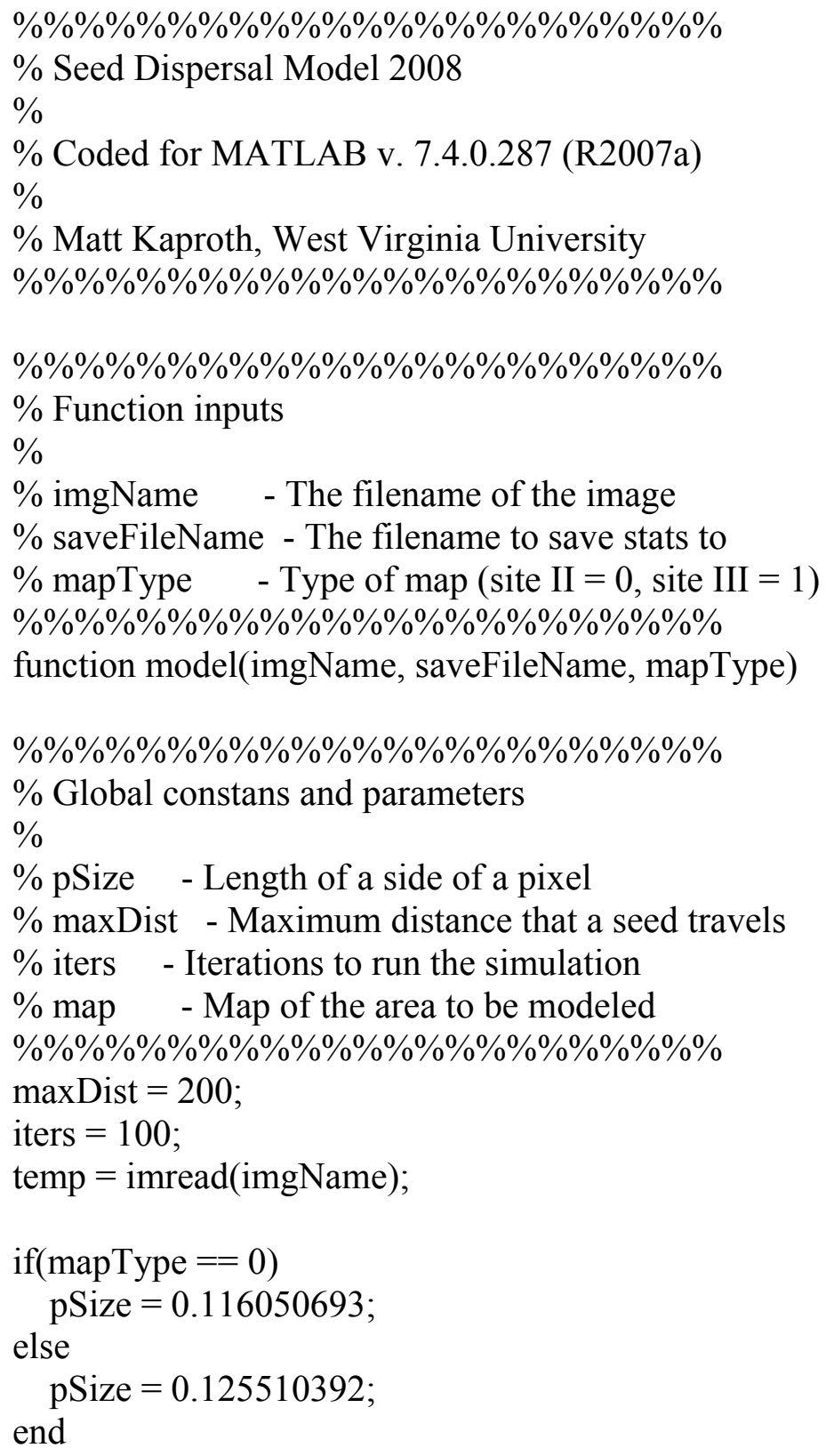


$\%$ Normalized with area under curve (in this case, 9.720886)

seedDist $=@(\mathrm{x}) 0.2054 / 9.720886 * \exp (-0.0208 * \mathrm{x})$;

$\% \% \% \% \% \% \% \% \% \% \% \% \% \% \% \% \% \% \% \% \% \% \%$

$\%$ Step 1:

$\%$ Locate all seed-bearing trees and get map of them

\%\%\%\%\%\%\%\%\%\%\%\%\%\%\%\%\%\%\%\%\%\%

fprintf('Locating seeds... ');

trees $=$ treeFinder(map, mapType);

fprintf('Done $\backslash n$ ');

$\% \% \% \% \% \% \% \% \% \% \% \% \% \% \% \% \% \% \% \% \% \% \%$

$\%$ Step 2:

$\%$ Using the array generated in step 1, iterate through all the trees of

$\%$ interest in the survey are, and model the path of each seed.

$\%$

$\%$ ASSUMPTIONS:

$\% *$ A seed is released at any angle (0-360) with equal probability

$\% *$ There is only one probability function governing the seed's flight

$\% \% \% \% \% \% \% \% \% \% \% \% \% \% \% \% \% \% \% \% \% \%$

fprintf('Modeling seed spread... $\backslash n ')$;

$\%$ Containers to hold the results of the runs

myAvg $=\operatorname{zeros}(\operatorname{size}(\operatorname{map}))$;

myStd = zeros(size(map));

for $(\mathrm{i}=1$ :iters $)$

fprintf('Iteration \%i $\backslash$ n', i);

$\%$ Create a blank map of where seeds have landed

temp $=\operatorname{zeros}(\operatorname{size}(\operatorname{map}))$;

$\%$ Iterate through all of the trees

for $(j=1$ :length(trees $)$ )

$\%$ Get the current tree

$\mathrm{Tx}=\operatorname{trees}(\mathrm{j}, 1)$;

$\mathrm{Ty}=\operatorname{trees}(\mathrm{j}, 2)$;

seeds $=\operatorname{trees}(\mathrm{j}, 3)$;

for $(\mathrm{k}=1$ :seeds $)$

$\%$ Randomly generate an angle

angle $=\operatorname{rand}() * 2 *$ pi;

$\%$ Use acceptance/rejection method to determine how far the $\%$ given

$\%$ seed will go with respect to the given pdf. Xc is the 
$\%$ distance. Model may overestimate local seed dispersion

$\%$ pattern because no seeds can travel past $200 \mathrm{~m}$.

$\mathrm{Xc}=\operatorname{maxDist} * \operatorname{rand}()$;

$\mathrm{Yc}=\operatorname{seedDist}(0) * \operatorname{rand}()$;

$\%$ Didn't generate a suitable random variable

while $(\mathrm{Yc}>\operatorname{seedDist}(\mathrm{Xc}))$

$X \mathrm{c}=\max$ Dist $* \operatorname{rand}()$;

$\mathrm{Yc}=\operatorname{seedDist}(0) * \operatorname{rand}()$;

end

$\%$ Generated a good distance. Convert Xc from meters into

$\%$ pixels

$\mathrm{Xc}=\mathrm{Xc} / \mathrm{pSize}$

$\%$ Find the coordinates of where the seed landed. This is an

$\%$ offset

$\%$ from the current tree

$\mathrm{x}=$ floor $(\mathrm{Xc} * \sin ($ angle $)+\mathrm{Tx})$;

$\mathrm{y}=$ floor $(\mathrm{Xc} * \cos ($ angle $)+\mathrm{Ty})$;

$\%$ Check to see if this point resides within the survey area.

$\%$ If

$\%$ not, discard. If it does, then record onto the spread map.

$\operatorname{if}((\mathrm{x}>0 \& \& \mathrm{x}<\operatorname{size}(\operatorname{map}, 1)) \& \&(\mathrm{y}>0 \& \& \mathrm{y}<\operatorname{size}($ map, 2$)))$ temp $(\mathrm{x}, \mathrm{y})=\operatorname{temp}(\mathrm{x}, \mathrm{y})+1$;

end

end

end

$\%$ Record the results of this trial

myAvg = temp + myAvg;

myStd $=$ temp. $.^{\wedge}+$ myStd;

end

fprintf('Post-processing: ');

$\%$ Calculate the average

fprintf('Average... ');

myAvg = myAvg / iters;

$\%$ Calculate the cell to cell standard deviation

myStd $=\operatorname{sqrt}((1 /$ iters $) *($ myStd $-($ iters * myAvg $)))$;

$\%$ Calculate the standard error

fprintf('Standard Error....n'); 
stdError $=$ myStd $/$ sqrt(iters);

fprintf('Saving results $\backslash n$ ');

save(saveFileName, 'myAvg', 'myStd', 'stdError');

fprintf('Done! You can now load \%s and access the $\backslash n$ ', saveFileName);

fprintf('variables myAvg, myStd and stdError $\backslash n ')$; 


\section{Tree Finder Code}

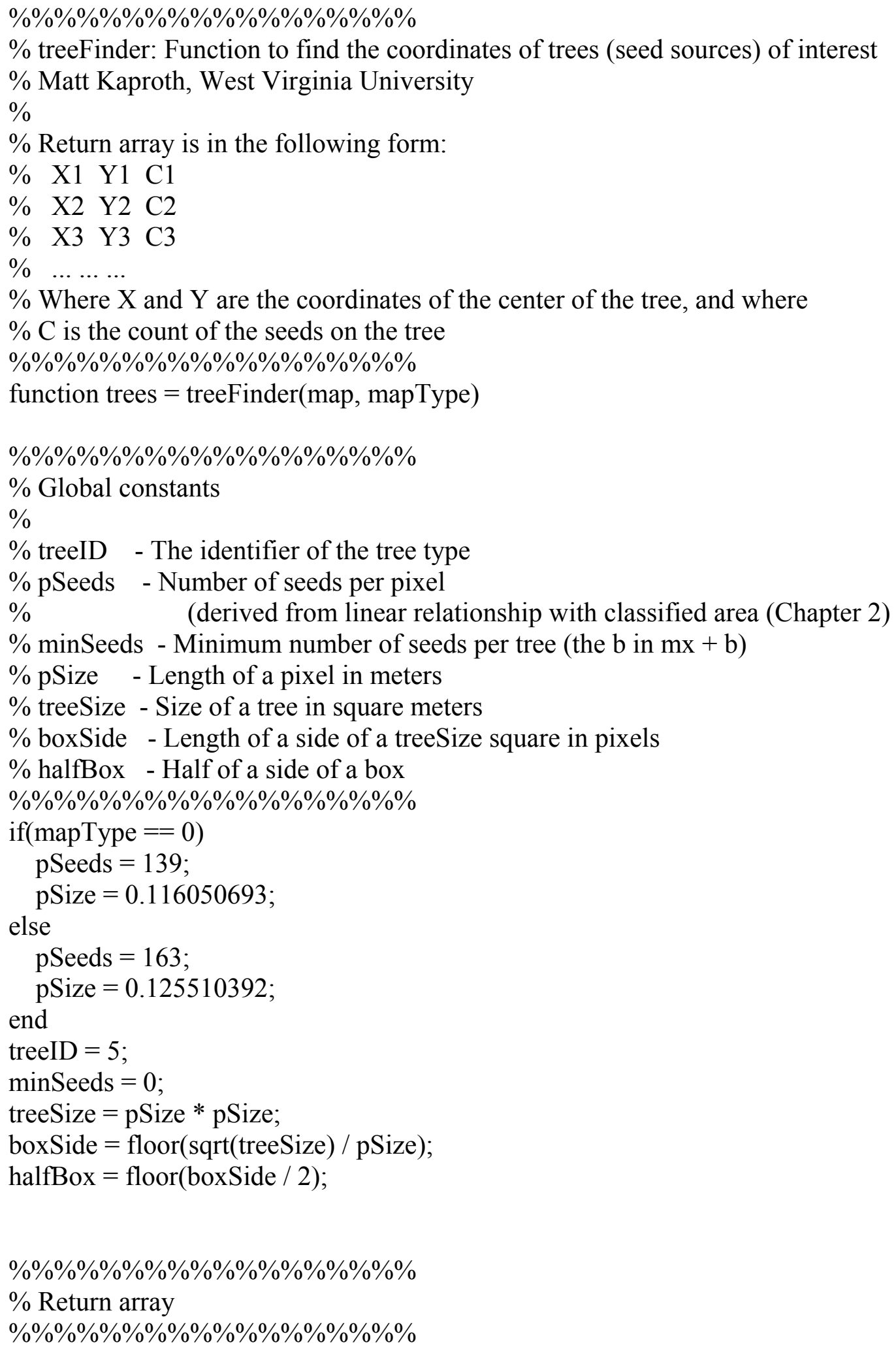




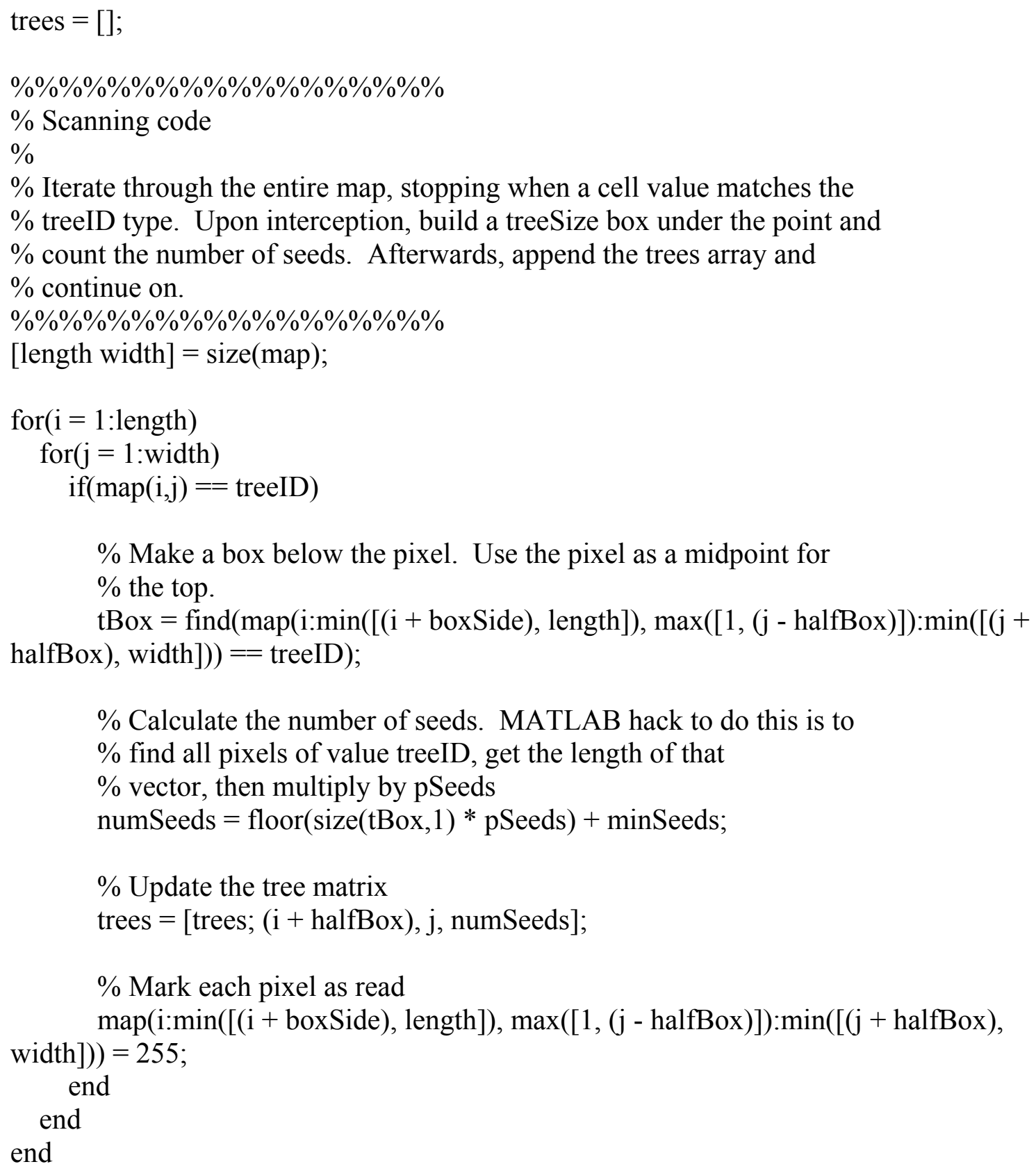




\section{Phenospectral Imagery}

Phenospectral images of an A. altissima samara cluster in Morgantown, WV.

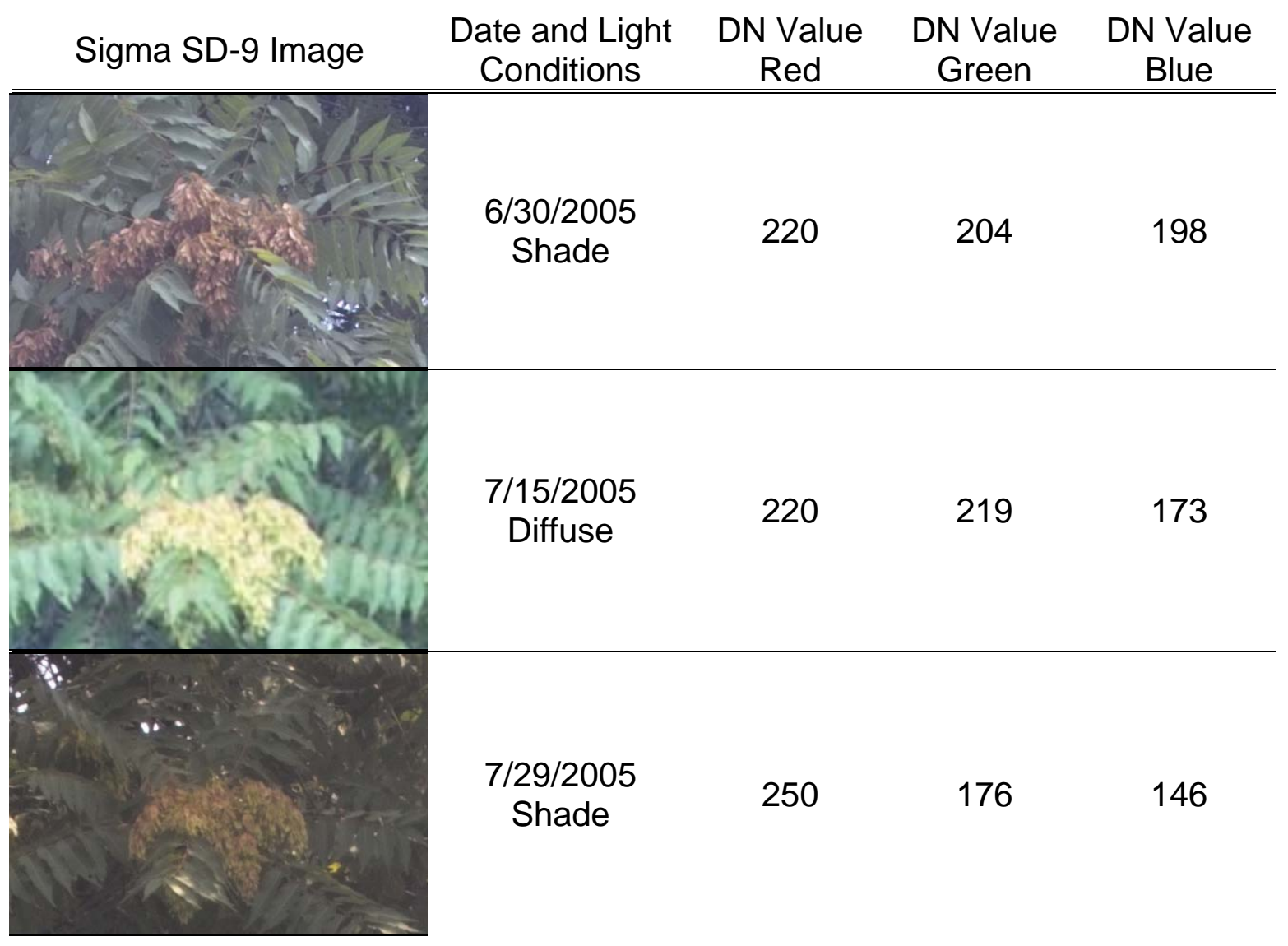




\section{Curriculum Vitae}

\section{Matthew A. Kaproth}

Primary (College):

7b LeClair Ave

Winooski, VT 05404

(802) 310-7860
Permanent (Home):

1160 Hinging Post Rd

Ithaca, NY 14850

MattK10@juno.com

\section{Education:}

Ph.D. (Anticipated 2011), University of Vermont, Department of Plant Biology. Overall GPA: 4.00.

M.S. (2008), West Virginia University, Department of Biology: Area emphasis in Ecology and Evolutionary Biology. Overall GPA: 3.96.

B.S. (2004), State University of New York College at Brockport. Overall GPA: 3.08.

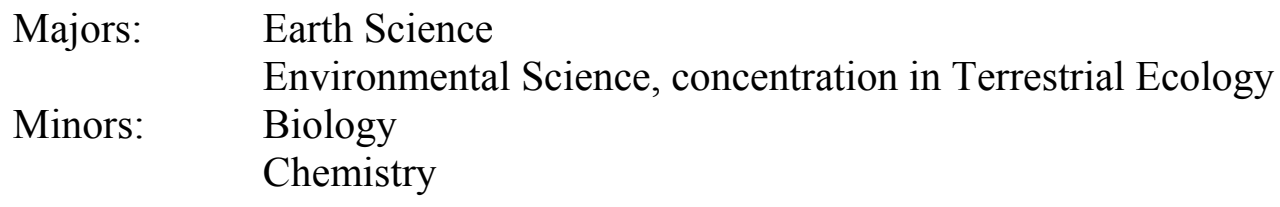

I have completed the following technical course work: Ecology, Plant Ecology, Plant Taxonomy, Advanced Plant Physiology, Plant Population Biology, Biogeography, Soils Science, Wetland Systems, Organic Chemistry I, Analytical Chemistry, Geochemistry, Calculus I, Computational Methods in Field Science (statistics), Biometry, Geo-Information Systems (GIS), GIS and Environmental Modeling, Introduction to and Advanced Remote Sensing, MATLAB computer programming, Environmental Law, Environmental Chemical Issues, Analytical Writing, Advanced Technical Writing (Independent Study), Ecological Grant Writing, and an Independent Senior Project on Lythrum salicaria.

\section{Experience:}

2007-Current. Teaching Assistant for the University of Vermont Department of Plant Biology: I am responsible for laboratory instruction and grading.

a. PBIO/PSS 117: Plant Pathology, required course for Plant and Soil Science undergraduates. Supervised by Dr. Terrance Delaney for Fall 2007. 
2004-2007. Teaching Assistant for West Virginia University Department of Biology: I

was responsible for two laboratory sections per semester.

b. BIOL 321: Total Science Experience, the capstone course of the department, allowing the students to propose, complete, and present a scientific

experiment. Supervised by Dr. James McGraw and Dr. William Peterjohn for Spring 2005 \& 2006.

c. BIOL 302: Biometry and BIOL 350: Plant Physiology. I assisted with assignments, office hours, and laboratories. Supervised by Dr. James McGraw and Dr. Jonathan Cumming for Fall 2006.

d. BIOL 117: Introductory Physiology, second introductory biology course for science majors. Supervised by Patricia Lutsie for Spring 2007.

e. BIOL 115: Principals of Biology, the introductory course for science majors. Supervised by Patricia Lutsie for Fall 2004 \& 2005.

2004-Current. Graduate Student Representative of the West Virginia University Department of Biology, Eberly College of Arts and Sciences. I have organized graduate student efforts during recruitment weekends, out-of-lab socialization, and acted as a liaison between students and faculty.

2004-2006, May-August. Field Assistant supervised by Dr. James McGraw of West Virginia University, in the detection, demographic monitoring, and collection of native Panax quinquefolius populations.

2003-2004. GIS Analyst on a USGS - ED MAP program, supervised by Dr. Whitney Autin. This project produced a multiple-layered digital geologic map of the Churchville Quadrangle, NY. Three other students and I worked collaboratively on the creation of the map. Upon completion, I was the senior writer of the final report, assisted by Dr. Whitney Autin and Dr. James Zollweg.

2001-2003. Lab Technician for the SUNY Brockport Limnology Lab, under the direction of Dr. Joseph Makarewicz, the Environmental Science and Biology Chair. I conducted statistical analysis of large collection sets, along with water quality tests, including total suspended solids (TSS), invertebrate surveys (Cercopagis $\mathrm{sp}$ ), and chemical preparations and inventories.

2002-2003. Independent study on the structure and classification of vascular plants and a literary review of invasive species. Dr. Jean Bobear, emeritus professor of plant taxonomy, mentored me. Both lab and field work were completed. The relevant text for this study was Gleason \& Cronquist's Manual of Vascular Plants of Northeastern United States and Adjacent Canada.

1998-2003, June-August. Camp Commissioner of Camp Barton Boy Scout Camp. I held different positions over the summers, with my most recent opportunity being one of three administrative positions, responsible for a staff of forty. I was directly responsible for troop/camp relations, the Counselor In Training (CIT) program, 
and staff morale. I also had worked as the head ecology instructor, teaching nature merit badges including forestry, plant science, and environmental science.

\section{Relevant Scientific Abilities:}

- Geo-Information Systems (GIS); Analysis and creation of map layers, using ArcView.

- GPS unit work.

- ESRI Imagine; Image classification and remote sensing applications.

- MATLAB computer programming.

- Advanced plant identification and classification - using Gleason and Cronquist.

- Analytical chemical preparation for testing.

- Field practices and surveys of soils, plants and environmental conditions.

- Advanced computer troubleshooting.

- Statistical use of MS Excel and SAS JMP.

\section{Interest/Research:}

I have a particularly strong interest in invasive species. I have conducted numerous studies on plants, such as Lythrum salicaria and Ailanthus altissima, focusing on their invasive patterns of habitat and spread. I've completed GIS mapping of the invaded plots and surrounding corridors, looking at soil type, hydrology, topography and other variables for each area. From this survey, I was able to determine the sites the plants occupy most frequently, and what conditions pertain to those sites, allowing for a predictive map of which non-invaded sites run the highest risk of invasion. I seek to develop these ecological models with predictions of seed dispersal.

Detection of the invasive tree species Ailanthus altissima using aerial imaging. Remote sensing detection capable of identifying and quantifying seed sources for this species, when processed from surveys of Eastern-hardwood forests. A spatiallyexplicit primary seed dispersal model (cellular automata) was used to project the species seed dispersion pattern across a landscape.

\section{Scholarly Work:}

Kaproth, M.A., R. Fanelli, D. Cannon, S. Dilger, W.J. Autin, and J. Zollweg, 2004. Quaternary geologic map of the Churchville, New York 7.5-minute quadrangle. USGS-EDMAP \#03HQAG0099.

Kaproth, M.A. and J.B. McGraw, 2006. Seed germinability of the invasive tree Ailanthus altissima after dispersal in aqueous environments. ESA's 91st Annual Meeting in Memphis, Tennessee. 
Kaproth, M.A. and J.B. McGraw, submitted. Seed dispersal and seed viability of the wind-dispersed invasive Ailanthus altissima in aquatic environments. Journal of Forest Science.

Kaproth, M.A., W.J. Autin, and J. Miller, in preparation. Comparison of habitat modeling of the invasive species Lythrum salicaria in western New York. Intended for Ecological Modelling.

Kaproth, M.A., T.A. Warner, and J.B. McGraw, in preparation. Remote Sensing Determination of Propagule Pressure for an Invasive Species. Intended for Remote Sensing of Environment.

\section{Organizations \& Awards:}

- Member of the Ecological Society of America.

- 2006-2007 HERF Supplementary Fellowship, West Virginia University Department of Biology. Awarded for outstanding performance of $2^{\text {nd }}$ or $3^{\text {rd }}$ year graduate students in completing graduate requirements, the timeliness with which requirements are completed, and the submission and content of a student's annual report.

- 2006 West Virginia View Grant. Grant provided necessary funds for aerial image acquisition of thesis study area.

- Brother of Alpha Phi Omega National Service Fraternity. I held the VicePresident of Service Chair and in 2003-2004 I served more than 100 community service hours. I made multiple contributions to the college newspaper in interest of Alpha Phi Omega philanthropies.

- Member of Order of Omega. Greek-leadership honor fraternity whose membership is awarded for scholarship, service to the campus, and inter-Greek leadership.

- Eagle Scout, with silver palm: Boy Scouts of America. 